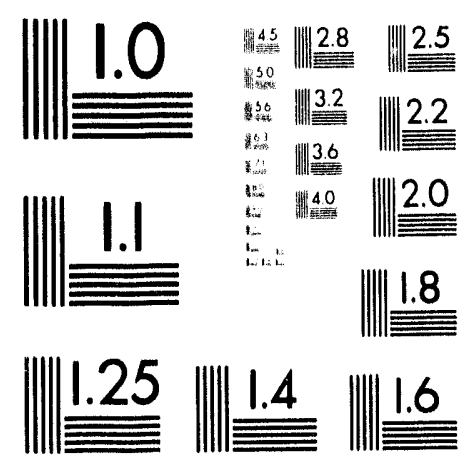



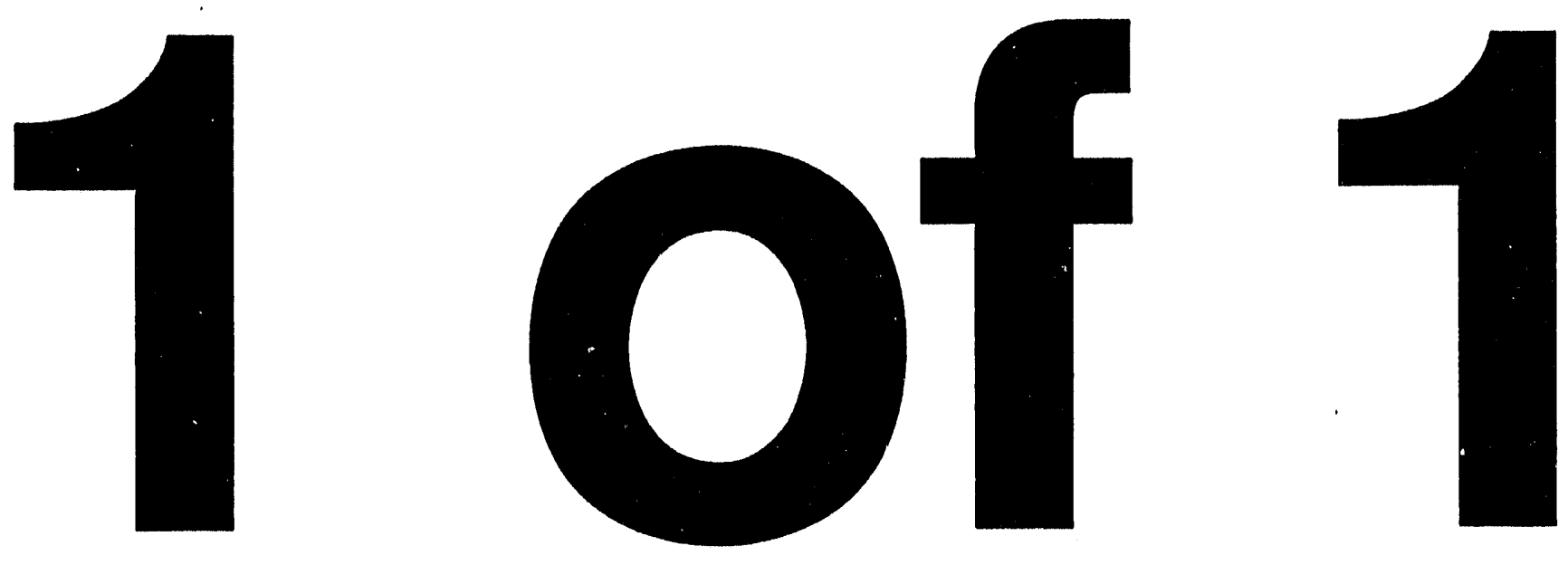
NUREG/CR-5981

CDNSWC/SSM-61-93/01

RF, R5

\section{The Effect of Electric Discharge Machined Notches on the Fracture Toughness of Several Structural Alloys}

Manuscript Completed: April 1993

Date Published: September 1993

Prepared by

J. A. Joyce, U.S. Naval Academy

R. E. Link, Naval Surface Warfare Center

U. S. Naval Academy

Annapolis MD 21402

Naval Surface 'Warfare Center

Annapolis, MD 21402

\section{Prepared for}

Division of Engineering

Office of Nuclear Regulatory Research

U.S. Nuclear Regulatory Commission

Washington, DC 20555

NRC FIN B6290 


\begin{abstract}
Recent computational studies of the stress and strain fields at the tip of very sharp notches have shown that the stress and strain fields are very weakly dependent on the initial geometry of the notch once the notch has been blunted to a radius that is 6 to 10 times the initial root radius. It follows that if the fracture toughness of a material is sufficiently high so that fracture initiation does not occur in a specimen until the crack-tip opening displacement (CTOD) reaches a value from 6 to 10 times the size of the initial notch tip diameter, then the fracture toughness will be independent of whether a fatigue crack or a machined notch served as the initial crack.

In this experimental program the fracture toughness $\left(J_{I c}\right.$ and $J$ resistance $(J-R)$ curve, and CTOD) for several structural alloys was measured using specimens with conventional fatigue cracks and with EDM machined notches. The results of this program have shown, in fact, that most structural materials do not achieve initiation CTOD values on the order of 6 to 10 times the radius of even the smallest EDM notch tip presently achievable. It is found furthermore that tougher materials do not seem to be less dependent on the type of notch tip present. Some materials are shown to be much more dependent on the type of initial notch tip used, but no simple pattern is found that relates this observed dependence to the material strength, toughness, or strain hardening rate.
\end{abstract}




\section{CONTENTS}

Page

ABSTRACT $\ldots \ldots \ldots \ldots \ldots \ldots \ldots \ldots \ldots \ldots \ldots \ldots \ldots \ldots \ldots \ldots$

LIST OF FIGURES $\ldots \ldots \ldots \ldots \ldots \ldots \ldots \ldots \ldots \ldots \ldots \ldots$

LIST OF TABLES $\ldots \ldots \ldots \ldots \ldots \ldots \ldots \ldots \ldots \ldots \ldots \ldots \ldots \ldots$

PRIOR REPORTS $\ldots \ldots \ldots \ldots \ldots \ldots \ldots \ldots \ldots \ldots \ldots \ldots \ldots \ldots$

ACKNOWLEDGEMENT $\ldots \ldots \ldots \ldots \ldots \ldots \ldots \ldots \ldots \ldots \ldots \ldots \ldots$

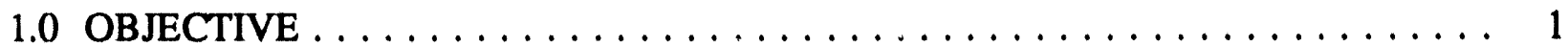

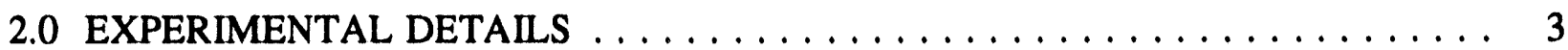

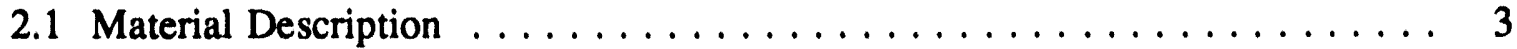

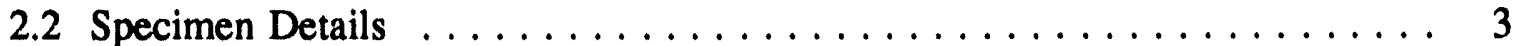

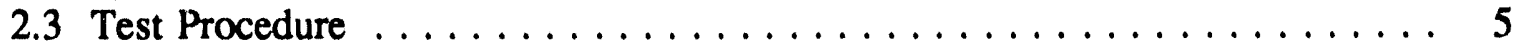

3.0 ANALYSIS $\ldots \ldots \ldots \ldots \ldots \ldots \ldots \ldots \ldots \ldots \ldots \ldots \ldots \ldots \ldots \ldots \ldots$

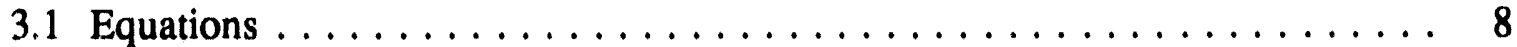

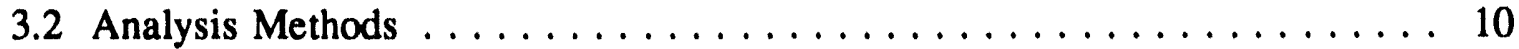

4.0 DISCUSSION OF RESULTS $\ldots \ldots \ldots \ldots \ldots \ldots \ldots \ldots \ldots \ldots$

4.1 Resistance Curve Results . . . . . . . . . . . . . . . . . . 17

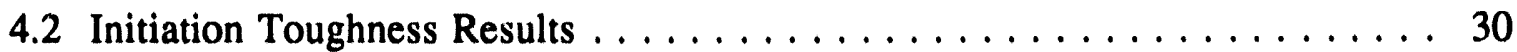

4.3 Improvement of the Common Method $\ldots \ldots \ldots \ldots \ldots$

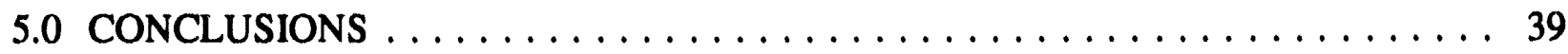

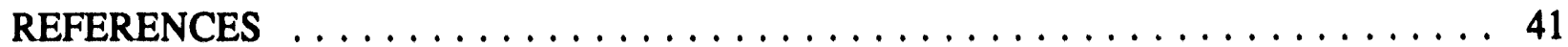

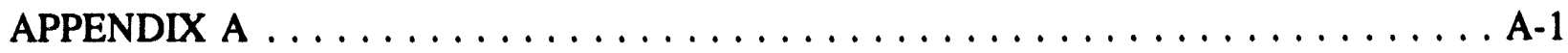




\section{LIST OF FIGURES}

No.

Page

1 EDM notch tip geometry appearance in (a) CS-19 aluminum specimen and (b) A533B steel specimen. ......................... 6

2 Schematic showing E813 procedure to obtain $\mathrm{J}_{\mathrm{Q}}$ using an offset construction line

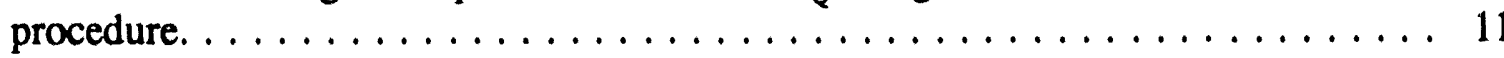

3 Schematic showing proposed procedure to evaluate the best initial crack length

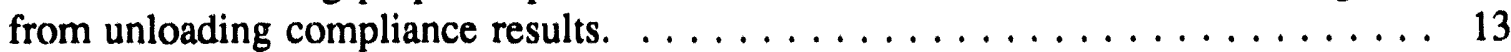

4 Schematic of E1290 procedure to obtain $\delta_{i} \ldots \ldots \ldots \ldots \ldots \ldots$

5 Schematic showing the Common Method offset construction line procedure used

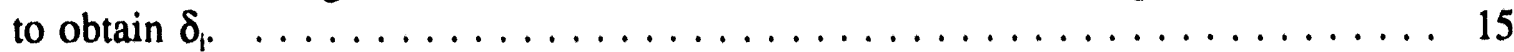

6 J-R curves for the ASTM A302 alloy showing EDM and fatigue precracked results. ............................. 18

7 J-R curves for the ASTM A515 alloy showing EDM and fatigue precracked results. ............................... 19

8 J-R curves for the ASTM A533B alloy showing EDM and fatigue precracked results. ................................ 20

9 J-R curves for the HY-100 alloy showing EDM and fatigue precracked results. . . 21

10 J-R curves for the ASTM A710 (HSLA-80) alloy showing EDM and fatigue precracked results. ........................ 22

11 J-R curves for the CS-19 alloy showing EDM and fatigue precracked results. . . . 23

$12 \delta$-R curves for the ASTM A302 alloy showing EDM and fatigue precracked results. .............................. 24

$13 \delta$-R curves for the ASTM A515 alloy showing EDM and fatigue precracked results. .............................

$14 \delta$-R curves for the ASTM A533B alloy showing EDM and fatigue precracked results. .............................. 26

$15 \delta$-R curves for the HY-100 alloy showing EDM and fatigue precracked results. . . 27 
$16 \delta$-R curves for the ASTM A710 (HSLA-80) alloy showing EDM and fatigue precracked results. ........................ 28

$17 \delta$-R curves for the CS-19 alloy showing EDM and fatigue precracked results. . . . 29

$18 \mathrm{~J}_{\mathrm{Ic}}$ evaluation for specimen FYW-512. $\ldots \ldots \ldots \ldots \ldots \ldots \ldots \ldots \ldots \ldots \ldots$

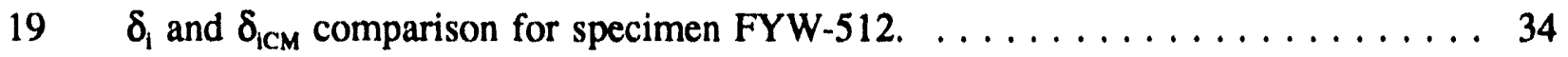

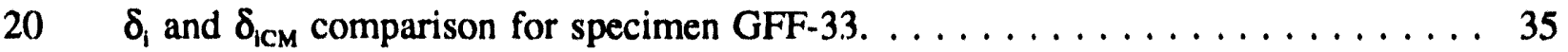




\section{LIST OF TABLES}

No.

1 Chemical composition and mechanical properties of materials used in this study

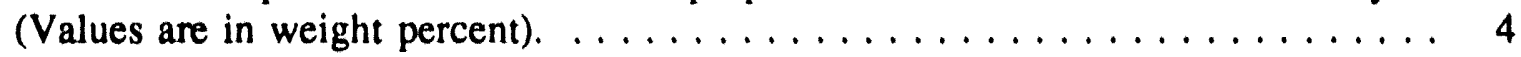

2 Comparison of the average tearing modulus for fatigue precracked and EDM notched specimens. . . . . . . . . . . . . . . . . . . 30

3 Fracture toughness values for EDM notched and fatigue precracked specimens. . . 31

4 Comparison of average fracture toughness measured for EDM notched and fatigue precracked specimens. . . . . . . . . . . . . . . . . 33

$5 \quad$ Comparison of $\Delta \mathrm{a}$ at initiation using construction line slopes of 2.0 and 1.4 . . . 38 


\section{PRIOR REPORTS}

Prior reports is this series are listed below:

1. J. A. Joyce, "Application of the Key Curve Method to Determining J-R Curves for A533B Steel," NUREG/CR-1290, U.S. Nuclear Regulatory Commission, Washington, DC (January 1980).

2. J. P. Gudas, M. G. Vassilaros, J. A. Joyce, D. A. Davis, and D. R. Anderson, "Summary of Recent Investigations of Compact Specimen Geometry Effects on the $J_{1}-R$ Curve of High Strength Steels," NUREG/CR-1813, U.S. Nuclear Regulatory Commission, Washington, DC (November 1980).

3. J. A. Joyce, "Static and Dynamic J-R Curve Testing of A533B Steel Using the Key Curve Analysis Technique," NUREG/CR-2274, U.S. Nuclear Regulatory Commission, Washington, DC (July 1981).

4. J. A. Joyce, "Instability Testing of Compact and Pipe Specimens Utilizing a Test System Made Compliant by Computer Control," NUREG/(-R-2257, U.S. Nuclear Regulatory Commission, Washington, DC (March 1982).

5. M. G. Vassilaros, J. P. Gudas, and J. A. Joyce, "Experimental Investigation of Tearing Instability Phenomena for Structural Materials," NLREG/CR-2570, Rev. 1, U.S. Nuclear Regulatory Commission, Washington, DC (August 1982).

6. Davis, D.A., Vassilaros, M.G., and Gudas, J.P., "Sfecimen Geometry and Extended Crack Growth Effects on $\mathrm{J}_{1}-\mathrm{R}$ Curve Characteristics for HY-130 and ASTM A533B Steels," USNRC Report NUREG/CR-3089, U.S. Nuclear Regulatory Commission, Washington, DC (November 1982).

7. Vassilaros, M.G. et al., "J-Integral Tearing Instat ility for 8-Inch Diameter ASTM A106 Steel Pipe." USNRC Report NUREG/cr-3740, U.S. Nuclear Regulatory Commission, Washington, DC (March 1984).

8. J. A. Joyce, "Development and Verification of C'onditions for Ductile Tearing Instability and Arrest," NUREG/CR-4528, U.S. Nuclear Regulatory Commission, Washington, DC (February 1986).

9. Hays, R.A., Vassilaros, M.G., and Gudas, J.P., "Fracture Analysis of Welded Type 304 Stainless Steel Pipe," USNRC Report NUREG/LR-4538 Vol. 1, U.S. Nuclear Regulatory Commission, Washington, DC (February 1986). 
10. Link, R.E., and Hays, R.A., "Investigation of Tearing Instability Phenomena in ASTM A106 Steel," USNRC Report NUREG/CR-4539, U.S. Nuclear Regulatory Commission, Washington, DC (February 1986).

11. Hackett, E.M., Kirk, M.T., and Hays, R.A., "An Evaluation of J-R Curve Testing of Nuclear Piping Materials Using the Direct Current Potential Drop Technique," USNRC Report NUREG/CR-4540, U.S. Nuclear Regulatory Commission, Washington, DC (June 1986).

12. J. A. Joyce and E. M. Hackett, "Application of the Key Curve and Multispecimen Techniques to Dynamic J-R Curve Testing of Alloy Steel, "NUREG/CR-4579, U.S. Nuclear Regulatory Commission, Washington, DC (April 1986).

13. J. A. Joyce and C. S. Schneider, "Application of Alternating Current Potential Difference to Crack Length Measurement During Rapid Loading," NUREG/CR-4699, U.S. Nuclear Regulatory Commission, Washington, DC (August 1986).

14. J. A. Joyce and E. M. Hackett, "Development of an Analytic Key Curve Approach to Drop Tower J-R Curve Measurement," NUREG/CR-4782, U.S. Nuclear Regulatory Commission, Washington, DC (December 1986).

15. J. A. Joyce and E. M. Hackett, "Transition Range Drop Tower J-R Curve Testing of A106 Steel," NUREG/CR-4818, U.S. Nuclear Regulatory Commission, Washington, DC (February 1987).

16. J. A. Joyce "Ductile to Brittle Toughness Transition Characterization of A533B Steel," NUREG/CR-5142, U.S. Nuclear Regulatory Commission, Washington, DC (June 1988).

17. J. A. Joyce, D. A. Davis, E. M. Hackett, and R. A. Hays, "Application of the J-Integral to Cases of Large Crack Extension," NUREG/CR-5143, U.S. Nuclear Regulatory Commission, Washington, DC (February 1989).

18. J. A. Joyce and E. M. Hackett, "Development of an Engineering Definition of the Extent of J Singularity Controlled Crack Growth," NUREG/CR-5238, U.S. Nuclear Regulatory Commission, Washington, DC (May 1989).

19. J. A. Joyce and E. M. Hackett, "Extension and Extrapolation of J-R Curves and Their Application to the Low Upper Shelf Toughness Issue," NUREG/CR-5577, U.S. Nuclear Regulatory Commission, Washington, DC (March 1991).

20. J. A. Joyce, E. M. Hackett, and C. Roe, "Comparison of $\mathrm{J}_{\mathrm{Ic}}$ and J-R Curves for Short Crack and Tensiley Loaded Specimen Geometries of a High Strength Structural Steel," NUREG/CR-5879, U.S. Nuclear Regulatory Commission, Washington, DC (November 1992). 
21. O'Dowd, N.P. and Shih, C.F., "Two-Parameter Fracture Mechanics: Theory and Applications," NUREG/CR-5958, U.S. Nuclear Regulatory Commission, Washington, DC (February 1993).

22. Kirk, M.T. and Dodds, R.H., Jr., "J and CTOD Estimation Equations for Shallow Cracks in Single Edge Notch Bend Specimens," NUREG/CR-5969, U.S. Nuclear Regulatory Commission, Washington, DC (July 1993).

23. Kirk, M.T. and Dodds, R.H., Jr., "Approximate Techniques for Predicting Size Effects on Cleavage Fracture Toughness $\left(J_{c}\right)$," NUREG/CR-5970, U.S. Nuclear Regulatory Commission, Washington, DC (July 1993).

24. Dodds, R.H., Jr., Shih, C.F., and Anderson, T.L., "Continuum and Micromechanics Treatment of Constraint in Fracture," NUREG/CR-5971, U.S. Nuclear Regulatory Commission, Washington, DC (July 1993). 


\section{ACKNOWLEDGEMENT}

This work was performed at the Naval Surface Warfare Center, and the U. S. Naval Academy, both in Annapolis Maryland, under the program, "Elastic-Plastic Fracture Evaluation of L.WR Alloys," Mr, R.E. Link, Program Manager. The program is sponsored by the Office of Nuclear Regulatory Research of the U.S. Nuclear Regulatory Commission (NRC). The technical monitor for the NRC is Dr. Shah N.M. Malik. The authors would also like to acknowledge the help of Mr. Charles Roe of the Naval Surface Warfare Center and Mr. Wayne Farmer and Mr. John Hein of the U.S. Naval Academy. 


\subsection{OBJECTIVE}

Standard techniques for evaluating the fracture toughness of a material involve testing a notched specimen that contains a real crack at the tip of the notch. The crack is introduced by fatigue loading the specimen at a load that is a small fraction of that required to initiate stable tearing. The fatigue cracking procedure results in a very sharp, natural crack that is designed to provide a high level of constraint and hence, a measurement of the fracture toughness near the lower bound. The fatigue cracking procedure can be a time-consuming process and adds to the cost and complexity of conducting fracture toughness tests. For many situations of practical interest such as the testing of weldments, it may be difficult, if not impossible, to produce a satisfactory fatigue crack that samples the material of interest. This is particularly true when trying to measure the fracture toughness of a heat affected zone or local brittle zone in a weldment. Residual stresses and inhomogeneity of material properties can lead to unsatisfactory crack fronts that do not sample the desired material or microstructure. Fracture toughness testing procedures could be greatly simplified if a very sharp, machined notch could be used as the initial crack in lieu of a real fatigue crack.

Conventional machining methods cannot produce a sharp enough notch that can adequately simulate a fatigue crack. Work by Joyce and Gudas[1] showed that machined notches with sharp tips $\left(\approx 0.001\right.$ in. radius) but with included angles of $60^{\circ}$ caused the measured $\mathrm{J}_{\mathrm{lc}}$ fracture toughness to be elevated by a factor of between three and four for an HY130 steel. Over the past decade, advances in electric discharge machining (EDM) equipment and procedures have made it possible to produce much narrower notches than previously available with notch tip radii on the order of 0.002 inches. It is a simple matter to produce slots in typical fracture specimens that are 0.004 in. wide with a 0.002 in. root radius at the tip of the notch. The advantage of an EDM notch over a fatigue crack is that the EDM notch can be located precisely at the microstructure of interest and the notch will be perfectly straight.

A basic assumption of elastic-plastic fracture mechanics is that a single parameter, the crack tip opening displacement (CTOD) or J integral is sufficient to describe the stress and strain distribution at the tip of a crack and that crack initiation occurs when this parameter attains a 
critical value. The fracture toughness is defined as the critical value of this parameter at the onset of significant ductile crack extension. Recent computational studies of the stress and strain fields at the tip of sharp notches have shown that the stress and strain fields are very weakly dependent on the initial geometry of the notch once the notch has been blunted to a radius that is 6 to 10 times the initial root radius ${ }^{1}$. It follows that if the fracture toughness of a material is sufficiently high so that fracture does not occur in a specimen until the CTOD reaches a value from 6 to 10 times the size of the initial notch tip diameter, then the fracture toughness will be independent of whether a fatigue crack or a smooth notch served as the initial crack.

The objective of this experimental program was to measure the fracture toughness, $\delta_{i}$ and $\mathrm{J}_{\mathrm{Ic}}$, and resistance curves (CTOD-R and J-R) for several structural alloys using specimens with conventional fatigue cracks and also with EDM notches. The results were then compared in terms of the ratio of the measured CTOD at crack initiation to the initial notch radius. It is expected from the preceding argument, that low toughness alloys will demonstrate a dependence of fracture toughness on the crack tip geometry, while tougher materials will not.

${ }^{1}$ Private communication, C.F. Shih, Brown University, USA, 1991. 


\subsection{EXPERIMENTAL DETAILS}

\subsection{Material Description}

Six steel alloys and one aluminum alloy were examined in this investigation. Three of the steels were pressure vessel steels, ASTM A302, A533 Grade B, and A515. Two were high strength structural steels, HY-100 and ASTM A710 and the aluminum was a magnesiummolybdenum aluminum alloy, CS-19. This selection of alloys provides a wide range of strength and toughness with which to evaluate the effects of EDM notches on toughness. The aluminum alloy and HY-100 steel have a CTOD fracture toughness (using standard fatigue pre-cracked specimens) on the order of the EDM notch width used in this study. The remaining steels have a CTOD fracture toughness which is greater than the width of the EDM notch to varying degrees. The chemical composition and mechanical properties of the materials used in this study are listed in Table 1. The strain hardening exponent, $\mathrm{N}$, was determined from the relationship ${ }^{2}$

$$
\frac{U T S}{Y S}=\frac{\left(\frac{n}{0.002}\right)^{n}}{\exp (n)}
$$

where $\mathrm{N}=1 / \mathrm{n}$.

\subsection{Specimen Details}

The specimen geometries used in this investigation were 1T C(T) and 1T SE(B) specimens. The $\mathrm{C}(\mathrm{T})$ specimens were used for the CS-19 aluminum and A710 steel and were 1 in. thick. SE(B) specimens were used for all other tests. The A302 and A515 steel specimens were 2 in. thick and the HY-100 and A533B steel specimens were 1 in. thick. All specimens were side grooved to a depth of $10 \%$ of the specimen thickness on each face. The $\operatorname{SE}(B)$ specimens had a flex bar mounted on one face of the specimen to measure the load-line displacement.

\footnotetext{
${ }^{2}$ Anderson, T.L. and Dodds, R.H., Jr., "Simple Constraint Corrections for Subsize Fracture Toughness Specimens," ASTM International Symposium on Small Specimen Test Techniques and Their Application to Nuclear Reactor Vessel Thermal Annealing and Plant Life Extension, January 29-30, 1992, New Orleans, LA.
} 
Table 1 Chemical composition and mechanical properties of materials used in this study (Values are in weight percent).

\begin{tabular}{|c|c|c|c|c|c|c|}
\hline & $\begin{array}{c}\text { ASTM } \\
\text { A302,Gr.B }\end{array}$ & $\begin{array}{c}\text { ASTM } \\
\text { A515,Gr.70 } \\
\end{array}$ & $\begin{array}{c}\text { ASTM } \\
\text { A533, Gr.B } \\
\end{array}$ & HY -100 & $\begin{array}{l}\text { ASTM } \\
\text { A710 }\end{array}$ & CS- 19 \\
\hline Carbon & 0.18 & 0.28 & 0.19 & 0.16 & 0.04 & - \\
\hline Manganese & 1.24 & 0.82 & 1.28 & 0.26 & 0.59 & 0.8 \\
\hline Phosphorus & 0.012 & 0.009 & 0.012 & 0.003 & 0.005 & - \\
\hline Sulphur & 0.023 & 0.028 & 0.013 & 0.009 & 0.004 & - \\
\hline Silicon & 0.22 & 0.21 & 0.21 & 0.19 & 0.25 & 0.08 \\
\hline Nickel & - & - & 0.64 & 2.76 & 0.90 & - \\
\hline Chromium & - & - & - & 1.57 & 0.70 & 0.10 \\
\hline Molybdenum & 0.47 & - & 0.55 & 0.42 & 0.19 & - \\
\hline Aluminum & - & - & - & - & - & Bal. \\
\hline Iron & Bal. & Bal. & Bal. & Bal. & Bal. & 0.07 \\
\hline Copper & - & - & - & - & 1.17 & - \\
\hline Vanadium & - & - & - & 0.003 & 0.003 & - \\
\hline Titanium & . & - & - & - & 0.06 & - \\
\hline Columbium & - & . & - & - & 0.03 & - \\
\hline Magnesium & - & - & - & - & - & 8.42 \\
\hline Beryllium & - & - & - & - & - & 0.001 \\
\hline $\begin{array}{c}0.2 \% \text { YS, Mpa } \\
\text { (ksi) }\end{array}$ & $\begin{array}{l}393 \\
(57)\end{array}$ & $\begin{array}{l}262 \\
(38)\end{array}$ & $\begin{array}{c}443 \\
(64.7)\end{array}$ & $\begin{array}{c}747 \\
(109)\end{array}$ & $\begin{array}{c}511 \\
(74.6)\end{array}$ & $\begin{array}{c}251 \\
(36.4)\end{array}$ \\
\hline $\begin{array}{l}\text { UTS, Mpa } \\
\text { (ksi) }\end{array}$ & $\begin{array}{r}538 \\
(78) \\
\end{array}$ & $\begin{array}{l}517 \\
(75)\end{array}$ & $\begin{array}{r}622 \\
(90.8) \\
\end{array}$ & $\begin{array}{c}877 \\
(128)\end{array}$ & $\begin{array}{c}601 \\
(87.7) \\
\end{array}$ & $\begin{array}{c}408 \\
(59.2)\end{array}$ \\
\hline $\begin{array}{l}\text { \%Elon. in } 50 \\
\text { mm (2 in.) }\end{array}$ & 33 & 35 & 26 & 16.5 & 33 & 24 \\
\hline $\begin{array}{c}\text { Red. of Area, } \\
\%\end{array}$ & 68 & 54 & 60 & 57 & 74 & 29 \\
\hline $\begin{array}{l}\text { Hardening } \\
\text { Exponent, } N\end{array}$ & 9 & 5 & 9 & 15 & 15 & 7 \\
\hline
\end{tabular}


Notches were prepared by wire electric discharge machining to extend the crack starter slot a minimum of 0.2 in., resulting in a final notch length, a/W, between 0.6 and 0.7 . The wire diameter was 0.004 in. The EDM operation resulted in approximately semi-circular notch tips with a radius of 0.002 in. Photographs of the notch tip in a CS-19 aluminum and an A533B steel specimen are shown in Figure 1.

\subsection{Test Procedure}

Fracture toughness tests were conducted using the unloading compliance technique and following the guidelines in the relevant ASTM standards, E813, E1152 and E1290. The loading was carried out until a total crack extension of approximately $0.2 \mathrm{in}$. was achieved. Some results for the fatigue pre-cracked specimens were obtained from pre-existing data, and these had been tested to different final crack extensions. All data sets were analyzed using the equations and methods described in the following sections. $J$ integral calculations were made using the crack growth corrected $J$ equations of ASTM E1152, and these calculations are acceptable for $\mathrm{J}_{\mathbf{l c}}$ calculations according to ASTM E813. The CTOD $(\delta)$ calculations were made using two different equations so that comparisons between ASTM E1290 and the new ASTM Task Group E24.08.01 "Common Method"3 procedure could be made. In order to obtain the most accurate comparison of $\mathrm{J}_{\mathrm{lc}}$ and $\delta_{\mathrm{i}}$ values, the initialization procedure that has recently been developed by ASTM Task Group E24.08.034 was applied to all data. This procedure evaluates an average initial crack length that is then used for all crack extension estimations. This method avoids arbitrary "eyeball" data shifts that have characteristically been applied to J-R curves before evaluation of both $\mathrm{J}_{\mathrm{Ic}}$ and $\delta_{1}$ values.

All testing was conducted at temperatures corresponding to the upper shelf for each

\footnotetext{
3"Standard Method for Measurement of Fracture Toughness," Draft 11, September 1992. Working document of ASTM Task Group E24.08.01, American Society for Testing and Materials, Philadelphia, PA 19103.

4"Standard Test Method for J-Integral Characterization of Fracture Toughness," Draft 8-4, January 1993, Working document of ASTM Task Group E24.08.03, American Society of Testing and Materials, Philadelphia, PA, 19103.
} 

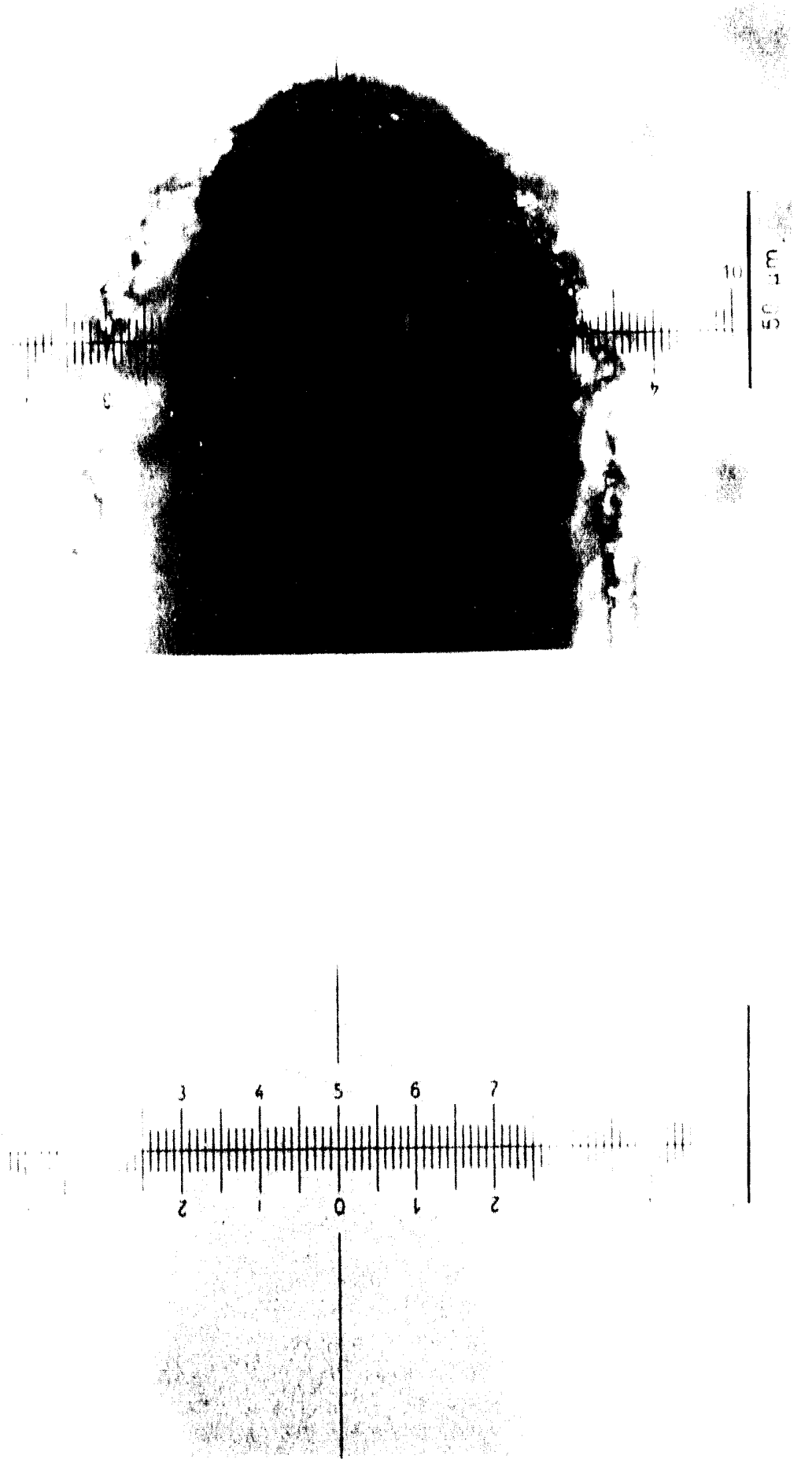

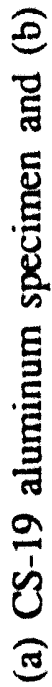
.

త

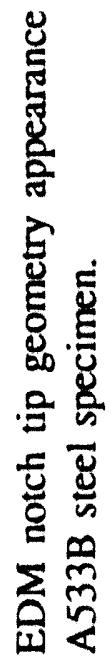
氙 
material. The HY-100, A710, A302 and CS-19 alloys were tested at room temperature. The A533B specimens were tested at $240^{\circ} \mathrm{F}$ and the $\mathrm{A} 515$ specimens were tested at $302^{\circ} \mathrm{F}$. 


\subsection{ANALYSIS}

\subsection{Equations}

The J resistance curves were calculated using the equations of E1152-87. The J integral was calculated using the relationship that:

$$
J_{(1)}=\frac{K_{(1)}{ }^{2}\left(1-v^{2}\right)}{E}+J_{N(1)}
$$

where $K_{(1)}$ is taken from Test Method E399-90 for the SE(B) specimen:

$$
K_{(0)}=\left[\frac{P_{1} S}{\left(B B_{N}\right)^{1 / 2} W^{3 / 2}}\right] R(a / W)
$$

with:

$$
f(a / W)=\frac{3(a / W)^{1 / 2}\left[1.99-(a / W)(1-a / W)\left(2.15-3.93(a / W)+2.7(a / W)^{2}\right)\right]}{2(1+2 a / W)(1-a / W)^{3 / 2}}
$$

and $K_{(i)}$ for the $C(T)$ is:

$$
K_{(1)}=\frac{P_{1}}{\left(B B_{N} W^{1 / 2}\right.} f(a / W)
$$

with:

$$
f(a / W)=(2+a / W) \frac{\left[0.866+4.64 a / W-13.32(a / W)^{2}+14.72(a / W)^{3}-5.6(a / W)^{4}\right]}{(1-a / W)^{3 / 2}}
$$


For hoth the $S E(B)$ and $C(T)$ specimens:

$$
J_{p(1)}=\left[J_{p(1-1)}+\left(\frac{\eta_{1}}{b_{1}}\right) \frac{A_{p(1)}-A_{p(1-1)}}{B_{N}}\right]\left[1-\gamma_{1} \frac{\left(a_{1}-a_{1-1}\right)}{b_{1}}\right]
$$

where for the $\mathrm{C}(\mathrm{T})$ specimen:

$\eta_{1}=2.0+0.522 b_{/} / W$, and $\gamma_{1}=1.0+0.76 b_{/} / W$,

and for the $\mathrm{SE}(\mathrm{B})$ specimen:

$\eta_{1}=2.0$ and $\gamma_{1}=1.0$

For CTOD calculations, individual $\delta$ values were calculated in two ways. For the ASTM E1290 8 calculations the equation used was:

$$
8=\frac{K^{2}\left(1-v^{2}\right)}{2 \sigma_{v^{2}}}+\frac{r_{p}\left(W-a_{0}\right) v_{v}}{r_{p}\left(W-a_{0}\right)+a_{0}+2}
$$

where the center of rotation is defined by $r_{p}$, with $r_{p}=0.44$ for the $S E(B)$ and $r_{p}=0.4(1+\alpha)$ for the C(T) specimen with $\alpha$ defined by:

$$
a=2 \sqrt{\left(\frac{a_{0}}{b_{0}}\right)^{2}+\frac{a_{0}}{b_{0}}+\frac{1}{2}}-2\left(\frac{a_{0}}{b_{0}}+\frac{1}{2}\right)
$$

and $V_{p(1)}$ is the plastic component of the crack mouth opening displacement measured at a distance $z$ outside of the specimen crack surface. This equation estimates the crack tip opening displacement at the position of the original crack tip using the original crack length for all 
calculations, i.e. for the calculation of $K, r_{p}$, and $b_{0}=\left(W-a_{0}\right)$.

For the ASTM E24.08.01 "Common Method"s $\delta$ calculations the equation used was:

$$
\delta_{(1)}=\frac{K_{(0)}^{2}\left(1-v^{2}\right)}{2 \sigma_{m} E}+\frac{\left[r_{p}\left(W-a_{(0)}\right)+\Delta a\right] v_{\nu(D)}}{\left[r_{p}\left(W-a_{(1)}\right)+a_{(0)}+2\right]}
$$

with $\Delta a$ being the crack extension that has occurred since the beginning of the test.

This "Common Method" equation is estimating the CTOD at the original crack tip using a specimen ceriter of rotation that is adjusted to account for the true crack length as the test proceeds.

\subsection{Analysis Methods}

Values of the fracture toughness at the initiation of stable tearing, $J_{\mathrm{lc}}$ and $\delta_{1}$ were determined for each specimen in accordance with the procedures in E813 and E1290, respectively. The $J_{1 c}$ procedure of ASTM E813 involves a fit of a two parameter power law equation to the J-R curve data in an "exclusion zone" just beyond the point of ductile crack initiation, as shown in Figure 2. The $J_{0}$ point is evaluated from the intersection of this best-fit power law and an offset line as shown on Figure 2 , and becomes $J_{\mathrm{lc}}$ if specimen size and other criteria are satisfied. This method of evaluating $\mathrm{J}_{\mathrm{Ic}}$ is very sensitive to value of the initial crack length used to estimate the crack extension of each data point on the J-R curve (or $\delta \cdot R$ curve). The ASTM E813 method requires the use of a pre-test initial crack length, which often is not the best value to use for the evaluation of $J_{k e}$. A new method has recently been developed by a

s "Standard Test Method for Measurement of Fracture Toughness," Draft 11, September 1992. Working Document of ASTM Task Group E24.08.01. American Society for Testing and Materials, Philadelphia, PA 19103. 


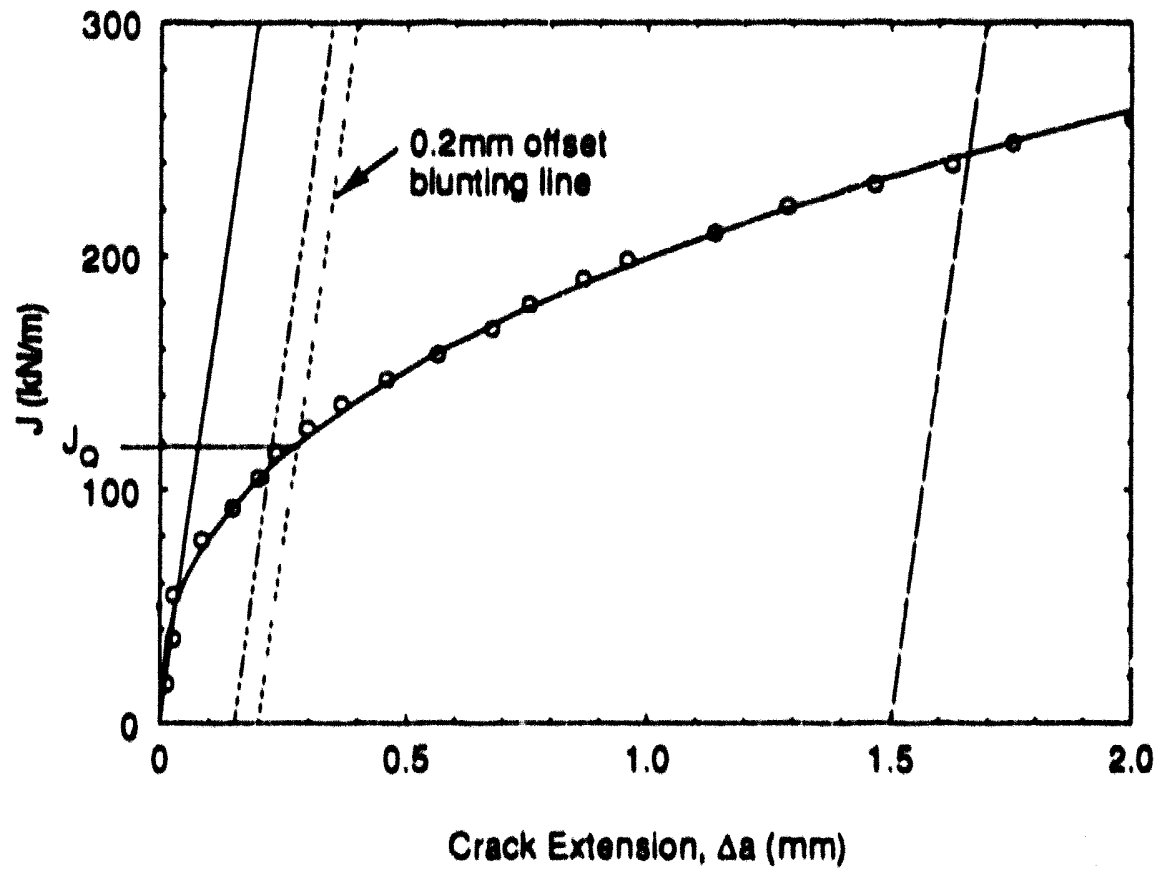

Figure 2 Schematic showing E813 procedure to obtain $\mathrm{J}_{Q}$ using an offset construction line procedure. 
working group of ASTM Subcommittee E:24.08.036 which fits a construction line to the initial $J_{1}-a_{1}$ data to evaluate a best-fit average initial crack length for use in estimating $\Delta a$ and hence the J-R curve and $J_{k}$. This proxedure has been used for all results presented here. The schematic in Figure 3 shows how this method fits a "construction" line with the equation $J=20, \Delta a$ to the J.R curve data with $0.2 \mathrm{~J}_{0} \leq J_{1} \leq 0.6 \mathrm{~J}_{Q}$ and then extrapolates to the abscissa to evaluate a average initial crack length. This crack length is used for the evaluation of the $J$ and $\delta$ resistance curves and then for the evaluation of $J_{16}$ and $\delta_{1}$.

The procedure for evaluating $\delta$, given in ASTM E1290) involves fitting a three-parameter power law to the initial region of the $\delta_{1} \cdot R$ curve, as shown in Figure 4 , and then evaluating the CTOD at a crack extension of $0.2 \mathrm{~mm}(0 .(0) 8 \mathrm{in}$.) using a vertical line as shown in Figure 4. This procedure is simpler than the ERI3 $J_{k}$ procedure described above, but it is even more sensitive to the initial crack length that is used to calculate the $\Delta a_{1}$ values used to generate the 8.R curve. As discussed further below, this procedure has serious flaws, and often results in toughness measures that severely underestimate the true loughness of the material.

The Common Meihod Subcommittee has proposed an alternative procedure for determining the CTOD initiation fracture toughness for implementation in a common fracture toughness testing standard under development. The proposed procedure is very similar to the E813 $\mathrm{J}_{\mathrm{le}}$ procedure with a (wo parameter power law fit to the data near crack initiation and defines the initiation point as the intersection of the filled curve with a line offset from the blunting line as in the procedure for $I_{16}$. A schematic of this method is shown in Figure 5 . This value of CTOD has been denoted as $\delta_{11}$ (subscript CM for Common Method) in this report 10 distinguish it clearly from the E129() 8, quantity. One objective of the "Common Method" is to make this value of CTOD at "initiation" correspond to the $J_{k}$ initiation point of the E81.3 procedure. In this work, correspondence is taken 10 mean that for a given specimen the $J_{\mid c}$ and

" Standard Test Method for J-Integral Characterization of Fracture Toughness," Draft 12, Working Document of ASTM Task Group E:24.()8.(1)3. American Society for Testing and Materials, Philadelphia, PA, 1910). 


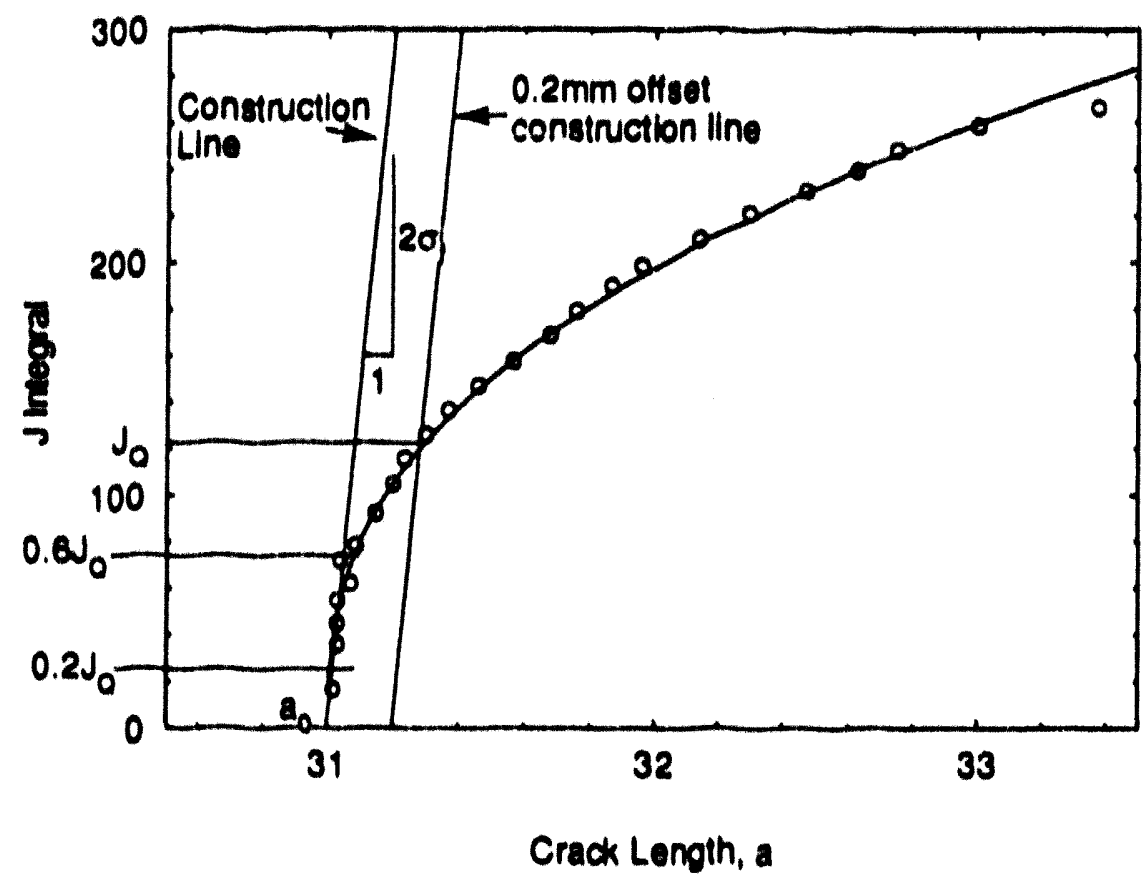

Figure 3 Schematic showing proposed procedure to evaluate the best initial crack length from unloading compliance results. 


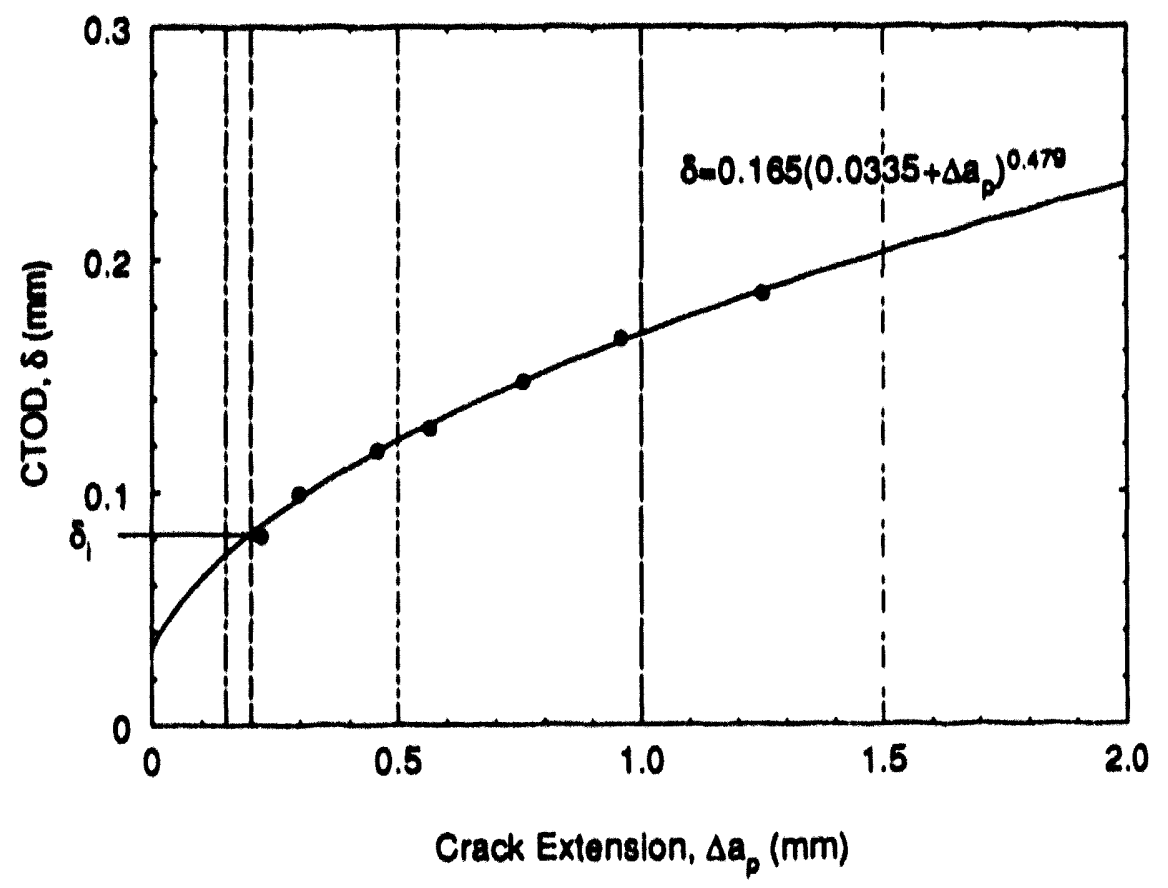

Figure 4 Schematic of E1290 procedure to obtain $\delta_{1}$. 


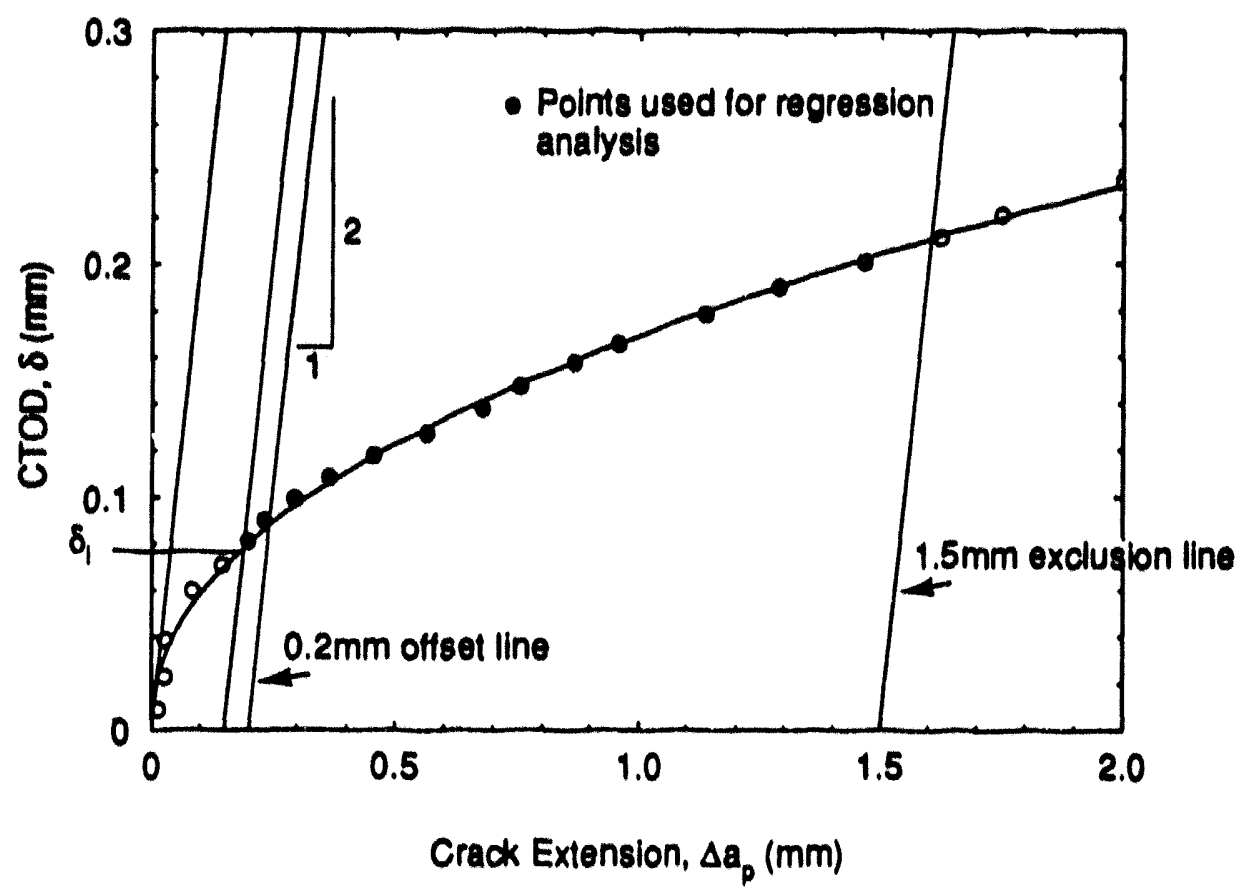

Figure 5 Schematic showing the Common Method offset construction line procedure used to obtain $\delta_{1}$. 
$\delta_{i}$ values obtained would relate to the same amount of ductile crack extension. In a later section a modification of the Common Method is proposed which improves the correspondence of the $\mathrm{J}_{\mathrm{Ic}}$ and $\delta_{\mathrm{iCM}}$ crack initiation measures. 


\subsection{DISCUSSION OF RESULTS}

\subsection{Resistance Curve Results}

J-integral resistance curves for EDM notched and fatigue cracked specimens are plotted in Figure 6-11 for each material. Detailed listings of the results from each test are included in Appendix A. A quick perusal of these figures shows that, as expected, some materials appear to be very sensitive to the type of notch used, while some materials are quite insensitive. Unfortunately, it does not appear that a simple toughness criteria amply predicts which materials are sensitive and which are not. CTOD resistance curves for the same set of specimens are presented in Figure 12-17 and they show exactly the same pattern as demonstrated by the J-R curves. In all cases the resistance curves of EDM specimens are elevated in comparison with the fatigue precracked specimens. In some instances, the elevation is small and the resistance curves overlap somewhat as shown by the A515 alloy while the A533B alloy shows a modest, but clear, elevation, and the CS-19 aluminum shows a dramatic effect, with an elevation by a factor of 3 at a given value of crack extension.

The material tearing resistance, defined as:

$$
T_{\text {max }}=\frac{E}{\sigma_{0}^{2}} \frac{d J}{d a}
$$

is evaluated for each material/notch geometry data set at a crack extension of $1 \mathrm{~mm}(0.039 \mathrm{in}$.) in Table 2. Both modest increases and decreases seem to result for the EDM notch geometry. The low toughness materials, HY-100 steel and CS-19 Aluminum show a 31\% decrease and a $55 \%$ increase, respectively. The high toughness A710 alloy seems to be unaffected by the notch geometry, while the intermediate toughness materials are only modestly affected by the presence of the EDM notch. The numbers in Table 2, for instance, show a toughness decrease of $19 \%$ for the A515 steel, yet this does not seem justified looking at the J-R curves of Figure 7 which shows that considerable data scatter is present for the four specimens tested in this case. It appears that the data is too limited to make any clear conclusion except that no strong effect seems to be present when the fatigue crack is replaced by an EDM notch. 


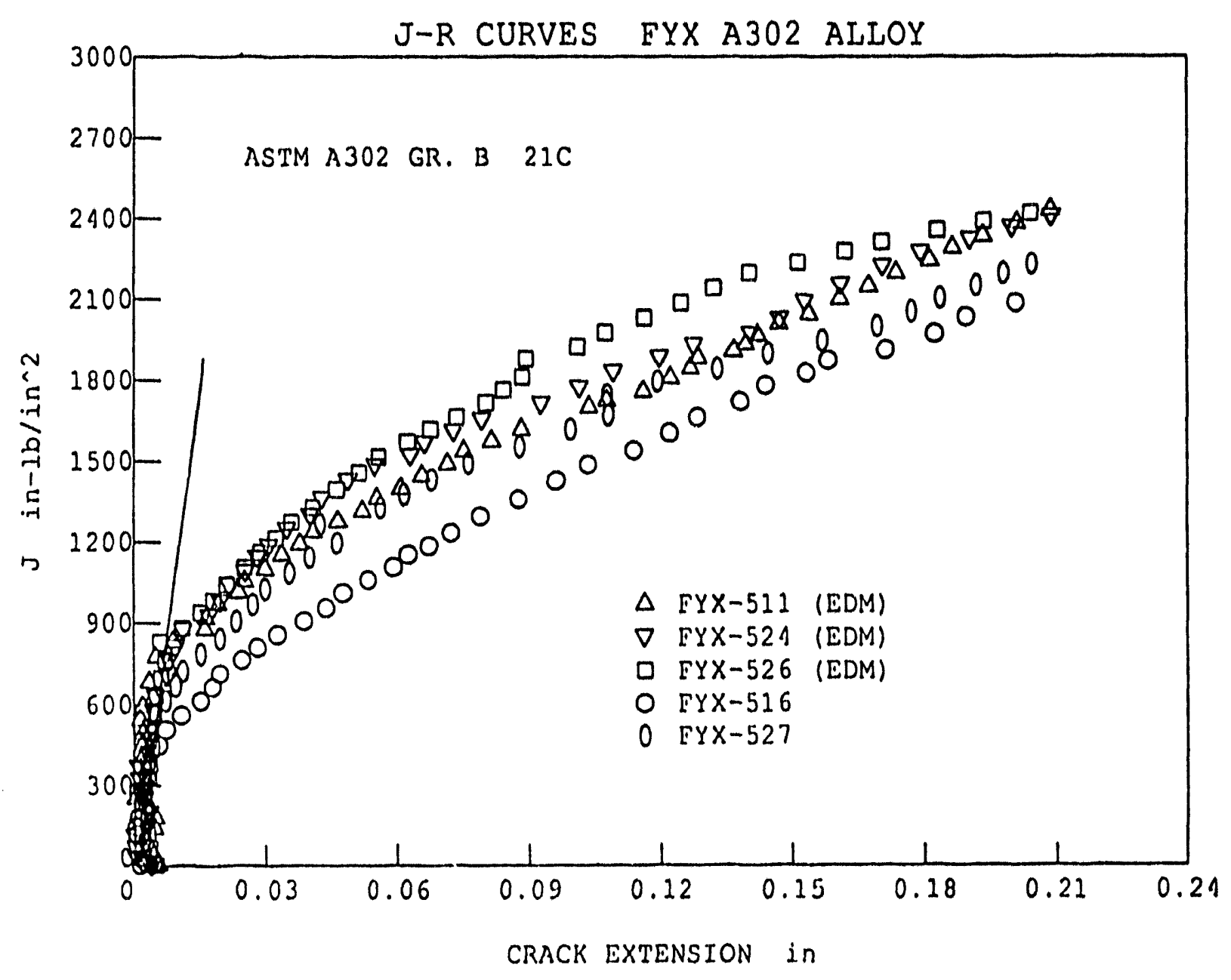

Figure 6 J-R curves for the ASTM A302 alloy showing EDM and fatigue precracked results. 


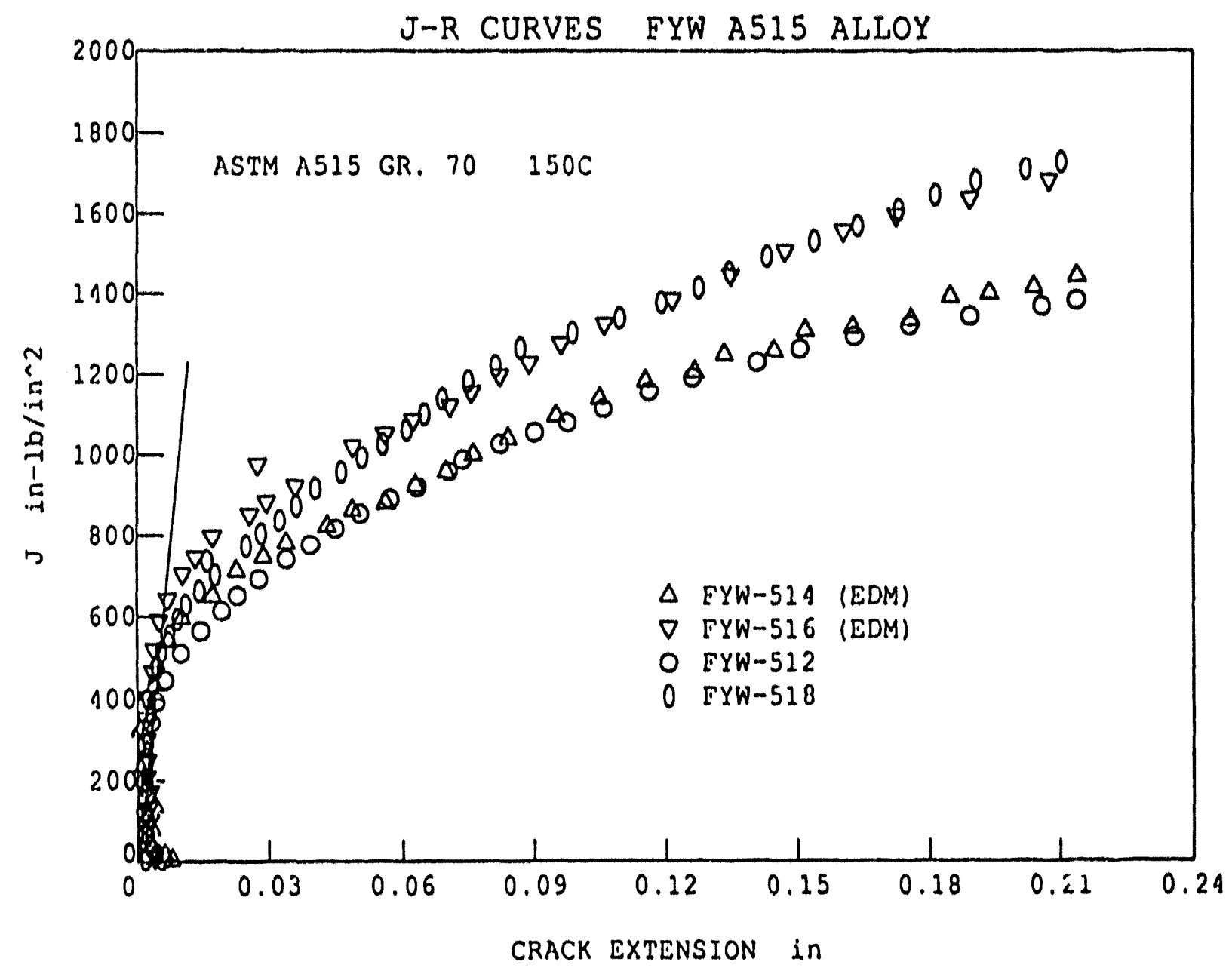

Figure 7 J-R curves for the ASTM A515 alloy showing EDM and fatigue precracked results. 


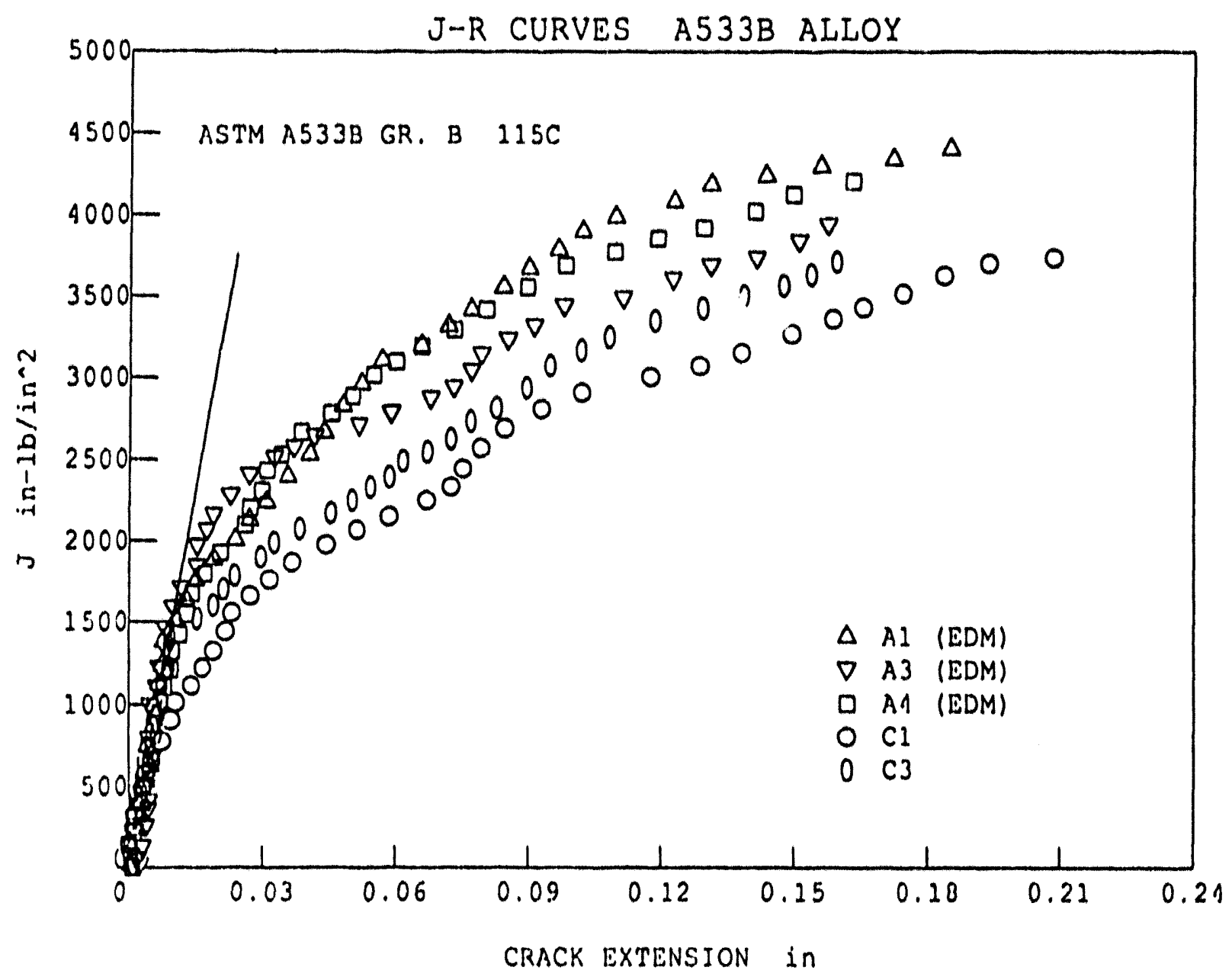

Figure 8 J-R curves for the ASTM A533B alloy showing EDM and fatigue precracked results. 


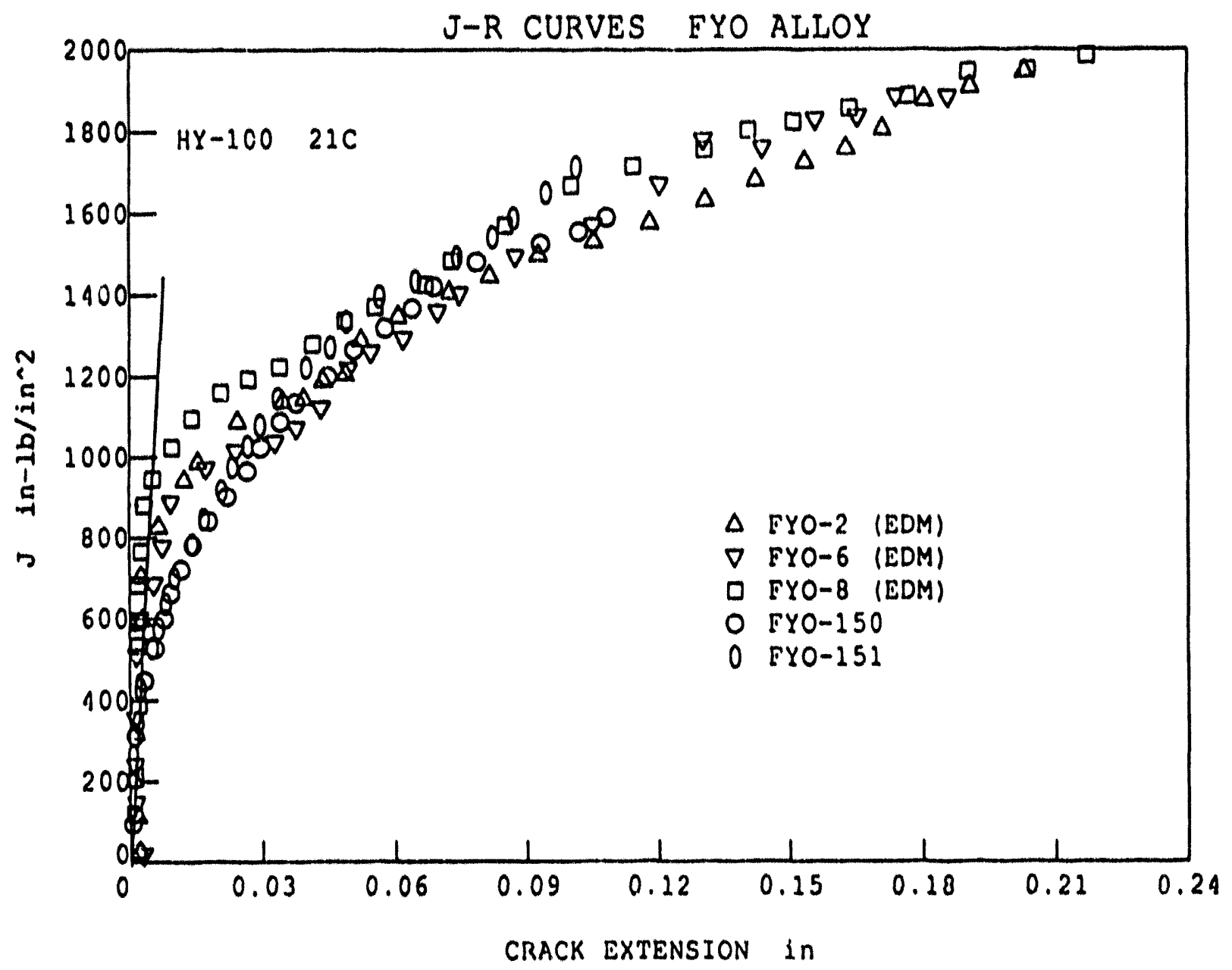

Figure 9 J-R curves for the HY-100 alloy showing EDM and fatigue precracked results. 


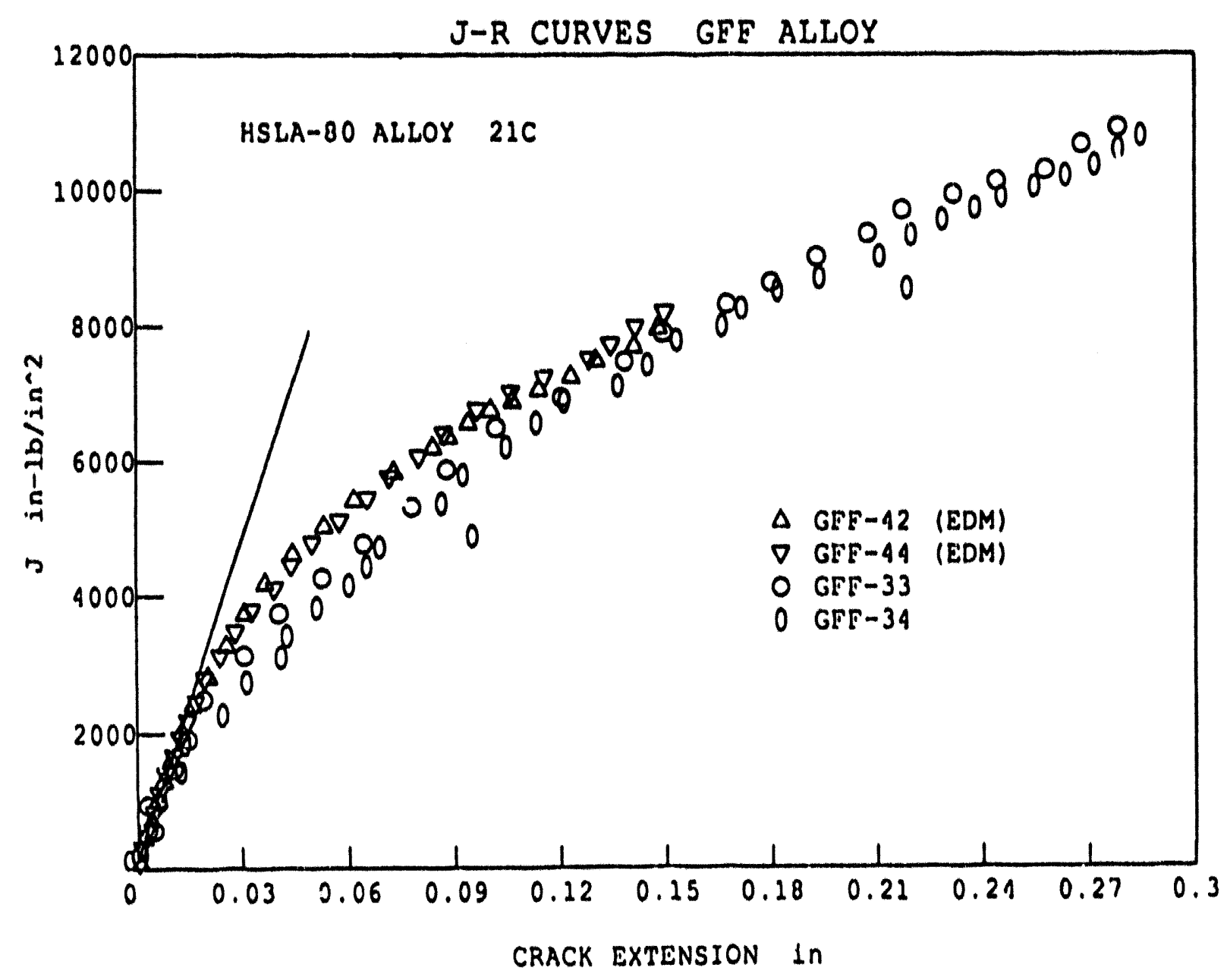

Figure 10 J-R curves for the ASTM A710 (HSLA-80) alloy showing EDM and fatigue precracked results. 


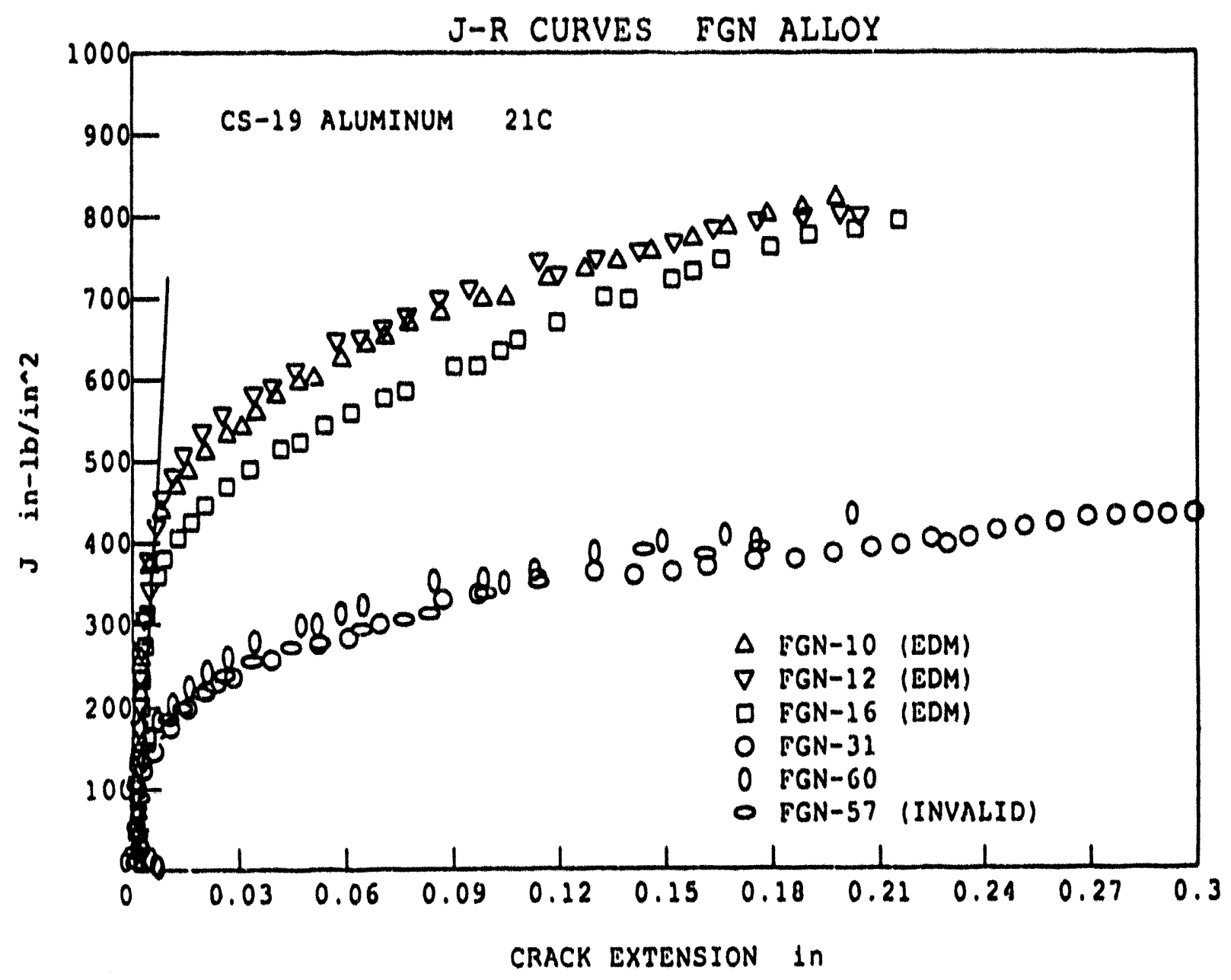

Figure 11 J-R curves for the CS-19 alloy showing EDM and fatigue precracked results. 


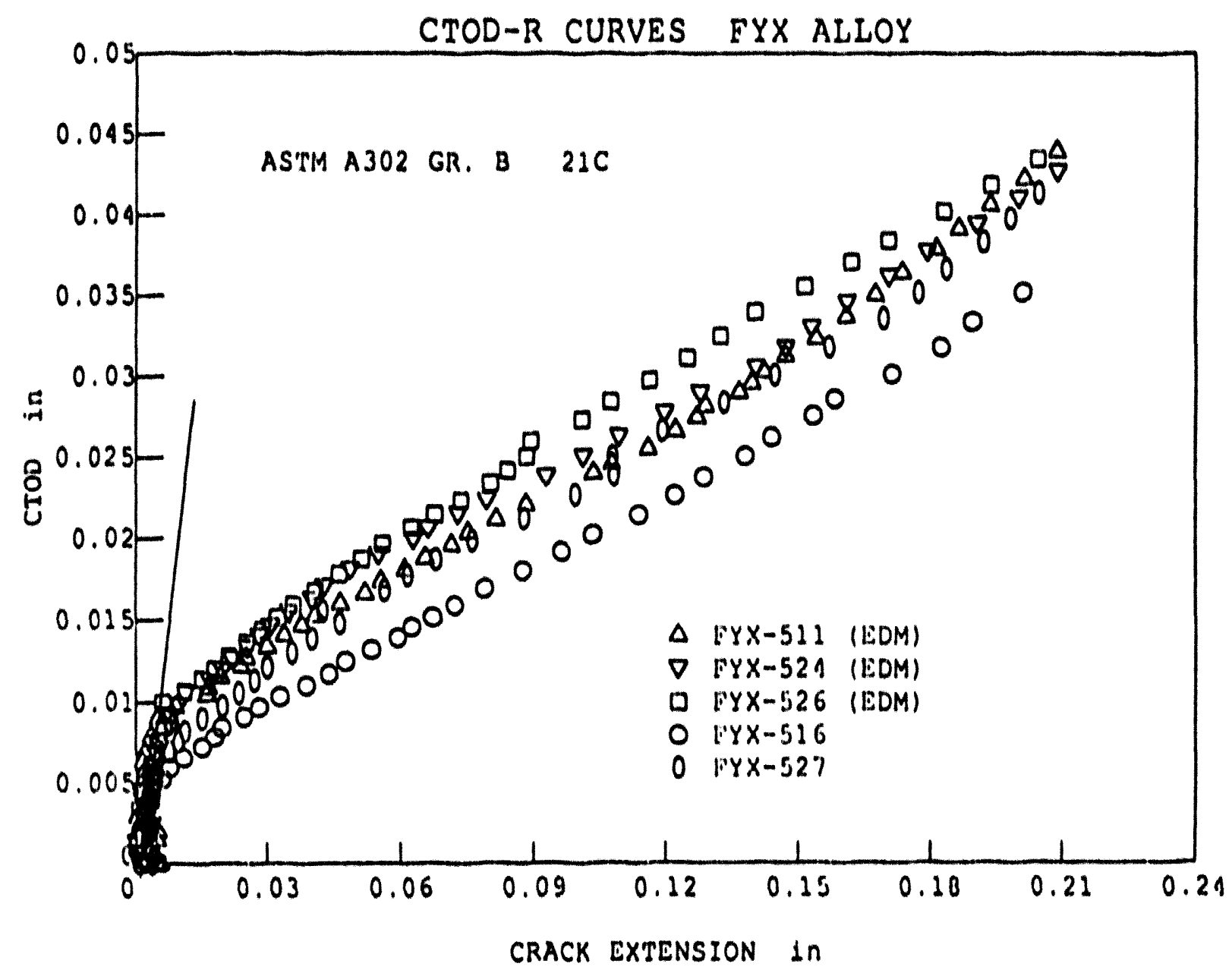

Figure 12 8.R curves for the ASTM A302 alloy showing EDM and fatigue precracked results. 


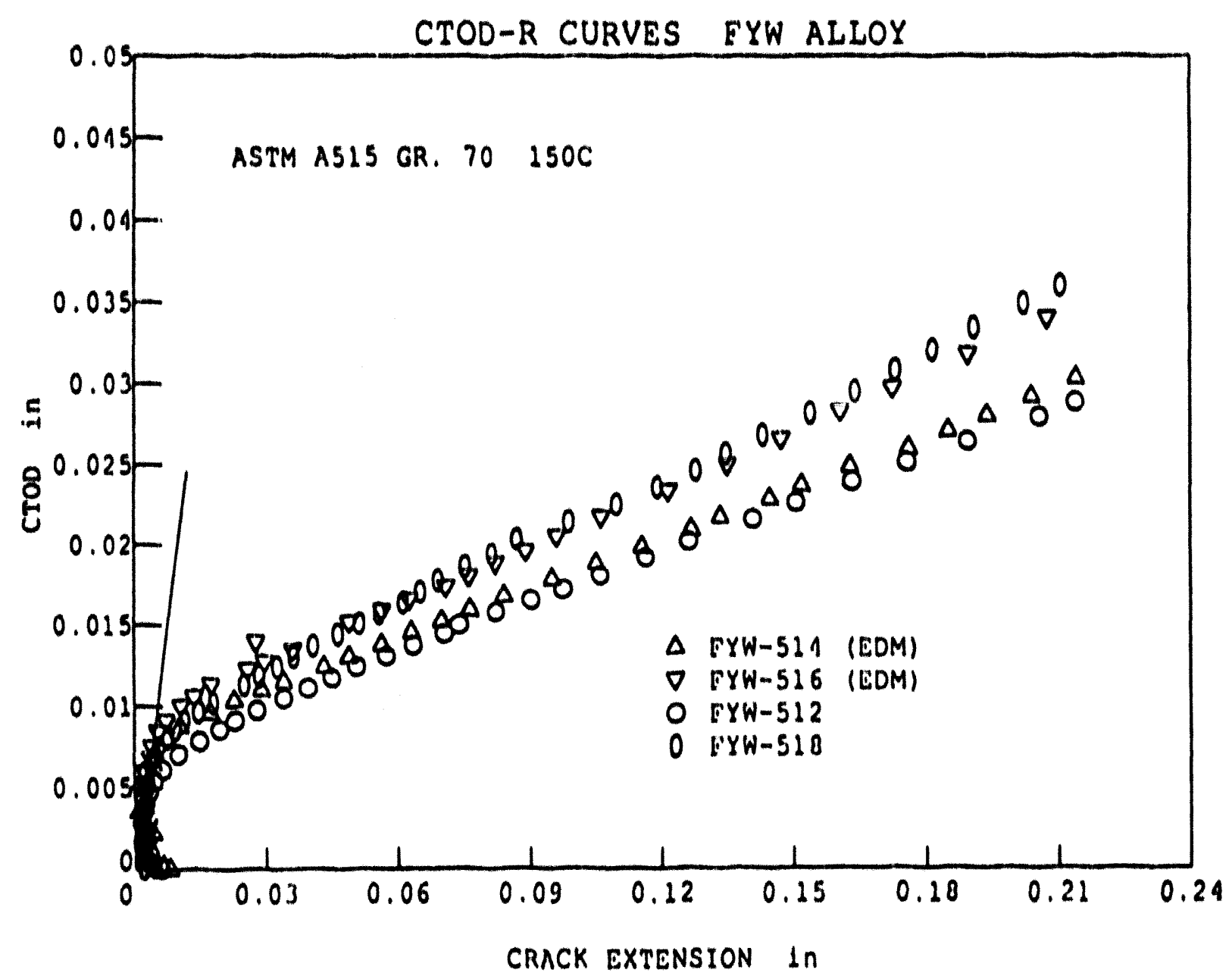

Figure $13 \quad$ 8-R curves for the ASTM AS15 alloy showing EDM and fatigue precracked results. 


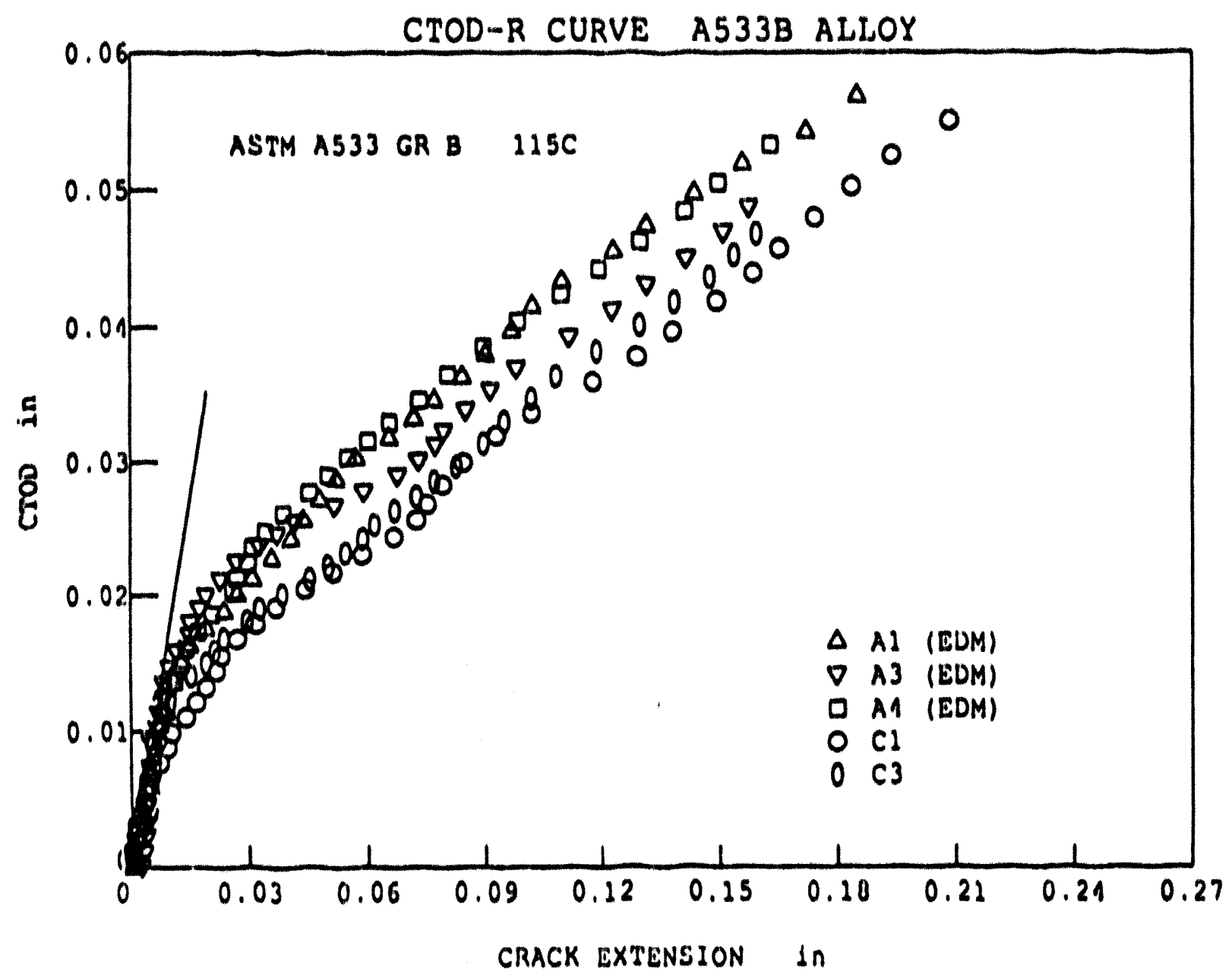

Figure 14 8-R curves for the ASTM A533B alloy showing EDM and fatigue precracked results. 
CTOD-R CURVES FY ALLOY

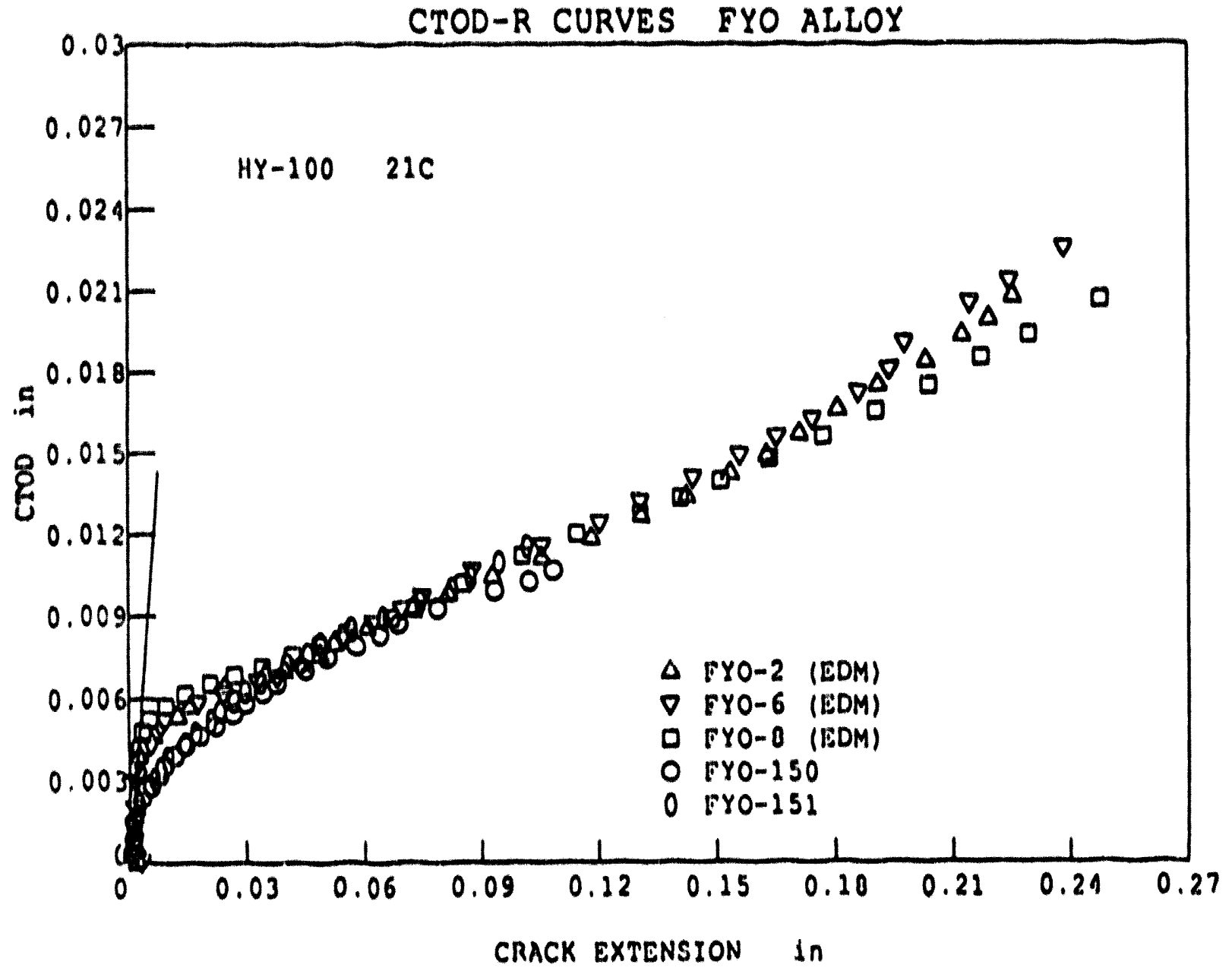

Figure 15 \&-R curves for the HY-100 alloy showing EDM and fatigue precracked results.

27 


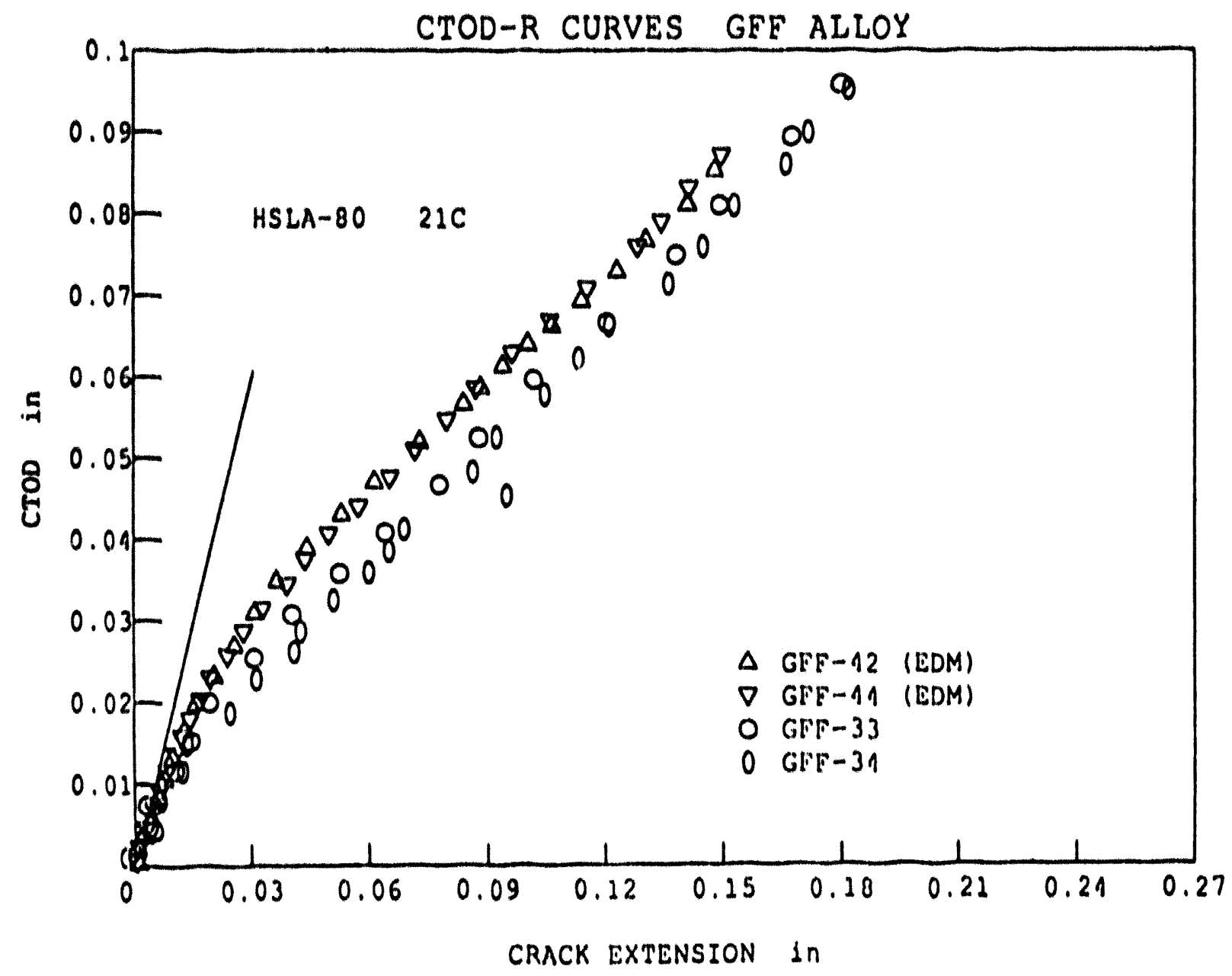

Figure $16 \quad \delta \cdot R$ curves for the ASTM A710 (HSLA-80) alloy showing EDM and fatigue precracked results. 


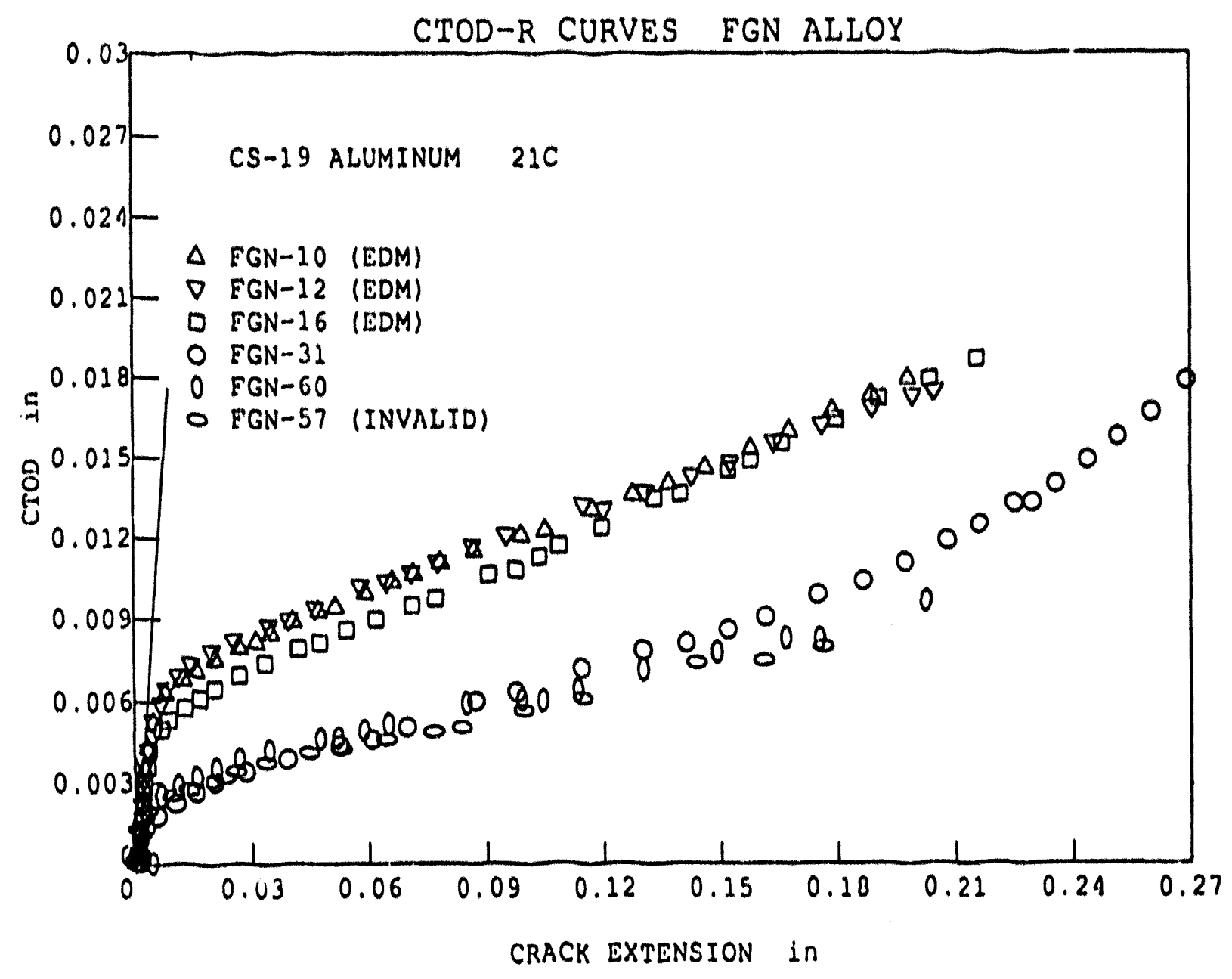

Figure 17 8-R curves for the CS-19 alloy showing EDM and fatigue precracked results. 
Table 2 Comparison of the average tearing modulus for fatigue precracked and EDM notched specimens.

\begin{tabular}{||c|c|c|c||}
\hline \multirow{2}{*}{ Material } & \multicolumn{3}{|c|}{$T$ i $1 \mathrm{~mm}}$. \\
\cline { 2 - 4 } & Fuligue & $\mathrm{EDM}$ & $\%$ diff. \\
\hline A302 & 134. & 141. & 5.2 \\
\hline A515 & 134. & 108. & .19. \\
\hline A533B & 152. & 162. & 6.6 \\
\hline HY-100 & 46.5 & 32. & .31. \\
\hline A710 & 240. & 240. & 0.0 \\
\hline CS-19 & 8.3 & 12.9 & 55. \\
\hline
\end{tabular}

\subsection{Initiation Toughness Results}

$\mathrm{J}_{\mathrm{Ic}}, \delta_{\mathrm{i}}$, and $\delta_{\mathrm{iCM}}$, calculated as described in the previous section, are tabulated in Table 3. The analysis used for $\mathrm{J}_{\mathrm{lc}}$ for specimen FYW-512 is shown in Figure 18, while the calculations of $\delta_{\mathrm{i}}$ and $\delta_{\mathrm{icm}}$ are shown for the same specimen in Figure 19. The average values of fracture toughness for each material are tabulated in Table 4. Some material scatter is clearly present with $\mathrm{J}_{\mathrm{lc}}$ values ranging by up to $17 \%$ from the average, $\delta_{i}$ values ranging up to $12 \%$ from the average, and $\delta_{\mathrm{iCM}}$ values ranging up to $16 \%$ from the average. In all cases, the EDM notched specimens exhibited higher initiation toughness than the fatigue precracked specimens. The elevation in fracture toughness varied from $11 \%$ to $152 \%$, depending on the material and specific measure of fracture toughness considered. As would be expected, the CTOD toughness designated in the Comm.nn Method is consistently higher than that measured according to ASTM E1290 and it ranks the materials in exactly the same fashion as does the $\mathrm{J}_{\mathrm{Ic}}$ measure of E813.

The E1290 definition of $\delta_{\mathrm{i}}$ unfairly penalizes higher toughness materials that exhibit substantial crack tip blunting prior to tearing. This is clearly evident in the case of the ASTM A710 steel. The A710 steel had the highest $\mathrm{J}_{\mathrm{Ic}}$ toughness of all materials tested. In terms of $\delta_{i}$, the A710 ranked third in toughness, just below that of the A302 steel, which had a $J_{I c}$ of approximately one-third that of the A710. According to E1290, the critical event occurs at a fixed amount of crack extension, 0.008 in., regardless of whether the crack has actually begun to tear. The A710 steel is still exhibiting blunting behavior at this point, and as shown on 
Table 3 Fracture toughness values for EDM notched and fatigue precracked specimens.

\begin{tabular}{|c|c|c|c|c|c|c|c|c|c|}
\hline Material & $\begin{array}{l}\text { Specimen } \\
\text { ID }\end{array}$ & $\begin{array}{l}\text { Notch } \\
\text { Type }\end{array}$ & $\left(\mathrm{in}-\mathrm{Ib} / \mathrm{in}^{2}\right)$ & $\begin{array}{c}\mathrm{T} \\
\text { at } 1 \mathrm{~mm}\end{array}$ & $\begin{array}{c}\delta_{1} \\
\text { (in.) }\end{array}$ & $\begin{array}{l}\delta_{\text {ras }} \\
\text { (in.) }\end{array}$ & $\begin{array}{c}\mathrm{Ja}_{10} \text { it } \\
(\text { in. })\end{array}$ & $\begin{array}{l}\text { Aa a } \\
\delta_{\text {ind }} \\
\text { (in.) }\end{array}$ & $\begin{array}{c}\text { Percent } \\
\text { Diff. } \\
\Delta\end{array}$ \\
\hline \multirow{5}{*}{$\begin{array}{c}\text { ASTM } \\
\text { A302 } \\
\text { Gr. B }\end{array}$} & FYX.511 & EDM & 864 & 128. & 0.0090 & 0.0096 & 0.0145 & 0.0129 & -11.0 \\
\hline & FYX-524 & EDM & 877 & 149. & 0.0091 & 0.0099 & 0.0146 & 0.0131 & -10.3 \\
\hline & FYX-526 & EDM & 913 & 147. & 0.0098 & 0.0104 & 0.0148 & 0.0133 & -10.1 \\
\hline & FYX.516 & Fatigue & 566 & 125. & 0.0061 & 0.00621 & 0.0123 & 0.0112 & .8 .9 \\
\hline & FYX-527 & Fatigue & 730 & 144. & 0.0072 & 0.00758 & 0.0135 & 0.0119 & -11.9 \\
\hline \multirow{4}{*}{$\begin{array}{r}\text { ASTM } \\
\text { A515 } \\
\text { Gr. } 70\end{array}$} & FYW-514 & EDM & 614 & 107 & 0.0086 & 0.00847 & 0.0135 & 0.0123 & .8 .9 \\
\hline & FYW-516 & EDM & 769 & 109. & 0.0097 & 0.01032 & 0.0149 & 0.0133 & -10.7 \\
\hline & FYW-512 & Fatigue & 534 & 128. & 0.0068 & 0.00702 & 0.0128 & 0.0116 & .9 .4 \\
\hline & FYW-518 & Fatigue & 653 & 139. & 0.0068 & 0.00909 & 0.0139 & 0.0127 & -8.6 \\
\hline \multirow{5}{*}{$\begin{array}{l}\text { ASTM } \\
\text { A } 533 \\
\text { Gr. B }\end{array}$} & Al & EDM & 1834 & 208. & 0.0122 & 0.0147 & 0.0198 & 0.0154 & -22.2 \\
\hline & A3 & EDM & 2287 & 108. & 0.0148 & 0.0198 & 0.0227 & 0.0179 & -21.1 \\
\hline & A4 & EDM & 2020 & 170. & 0.0110 & 0.0169 & 0.0210 & 0.0165 & .21 .4 \\
\hline & $\mathrm{Cl}$ & Fatigue & 1292 & 156. & 0.0084 & 0.0117 & 0.0163 & 0.0140 & .14 .1 \\
\hline & $\mathrm{C} 3$ & Fatigue & 1599 & 149. & 0.0106 & 0.0135 & 0.0183 & 0.0148 & -19.1 \\
\hline \multirow[t]{7}{*}{ HY-100 } & FYO-2 & EDM & 929 & 32.6 & 0.0050 & 0.00507 & 0.0120 & 0.0106 & -11.7 \\
\hline & FYO-6 & EDM & 847 & 35.3 & 0.0051 & 0.00472 & 0.0117 & 0.0105 & -10.3 \\
\hline & FYO-8 & EDM & 1065 & 28.1 & 0.0058 & 0.00569 & 0.0126 & 0.0109 & -13.5 \\
\hline & FYO-J3 & Futigue & 748 & 38.1 & 0.0039 & 0.00385 & 0.0113 & 0.0100 & -11.5 \\
\hline & FYO-J4 & Fatigue & 658 & 43.2 & 0.0038 & 0.00348 & 0.0109 & 0.0098 & -10.1 \\
\hline & FYO-150 & Fatigue & 701 & 50.1 & 0,0034 & 0.00356 & 0.0111 & 0.0099 & -10.9 \\
\hline & FYO-151 & Fatigue & 715 & 54.6 & 0.0035 & 0.00363 & 0.0111 & 0.0099 & -10.5 \\
\hline \multirow[t]{4}{*}{ HSLA. 80} & GFF-42 & EDM & 4063 & 229. & 0.0097 & 0.0243 & 0.0339 & 0.0202 & -40 \\
\hline & GFF-44 & EDM & 3659 & 250. & 0.0103 & 0.0217 & 0.0311 & 0.0189 & .39 \\
\hline & GFF-33 & Fatigue & 2836 & 235 & 0.0087 & 0.0172 & 0.0256 & 0.0166 & -35 \\
\hline & GFF-34 & Fatigue & 2010 & 244. & 0.0079 & 0.0125 & 0.0204 & 0.0143 & .29 .9 \\
\hline \multirow{6}{*}{$\begin{array}{c}\text { CS-19 } \\
\text { Aluminum }\end{array}$} & FGN-10 & EDM & 464 & 13.6 & 0.0064 & 0.00640 & 0.0129 & 0.0113 & -12.4 \\
\hline & FGN-12 & EDM & 488 & 12.4 & 0.0066 & 0,00686 & 0.0133 & 0.0115 & .13 .5 \\
\hline & PON-16 & EDM & 408 & 12.7 & 0.0055 & 0.00560 & 0.0123 & 0.0108 & -12.2 \\
\hline & FGN-31 & Fatigue & 175 & 8.5 & 0.0022 & 0.00214 & 0.0099 & 0.0092 & -7.6 \\
\hline & FON-57 & Fatigue & 171 & 7.4 & 0.0028 & 0.00241 & 0.0099 & 0.0094 & -6.7 \\
\hline & $\mathrm{FON} \cdot 60$ & Fatigue & 200 & 9.0 & 0.0029 & 0.00272 & 0.0102 & 0.0093 & -7.2 \\
\hline
\end{tabular}




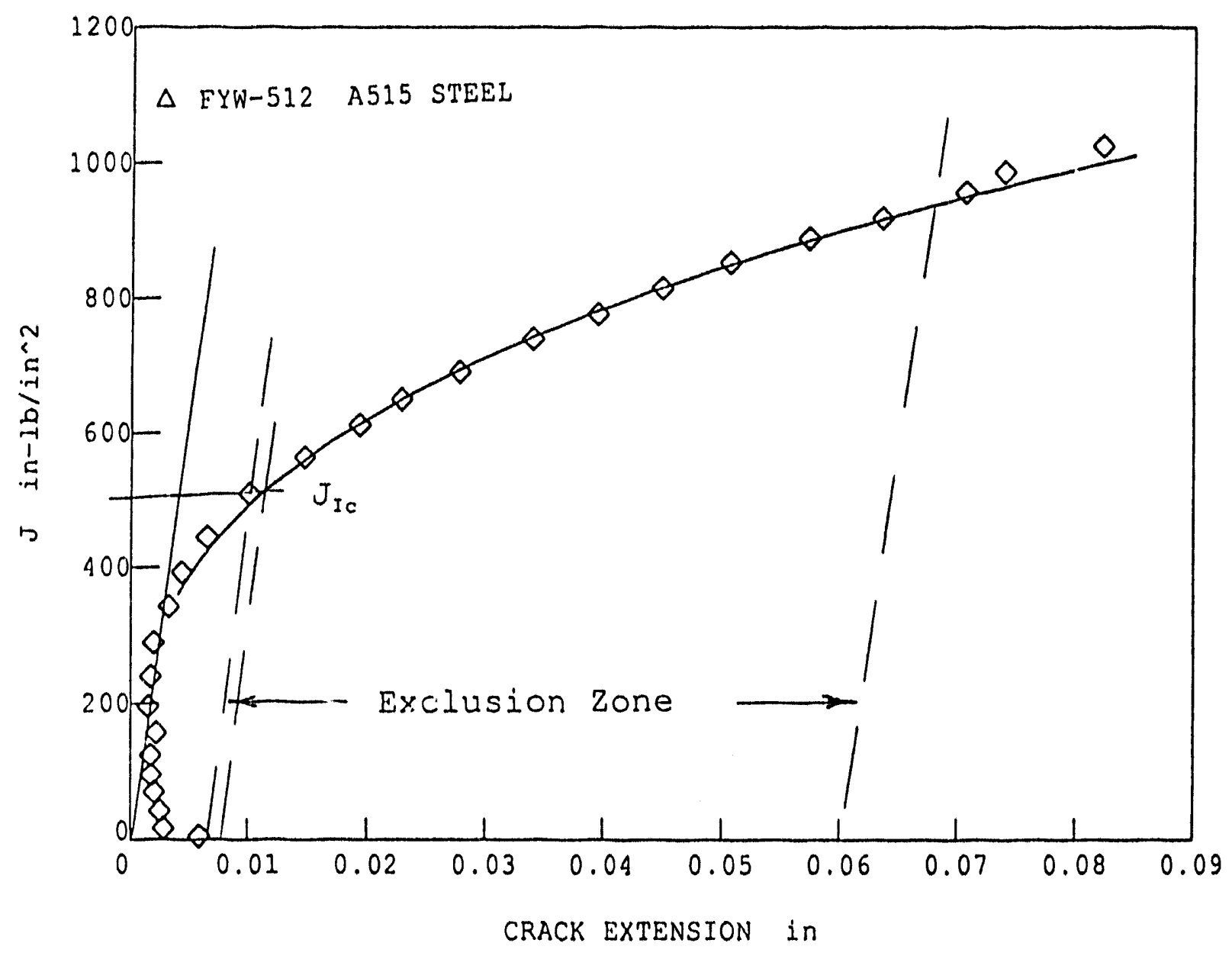

Figure $18 \quad J_{l c}$ evaluation for specimen FYW-512. 
Table 4 Comparison of average fracture toughness measured for EDM notched and fatigue precracked specimens.

\begin{tabular}{|c|c|c|c|c|c|c|c|c|c|}
\hline \multirow{2}{*}{ Material } & \multicolumn{3}{|c|}{$J_{n}\left(i n \cdot 1 b / n n^{2}\right)$} & \multicolumn{3}{|c|}{8, (in.) } & \multicolumn{3}{|c|}{$\delta_{k x}$ (in.) } \\
\hline & Futigue & BDM & \% diff. & Faligue & EDM & \$o diff. & Faligue & HDM & to diff. \\
\hline A 302 & 648 & 884 & 36 & 0.0066 & 0.0093 & 41 & $0.0 \times 69$ & 0.010 & 45 \\
\hline A515 & 594 & 692 & 16 & 0.0068 & 0.0092 & 44 & 0.0081 & 0.0094 & 16 \\
\hline А533B & 1445 & 1987 & 38 & 0.0100 & 0.0135 & 35 & 0.0126 & 0.0171 & 36 \\
\hline $11 Y-100$ & 706 & 947 & 34 & $0.00) 36$ & $0.0 \times 153$ & 47 & 0.0036 & 0.0052 & 43 \\
\hline A710 & 2423 & 3861 & 59 & 0.00083 & 0.01 & 20 & 0.015 & 0.023 & 54 \\
\hline Cs. 19 & 181 & 453 & 150 & 0.0028 & 0.0062 & 121 & 0.0026 & 0.0063 & 142 \\
\hline
\end{tabular}

Figure 20, it does not start to tear beyond blunting until approximately $0.4 \mathrm{~mm}$ of crack tip blunting has occurred. The definition of CTOD initiation proposed in the Common Method is (nearly - see below) consistent with the definition of $\mathrm{J}_{\mathrm{Ic}}$ given in E813, and hence makes some allowance for blunting behavior by specifying that initiation is defined to occur at a fixed offset from the blunting line.

None of the fatigue precracked specimens had an initiation CTOD toughness that was on the order of 10 times the initial diameter of the EDM notch tip. The toughest materials, A533B and $A 710$ had average $\delta_{\mathrm{ICM}}$ 's of $0.0126 \mathrm{in}$. and $0.023 \mathrm{in}$., respectively, which is from 3.1 to 5.7 times the initial notch tip diameter. It is not clear that structural materials indeed exist which will demonstrate a $\delta_{1}$, measured in any reasonable fashion, that is on the order of $0.040 \mathrm{in}$., and it certainly seems clear that weldments of this toughness are not a likely development in the near future. Thus, while the original hypothesis could not be verified, it seems clear that the use of EDM notches must be expected to result in higher initiation toughnesses, and if they are used to position a crack tip in a specific microstructure, some procedure would have to be used to correct the data for the presence of the EDM notch root radius.

It was expected that the tougher materials would show lower elevation than less tough 


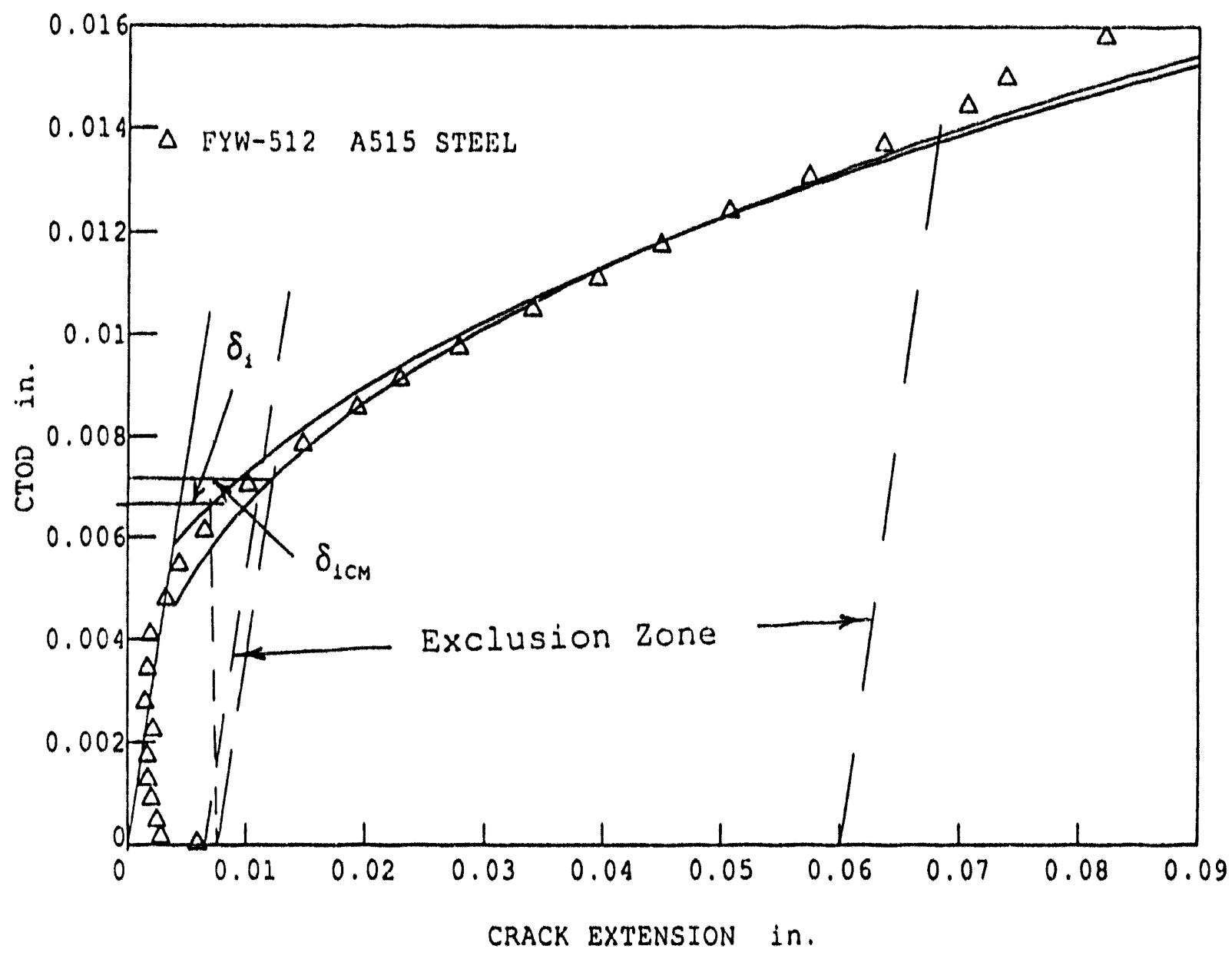

Figure $19 \quad \delta_{1}$ and $\delta_{I C M}$ comparison for specimen FYW-512. 


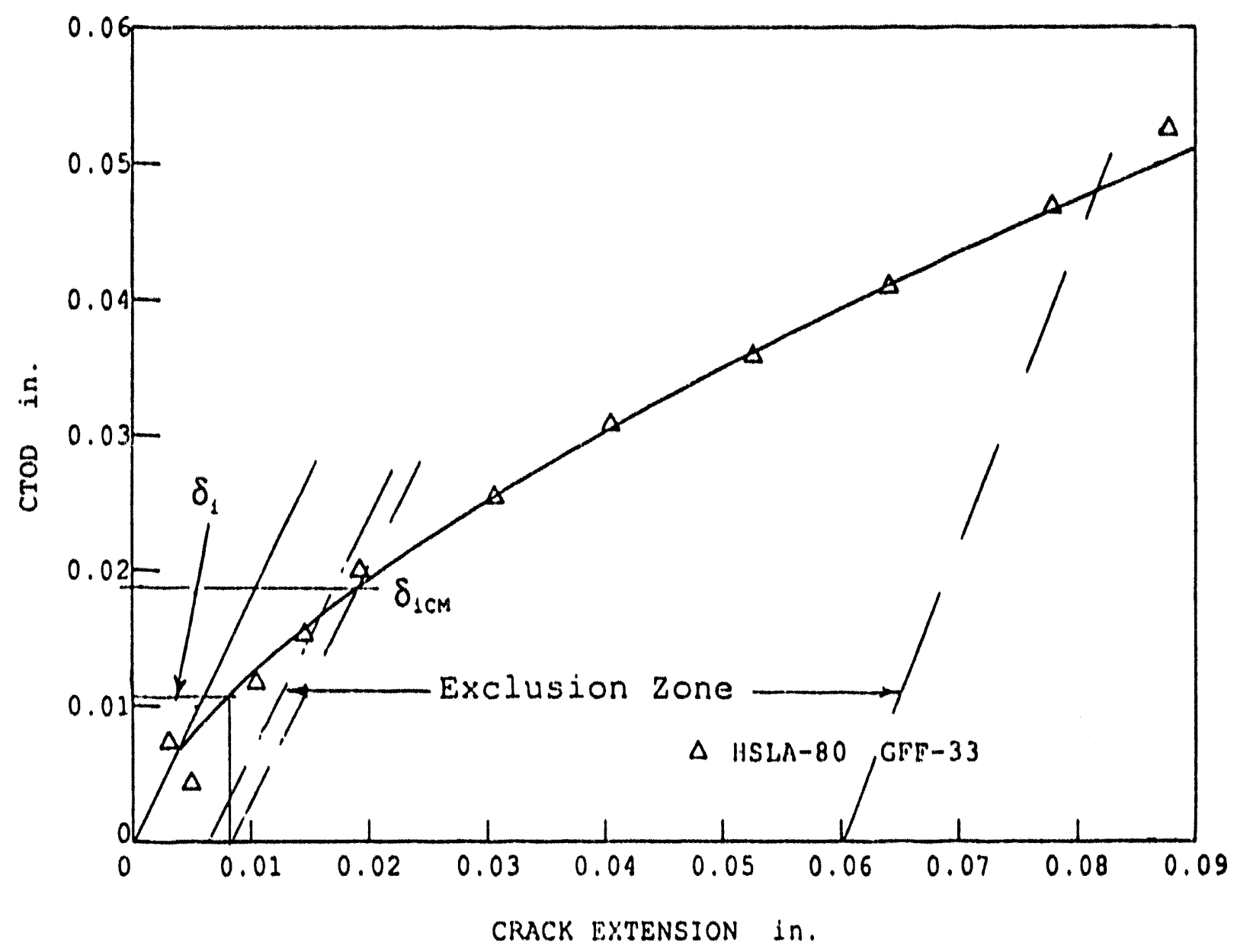

Figure $20 \quad \delta_{i}$ and $\delta_{1 C M}$ comparison for specimen GFF-33. 
materials. This trend was not observed in this investigation. The lowest toughness material, CS19 aluminum, acted as expected by showing the greatest increase in toughness due to the EDM notch. For this material, the EDM notch tip diameter was approximately equal to the initiation toughness of a precracked specimen and the EDM notch specimen had an elevation on the order of $140 \%$ over the precracked specimen. The highest toughness materials, A.533B and A710, showed smaller, but still substantial increases in crack initiation toughness $\left(38 \%\right.$ and $59 \%$ for $J_{l c}$ and $75 \%$ and $36 \%$ for $\delta_{1 \mathrm{~cm}}$ ). On the other hand, the $A .3(2)$ and $A .51 .5$ materials, with intermediate CTOD toughness, showed less sensitivity to the EDM notch, with increases in $J_{k c}$ of $36 \%$ and $16 \%$ respectively, and iiicreases in $\delta_{I C M}$ of $45 \%$ and $16 \%$. The HY-I(X) alloy, with the second lowest toughness in CTOD terms, shows the second lowest dependence on the notch tip radius.

The sensitivity of the initiation fracture loughness to the EDM notch does not seem to correlate with the strain hardening of the steel either. The HY-I(X) and $A 710$ steel both have strain hardening exponents, $N=1.5$ and the tougher $A 710$ showed a greater sensitivity to the EDM notch than the HY-I(X). On the other hand, the $A .3(1) 2$ and $A 533 B$ both have Nw9. For these two materials, the tougher A.533B showed less sensitivity to the EDM notch than the A.3(1)2. These conflicting trends indicate that there is not a one-10-(one relationship between strain hardening and sensitivity of the fracture toughness to the presence of an EDM notch.

\subsection{Improvement of the Common Method}

The slope of the Common Method construction line that is used to evaluate $\delta_{\text {Ic }}$ was set as 2.(), assuming a circular opening of the crack tip. Comparing the crack extension at crack initiation that results from this assumption with the crack initiation at $J_{\mathrm{lc}}$ of $\mathrm{E} 813$, as shown in Table 3, demonstrates that this definition of $\delta_{\mathrm{icm}}$ is not very consistent with $J_{\mathrm{lc}}$. An improvement can be made if work of Paris et. al.|2|, Shih $|3|$ or Rice et. al.|4| is used giving:

$$
\frac{d \delta}{d a}=\alpha \frac{\frac{d J}{d a}}{\sigma_{f}}
$$


with $\alpha=0.65$ to 0.7 , and substituting $d J / d a=2 \sigma_{1}$ gives

$$
\frac{d 8}{d a}=2 \alpha=1.3-1.4
$$

which implies that the slope of the $\delta$ blunting/construction line should have a slope of between 1.3 and 1.4 to be consistent with the slope of $2 \sigma$, used by E813 and the Common Method for the case of bend type, plane strain test specimens. Recalculating $8_{1} \cdot \mathrm{m}$ using a construction line slope of 1.4 gives the results shown in Table 5 . It is clear that the $\delta_{i c m}$ values have changed only slightly, but the crack extension at the initiation point has become much more consistent with that resulting from E813. The difference between the crack extension at $J_{10}$ and $\delta_{1 \mathrm{~cm}}$, however, is greatly reduced using the smaller construction line slope, with the differences being reduced from a maximum of $40 \%$ to a maximum of $12.5 \%$. 
Table 5 Comparison of $\Delta a$ at initiation using construction line slopes of 2.0 and 1.4 .

\begin{tabular}{|c|c|c|c|c|c|c|}
\hline Muerial & Spaximan ID & $\begin{array}{l}\text { Noleh } \\
\text { Type }\end{array}$ & $\begin{array}{c}b_{\operatorname{man}} \\
\text { (in) } \\
\operatorname{sinpe}=1.4\end{array}$ & $\begin{array}{c}A \Delta \sim I_{4} \\
\text { (in.) }\end{array}$ & $\begin{array}{c}A 0 \backsim B_{\operatorname{man}} \\
\text { (in) }\end{array}$ & D Difromene \\
\hline \multirow{5}{*}{$\begin{array}{c}\text { AsTM } \\
\text { A } 102 \\
\text { Ch B }\end{array}$} & FYX-3|| & KI)M & no103 & 0.0143 & 00154 & 0.2 \\
\hline & $N \gamma \times \cdot 524$ & IIDM & $0010 \%$ & 0.0146 & 0.0191 & 12 \\
\hline & INX.526 & IIDM & 00111 & 0.0148 & 0.0161 & 11 \\
\hline & $1 \gamma \times \cdot 510$ & Pengue & 0.0004 & 0.0121 & 0.0129 & 49 \\
\hline & $1 \gamma \times \cdot 9 n$ & Paigus & $000 \mathrm{~m} 2$ & 00135 & 00140 & 17 \\
\hline \multirow{4}{*}{$\begin{array}{r}\text { AstM } \\
\text { Asis } \\
\text { ih } 70\end{array}$} & Irw-314 & HDM & $0.00 \mathrm{ay}$ & 0.0135 & 00144 & 67 \\
\hline & HYW.\$16 & HDM & 00104 & 00149 & 0.0198 & 00 \\
\hline & $|r| s \mid s$ & Palgu & 0.0014 & 00120 & 0014 & 4.7 \\
\hline & IFW.st8 & Falgu & 0.0000 & 00110 & 0.0149 & 7.2 \\
\hline \multirow{5}{*}{$\begin{array}{l}\text { AstM } \\
\text { A sis } \\
\text { CH: }\end{array}$} & AI & IIDM & 00170 & 00101 & 00201 & 15 \\
\hline & A) & HDM & 0.0211 & $002 n$ & 0.0212 & 22 \\
\hline & 14 & IIDM & 00194 & 0.0210 & 0.0210 & 41 \\
\hline & cl & Valgue & 0.0129 & 00161 & 00173 & 61 \\
\hline & CI & Naigine & 0.0147 & 001111 & oul1s & 11 \\
\hline \multirow[t]{7}{*}{$11 Y \cdot 100$} & Mro.2 & $\mathrm{BDM}$ & 0.0052 & 00120 & 00118 & .17 \\
\hline & mro. & IIDM & 00049 & 00117 & 00116 & 01 \\
\hline & MO: & HDM & onoss & 00120 & 00122 & 12 \\
\hline & rYo.11 & ratign & 00040 & 00111 & 0.0109 & 15 \\
\hline & 1Yo-14 & Haigue & 00016 & 00160 & $0010 n$ & .11 \\
\hline & 170.150 & Palgue & 06007 & 001111 & 00100 & 27 \\
\hline & mYo 151 & Valgu & 00011 & 00111 & 00104 & .27 \\
\hline \multirow[t]{4}{*}{ IIIIA.mo } & $(1114 \cdot 42$ & IUIM & 00109 & 00119 & $00 \mathrm{us}$ & 47 \\
\hline & $0117 \cdot 4$ & IIDM & 00274 & 001111 & 002112 & 91 \\
\hline & (1) 31 & Haigue & 00202 & 001250 & 0.0224 & .125 \\
\hline & $(11+14$ & Paigue & 00131 & 00204 & 001118 & 11 \\
\hline \multirow{6}{*}{$\begin{array}{c}\text { Cs.19 } \\
\text { Aluminum }\end{array}$} & MUN.10 & III) & 0.0000 & 00129 & 00124 & .01 \\
\hline & $101 N \cdot 12$ & IIDM & $0.0 \mathrm{rr} / 0$ & 0.0131 & 0.0131 & 15 \\
\hline & $143 N \cdot 16$ & UDM & 00056 & 0.0121 & 00121 & .10 \\
\hline & IXIN II & Naigum & $0(0) 22$ & 00009 & $00(x \times n$ & 21 \\
\hline & $141 N .57$ & Vesigue & 00023 & 00102 & 0.0101 & 10 \\
\hline & $\mid(1) \cdot(x)$ & Fevigue & 0012: & $001(x)$ & $0(x \times)$ & .15 \\
\hline
\end{tabular}




\subsection{CONCLUSIONS}

The following are the principal conclusions derived from this effort:

1) Wire EDM notches cannot be substituted for fatigue pre-cracks in fracture mechanics tests for any of the muterials studied in this program without large changes in the measured initiation toughness resulting. The smallest EDM notch tip radil that could be cut were approximately $0.002 \mathrm{in} .(0.05 \mathrm{~mm})$ which was on the order of 1/5 the intiation CTOD measured - using the Common Method technique. The original precept of the work was that structural materials with initiation CTOD values on the order of 6 to 10 times the initial notch radius would likely be independent of the initial notch or fatigue crack geometry. This precept was not fully tested since it was found that few, if any, structural materials were tought enough to meet this criterion.

2) A pattern relating the initiation toughness notch geometry to material toughness was not found in this work. High toughness alone did not seem to make a material less sensitive to the initial crack tip geometry. Some materials were much more sensitive to the initial notch radius, but it was not necessarily the less tough materials that were the more sensitive.

3) The J-R curves slope, and the general shape of both the J-R and $8 \cdot R$ curves seemed quite insensitive to the type of notch geometry present in the specimen. If ductile tearing instability was the mode of failure of principal interest, then the use of EDM notches might be practical.

4) In general, if EDM notches were to be used, a research study is necessary to evaluate the effects of the blunt notches, and in all likelihood a correction would be necessary to estimate the true $J_{l e}, \delta_{1}$, or resistance curve that would be present if fatigue cracks existed in the structural application. 
5) The Initiation CTOD method of the ASTM E24.08.01 Common Method is strongly preferred in comparison with that of ASTM E1290. The E1290 method arbitrarily shortchanges the tougher materials by assuming that the onset of ductile tearing always occurs at $0.2 \mathrm{~mm}$ or 0.008 inches. The results of this work show that this is certainly not the case. The offset blunting line method of the Common Method document seems in give an initiation point consistent with the $J_{k}$ measurement point of ASTM E813. A modification of the Common Method construction line slope is recommended, based on these results, which improves the correspondence between $J_{k}$ and the Common Method $\mathbf{8}_{\text {. }}$. 


\section{REFERENCES}

III Joyce, J.A. and Gudas, J.P., "Computer Interactive Jk Testing of Navy Alloys," Elastic. Plastic Fracture, ASTM STP 608, J.D. Landes and O.A. Clarke, Eds., American Society for Testing and Materialy, 1979, pp. 451.468.

(2) Paris, P.C., Tnda, H., Zahoor, A., and Ernst, H., "The Theory of Instability of the Tearing Mode of Elastic-Plautic Crack Orowth," Elastic-Plastic Fracture, ASTM STP 668, J.D. Landes and G.A. Clarke, Eds., American Society for Testing and Materials, 1979, pp. 5. 36.

[3] Shih, C.F., "Relationahipa Between the J-Integral and the Crack Opening Displacement for Sutionary and Extending Cracks," Journal of the Mechanics and Physics of Sollds, Vol. 29, 1981, pp. 305-326.

14) Rice, J.R. and Rosengren, O.P., "Plane Strain Deformation Near a Crack Tip in a PowerLaw Hardening Material," Journal of the Mechanics and Physics of Sollds, Vol. 16. 1968, pp. 1.12. 


\section{APPENDIX A}

Data Tables for Individual Specimens

A-1 


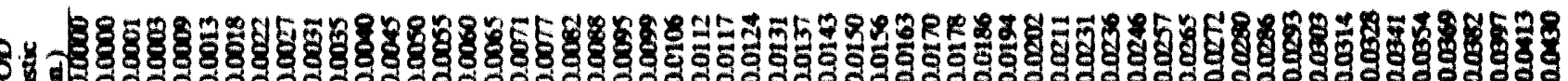
ชำ

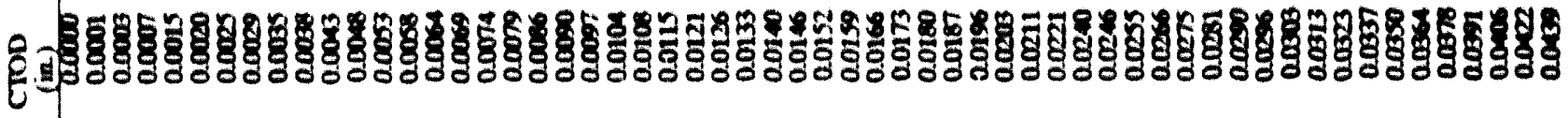
萬 . $-\frac{5}{1}$

马.

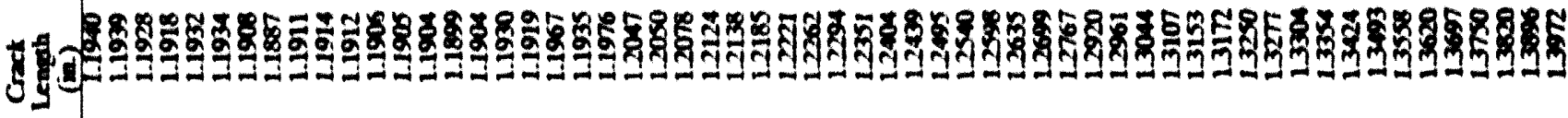

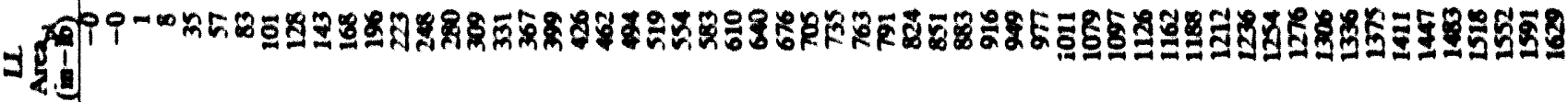

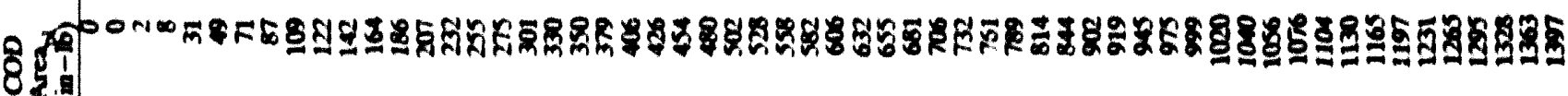

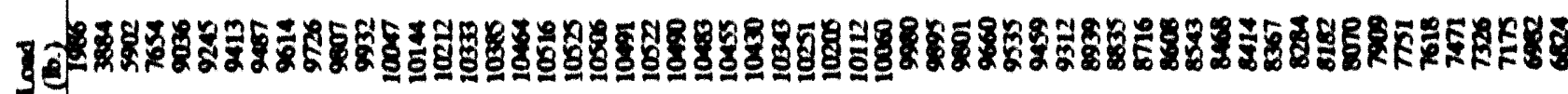

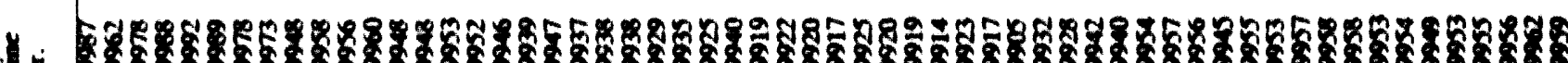

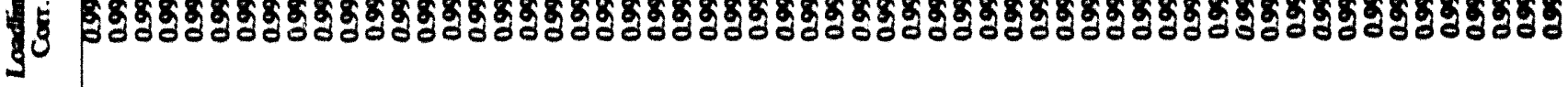
4 乌人

ช

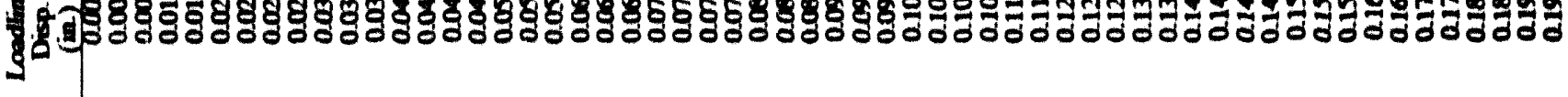

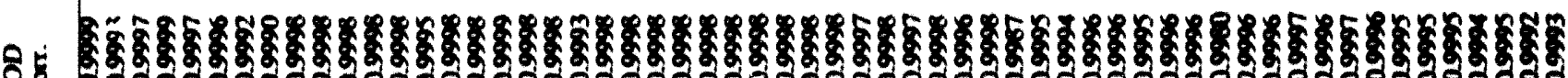

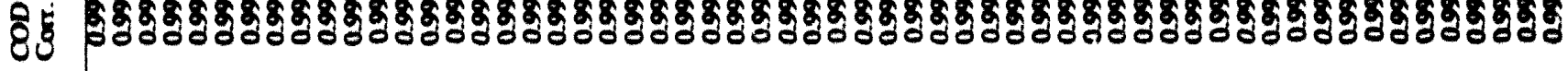
8\% خ

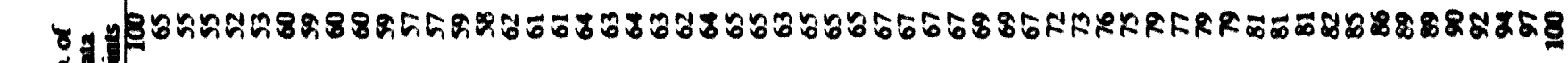

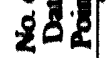

8

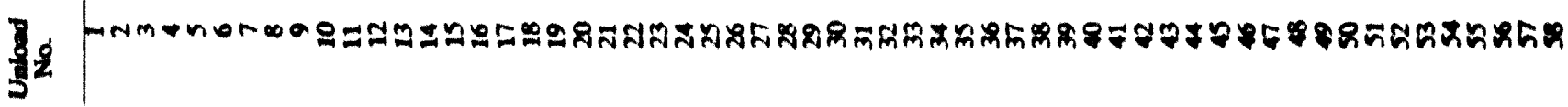




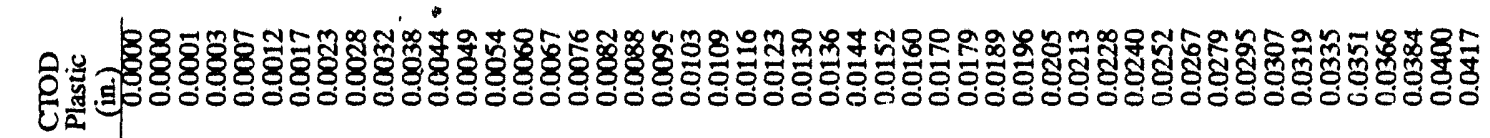

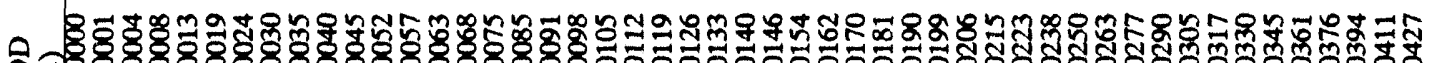
ำ

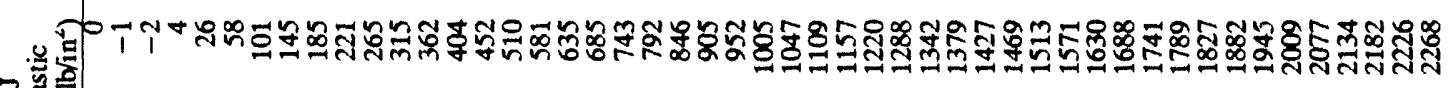

$\frac{3}{2}=$

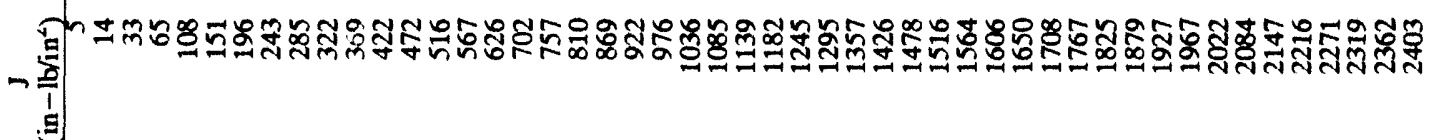

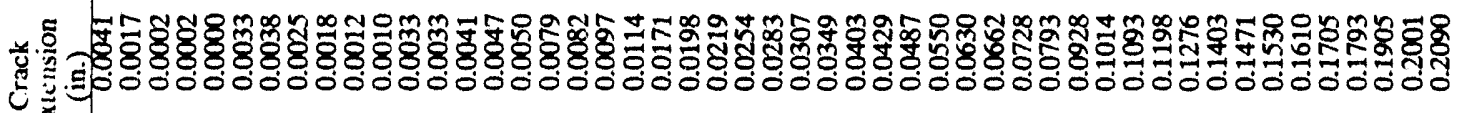
U⿺辶寸

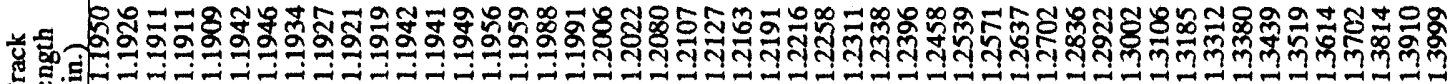
5 $\exists=$

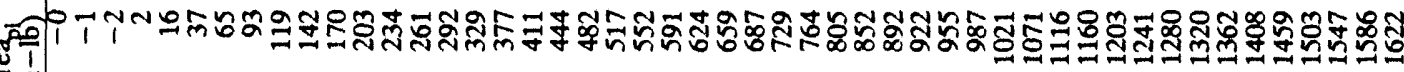

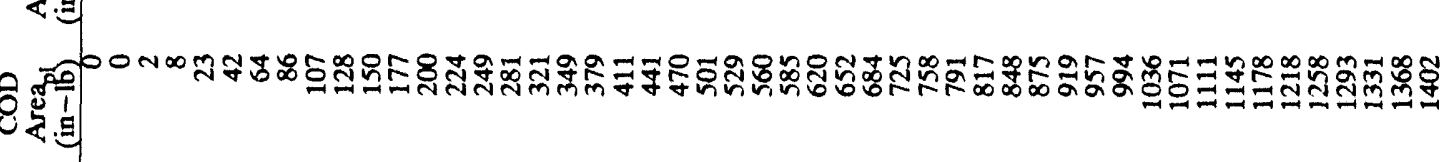

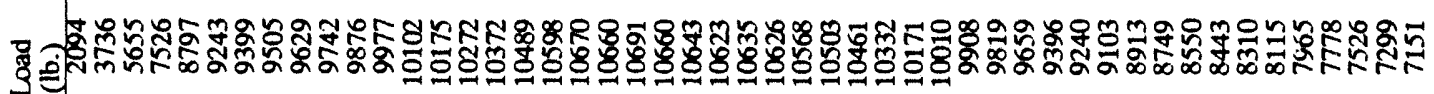

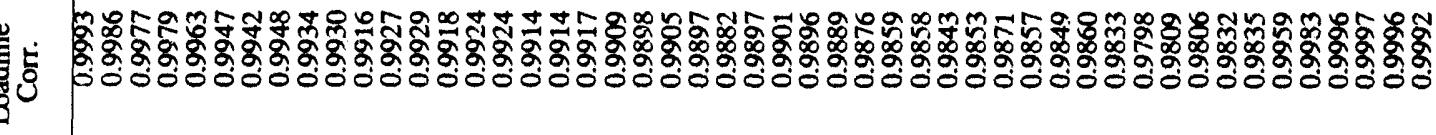

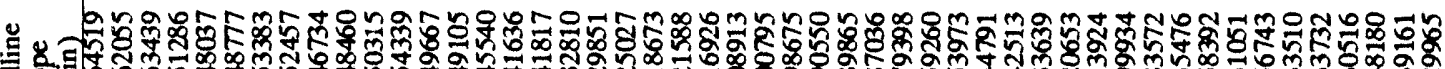

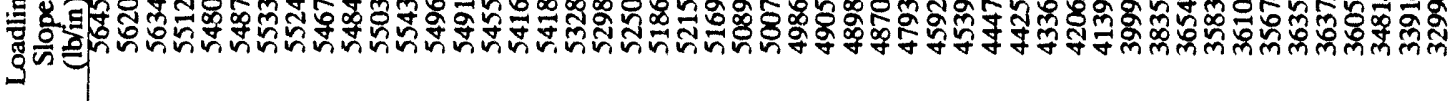

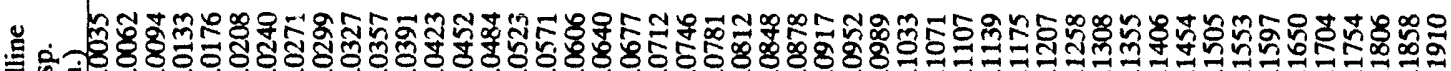

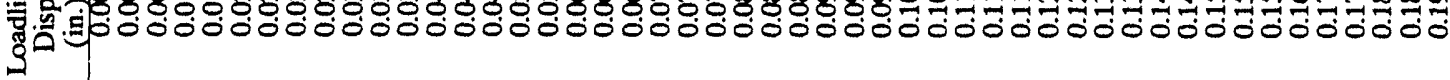

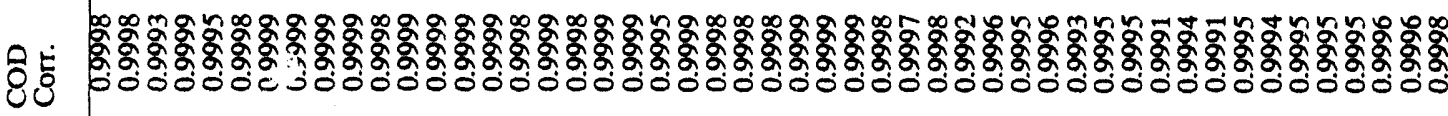

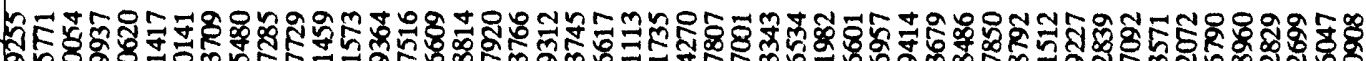

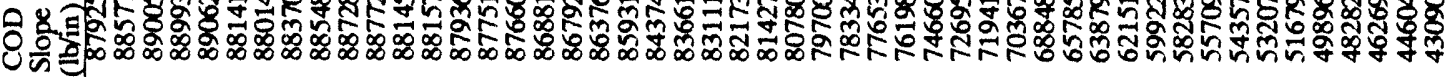

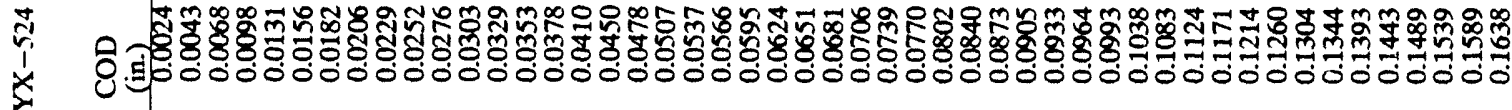

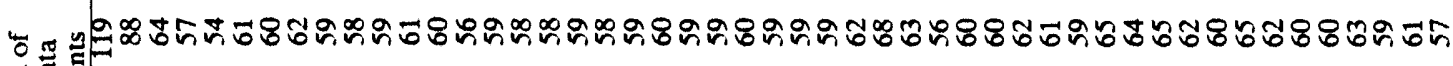
zंढ口:

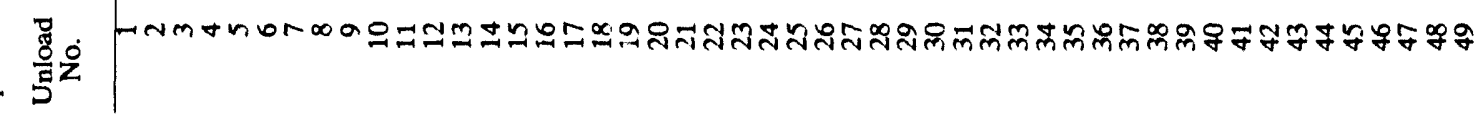




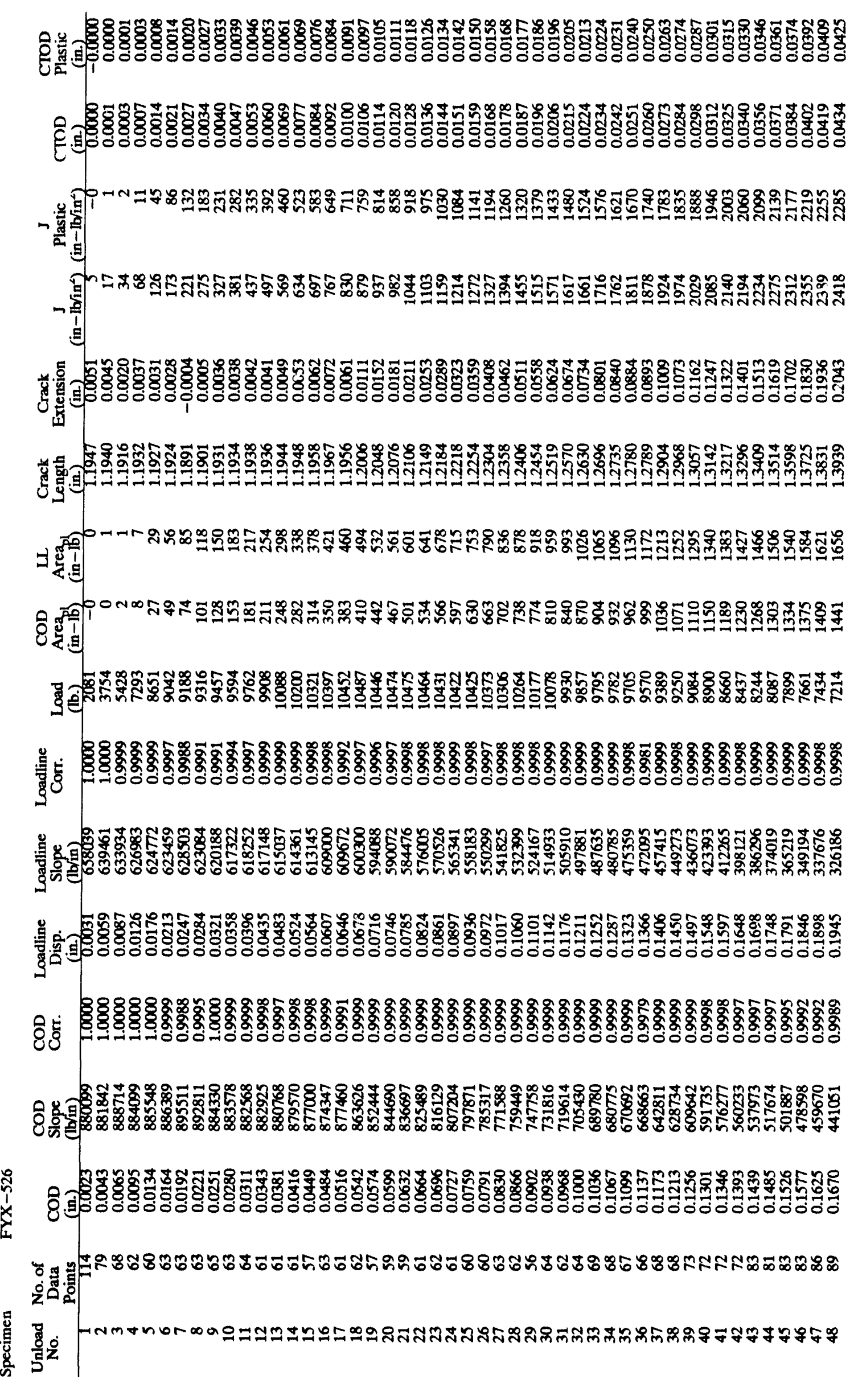




\section{争

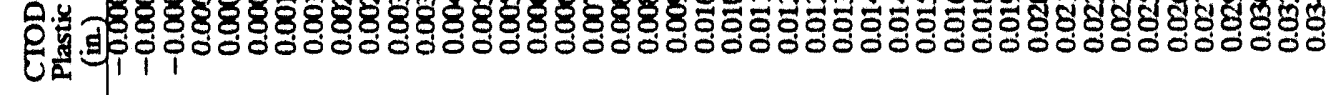 \\ (7) ำ

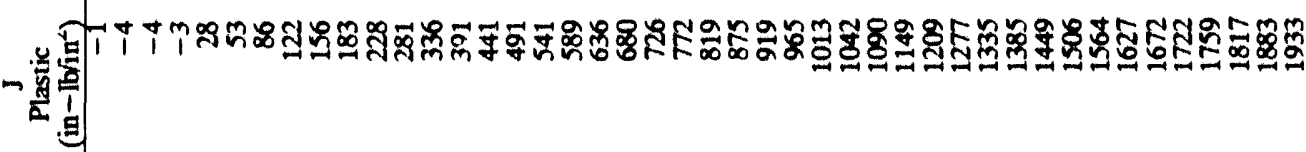 \\ है

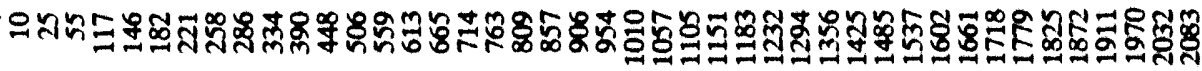 \\ g}

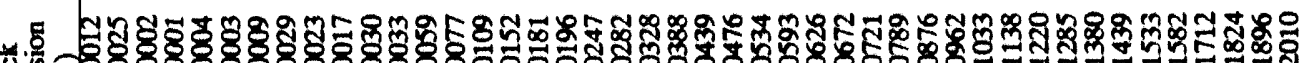
苟

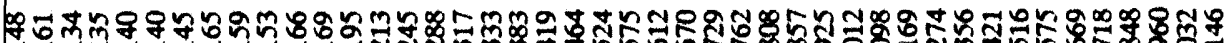
४ै U.

$\exists$ 볼ำ

ค ㅇำ $8 \%$

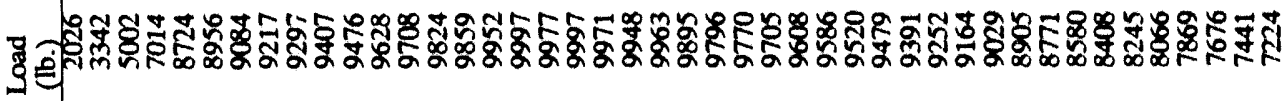

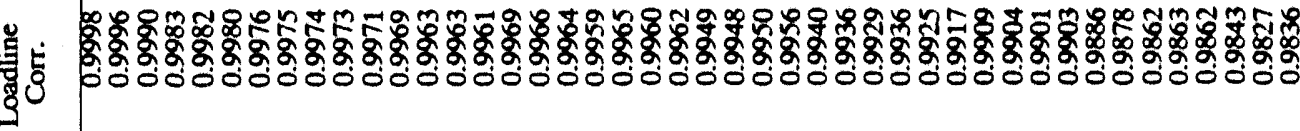

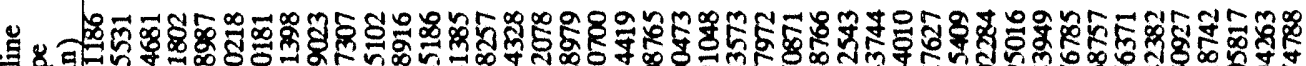

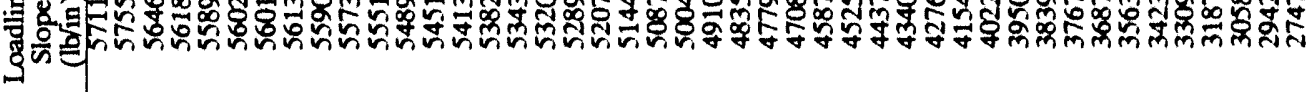

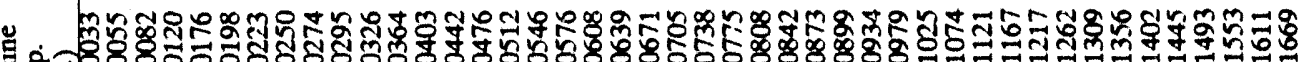

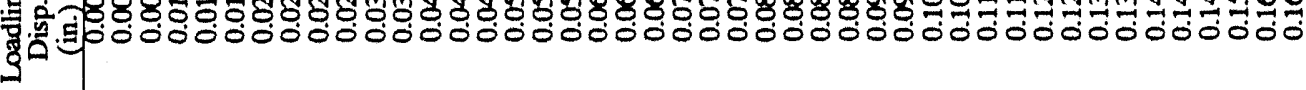

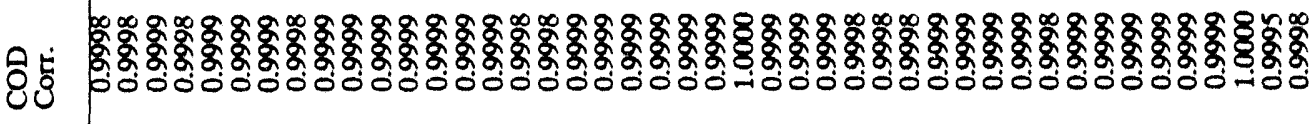

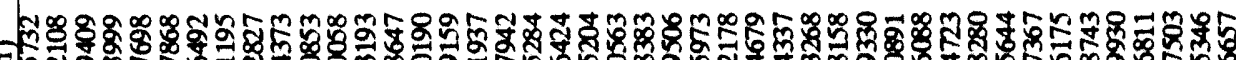

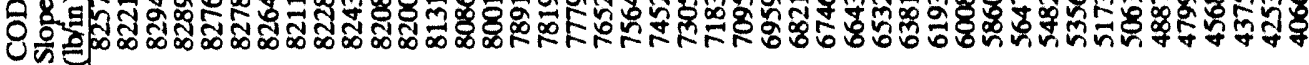

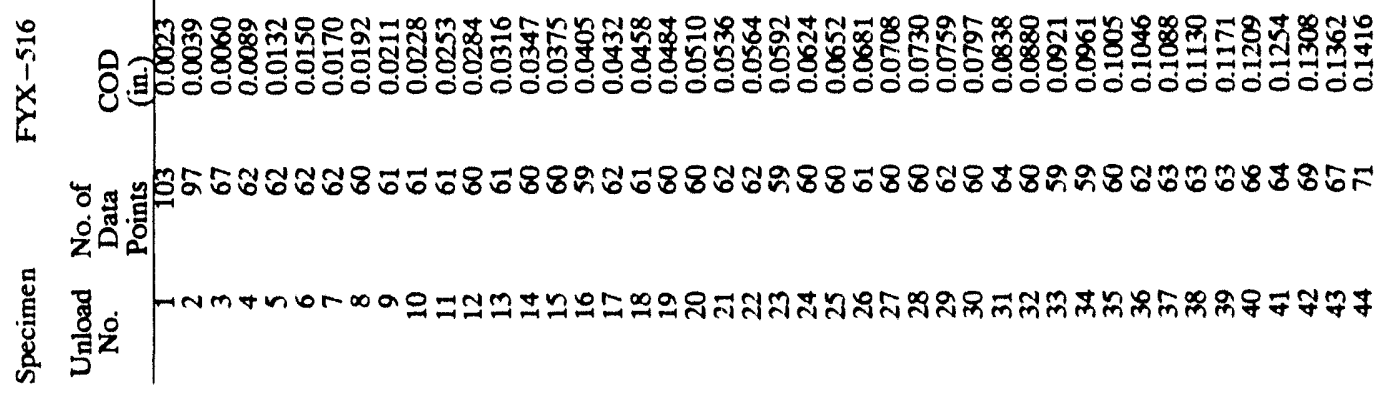


这

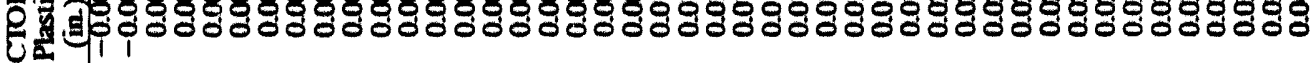

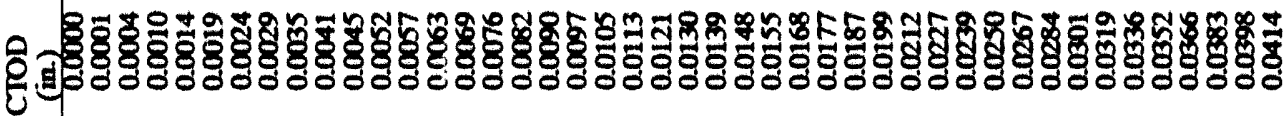

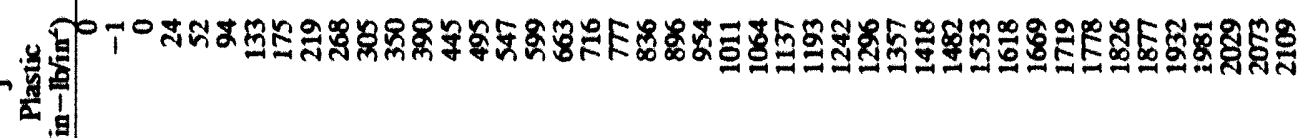

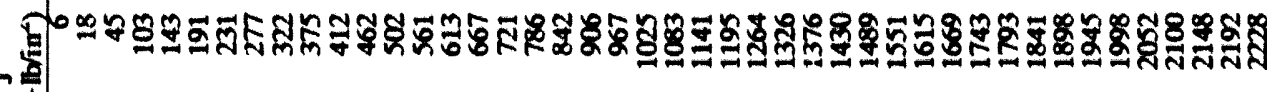
思

4.

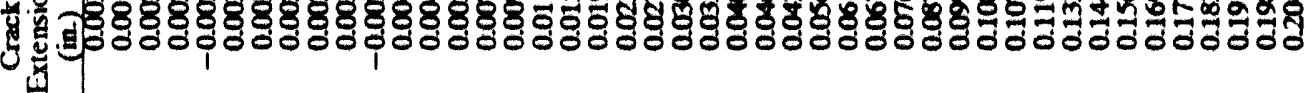

โิ

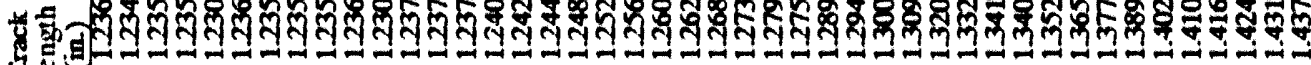

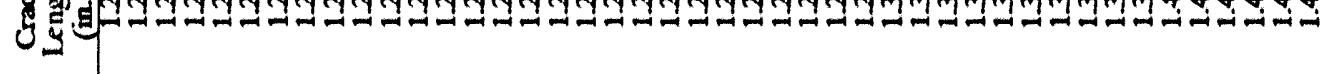

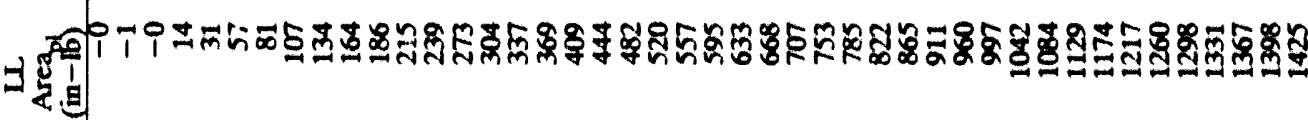
8ิ 承

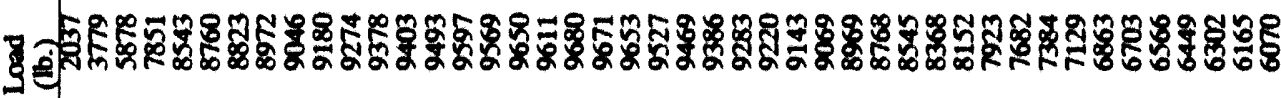

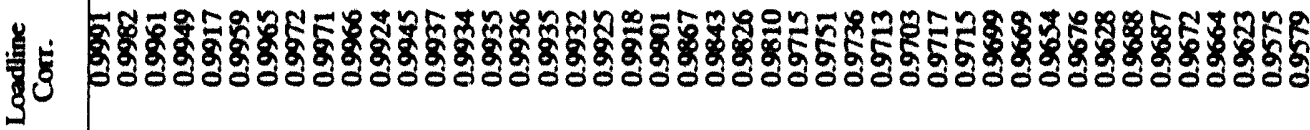

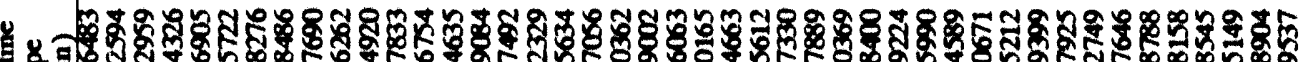

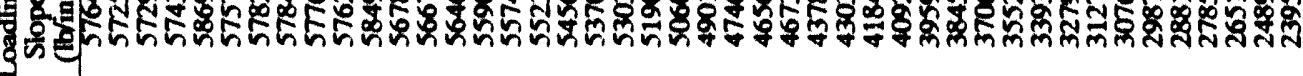

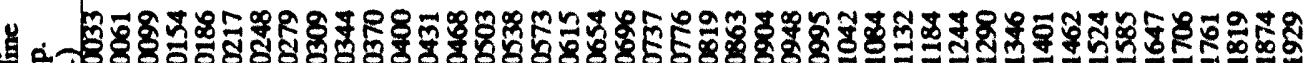
รु.

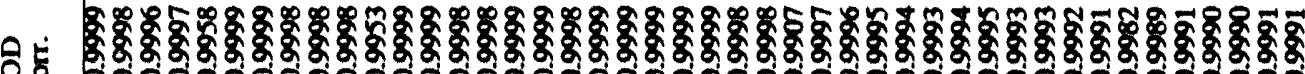

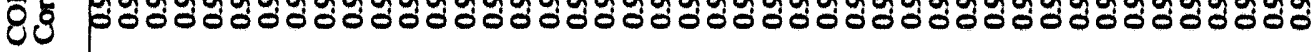

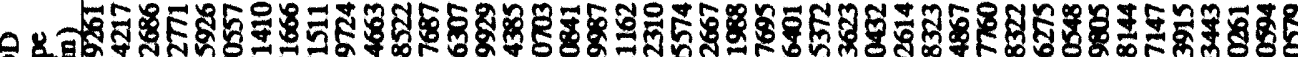

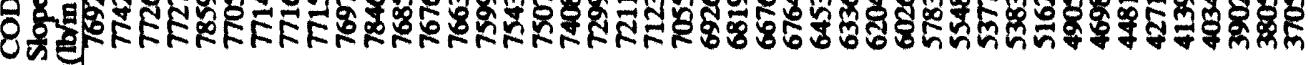

స

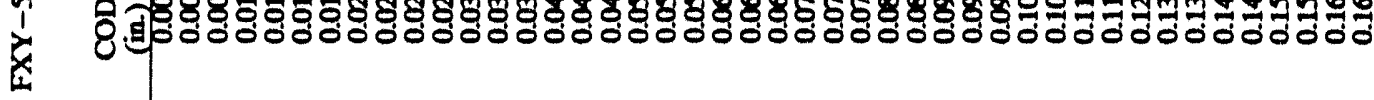

息

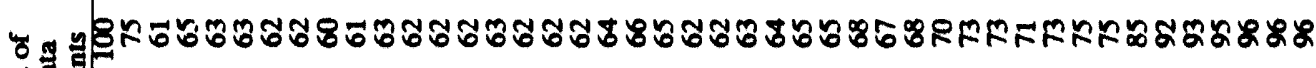
之ें:

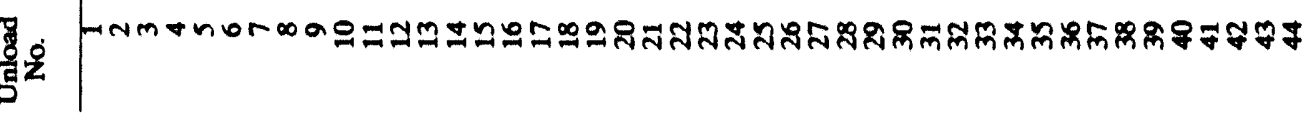




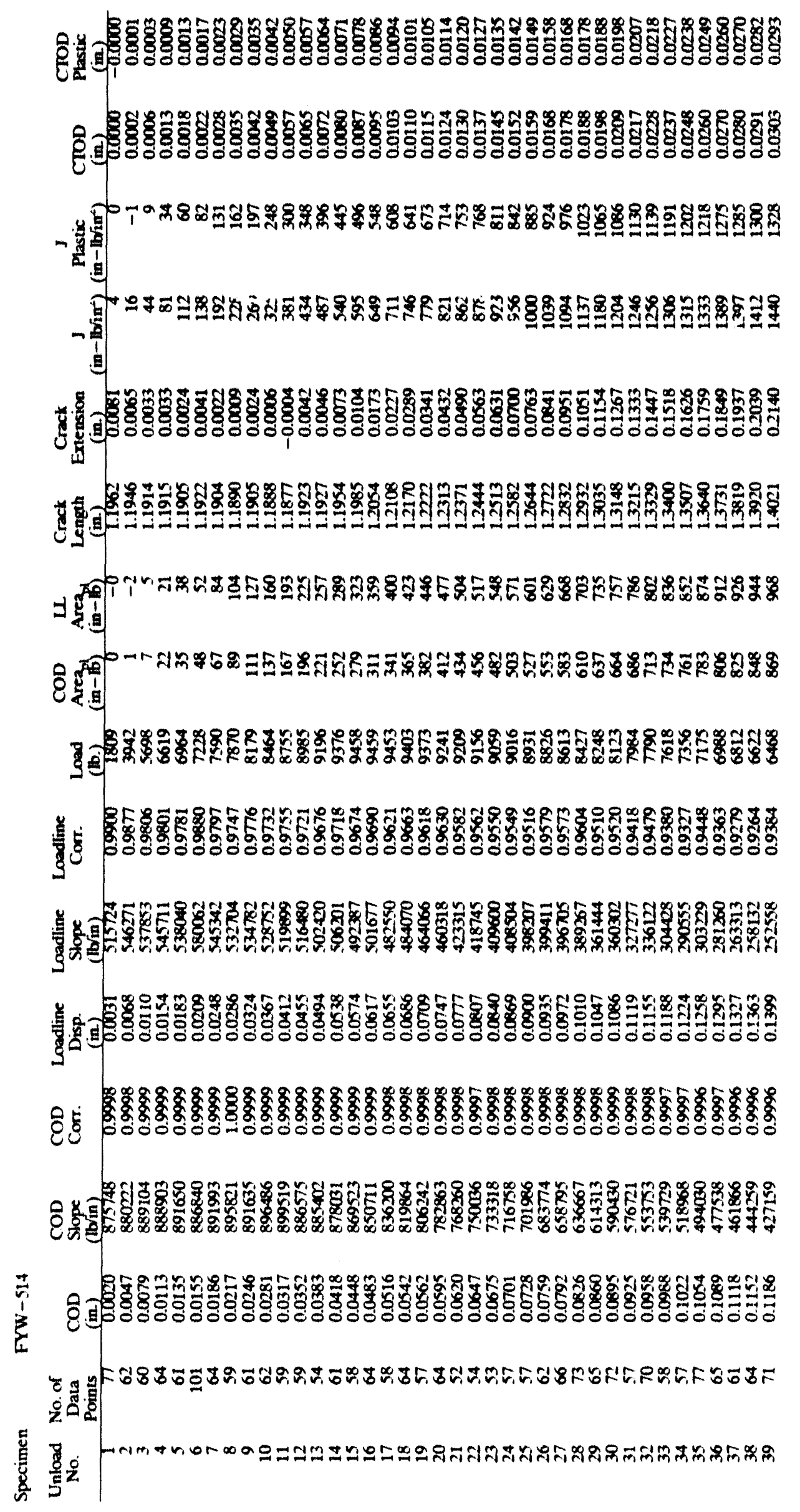




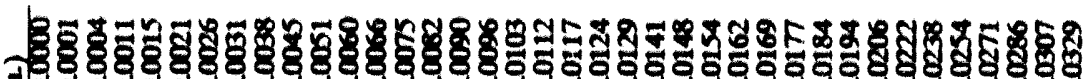
ำ

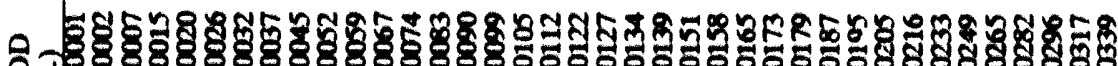
กับ $-4$

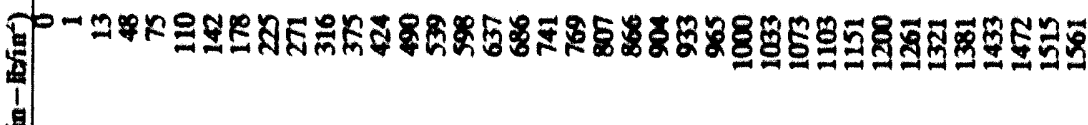

武

西

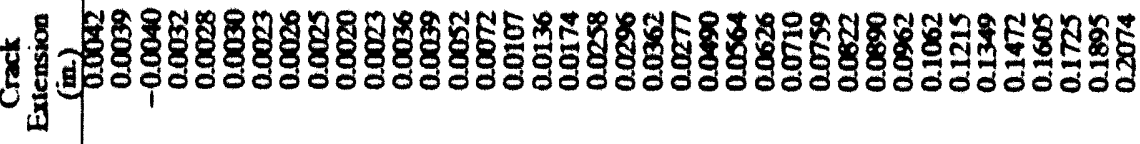

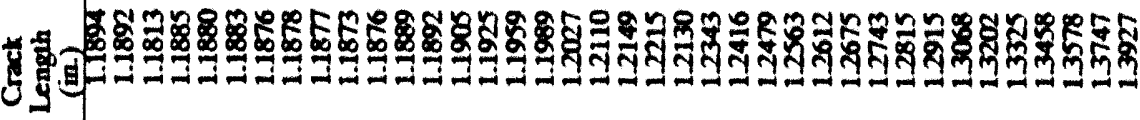

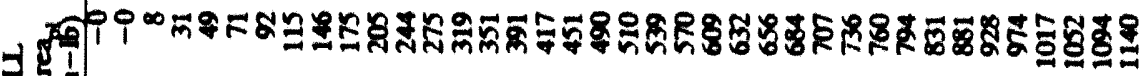

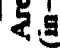

8ิ

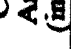

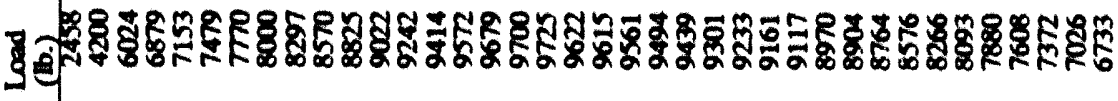

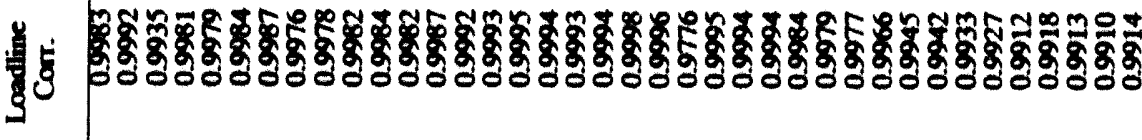

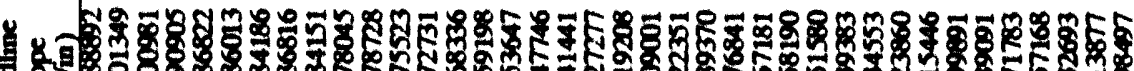

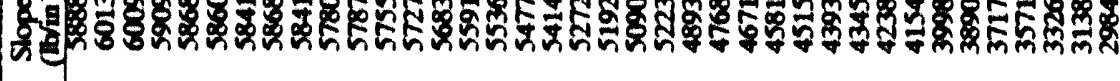

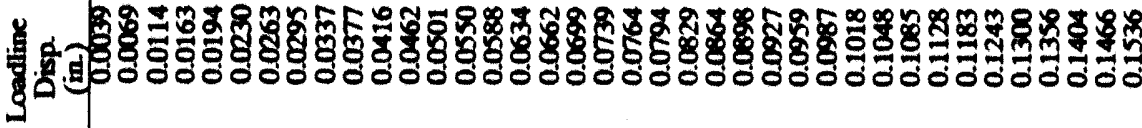

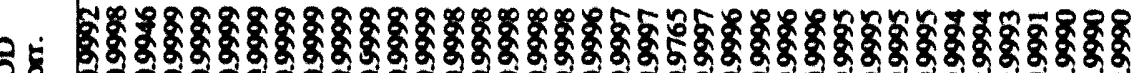
83 508

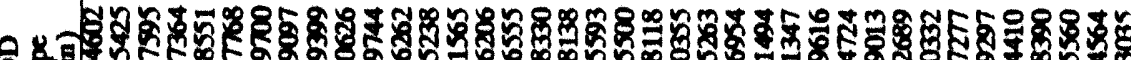
8

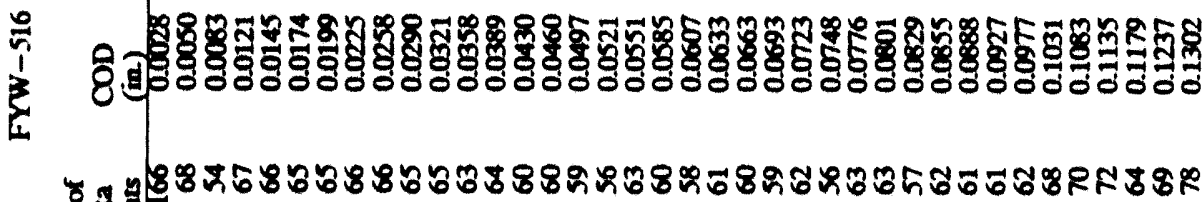
息

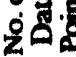

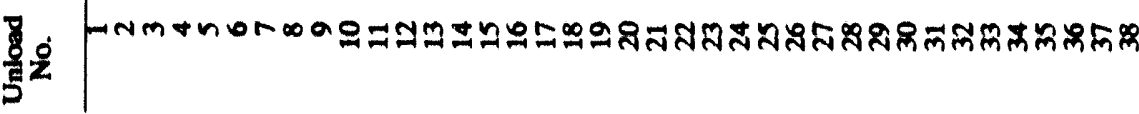




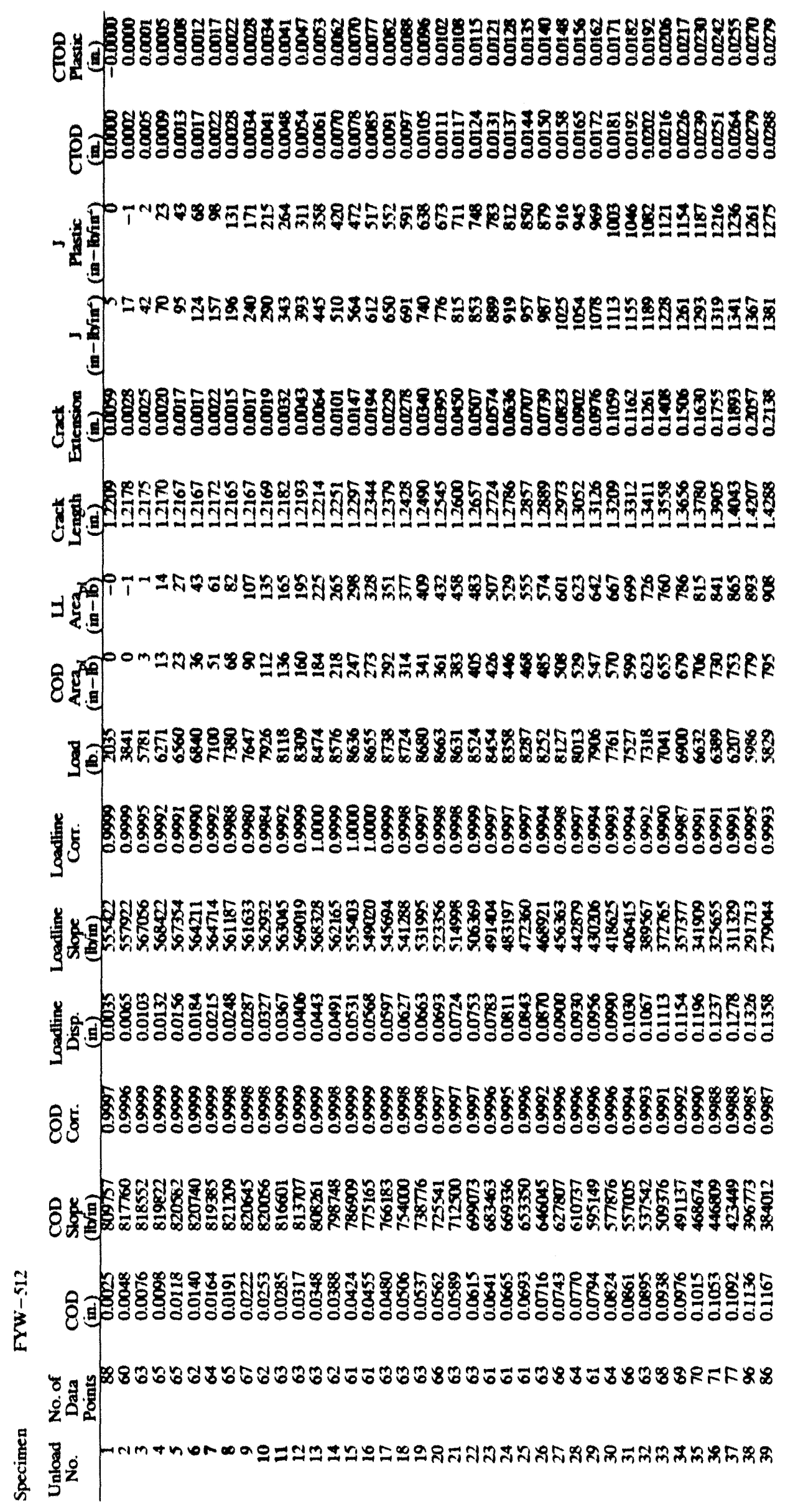




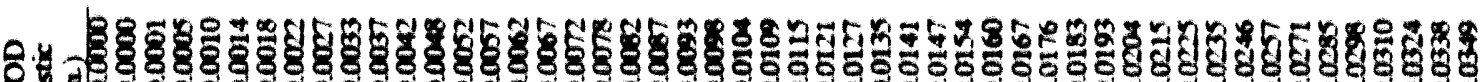
ำ

은 ํำ $-7$

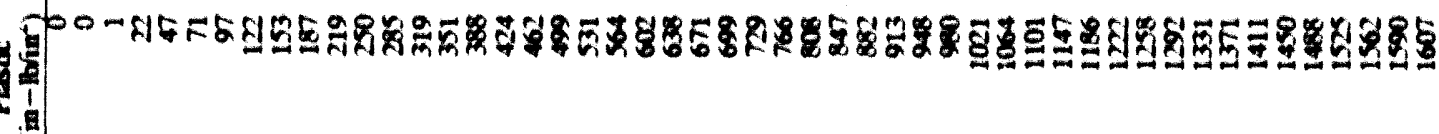

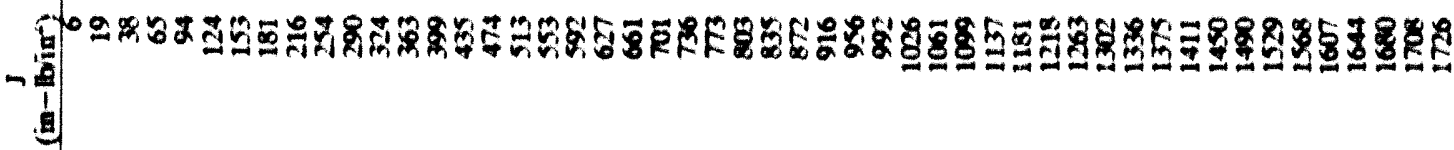

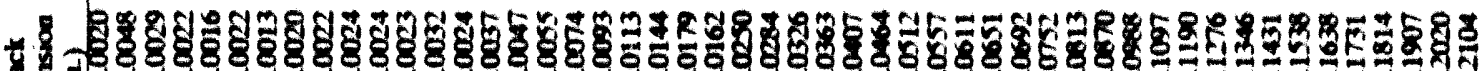
배

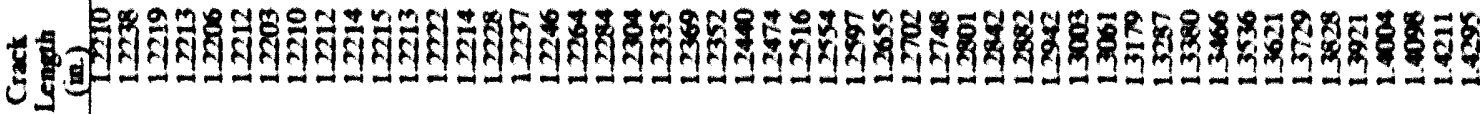
士

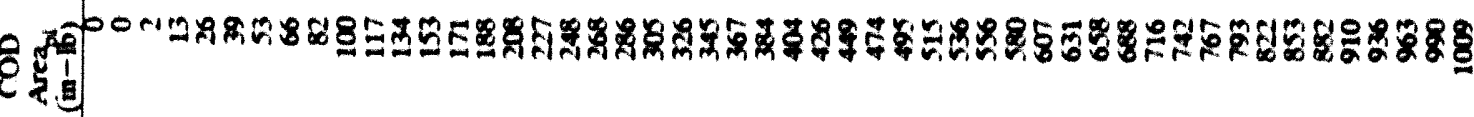

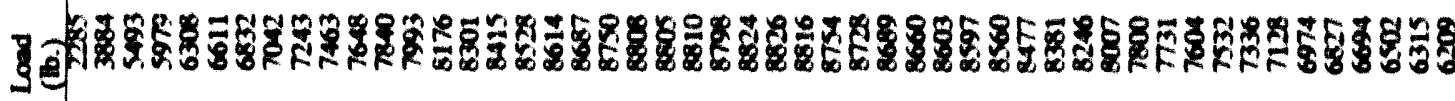

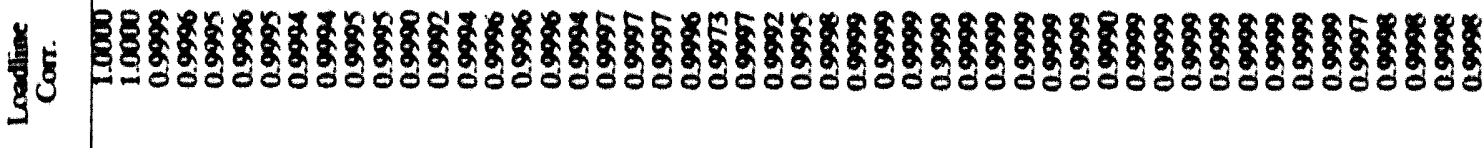

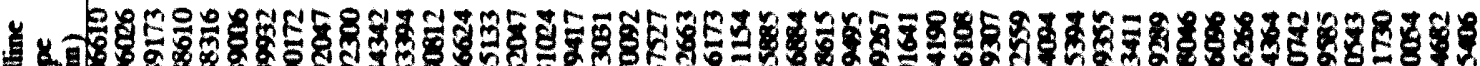

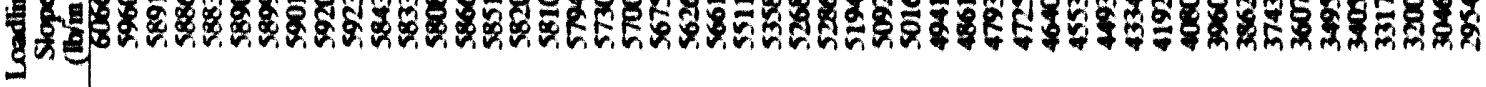

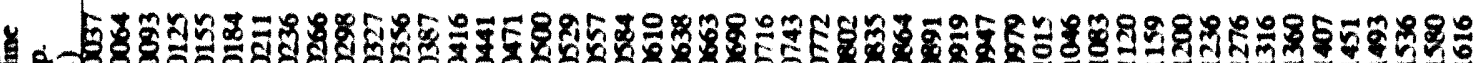

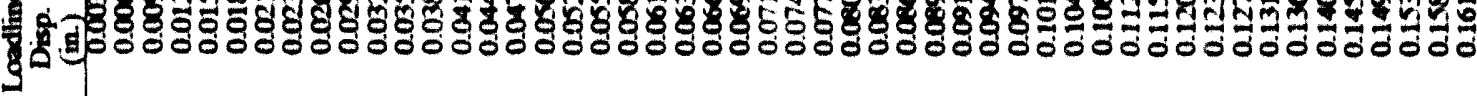

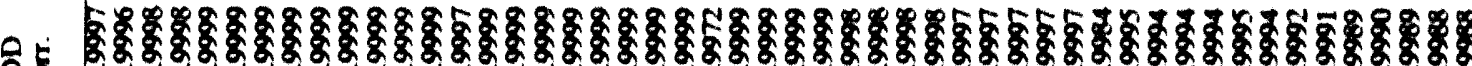

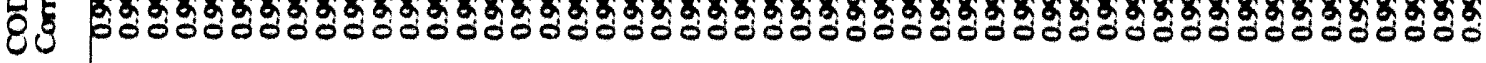

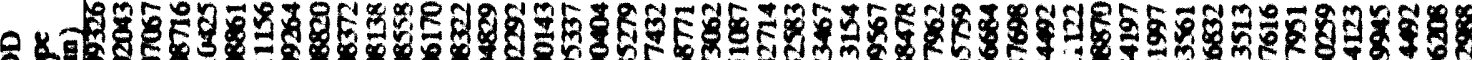

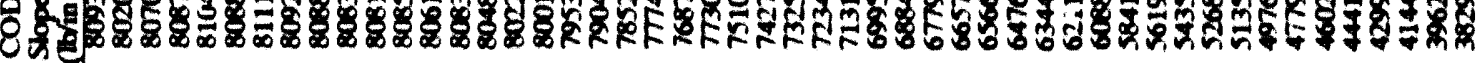

จ 8ิ

$\frac{8}{8}$

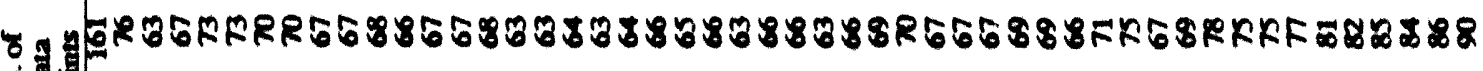
之.

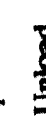
鄫宝 


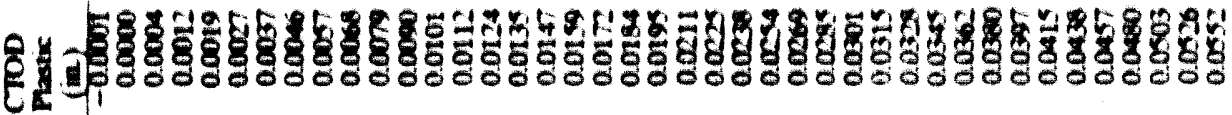

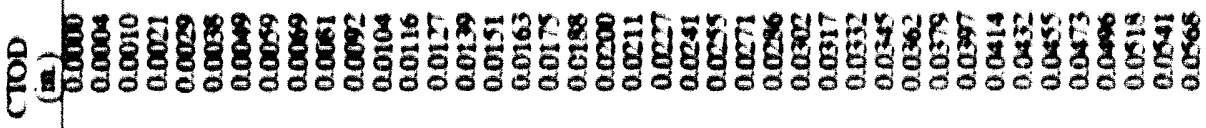
$-10^{6}$

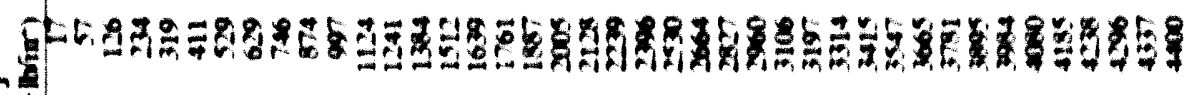
1

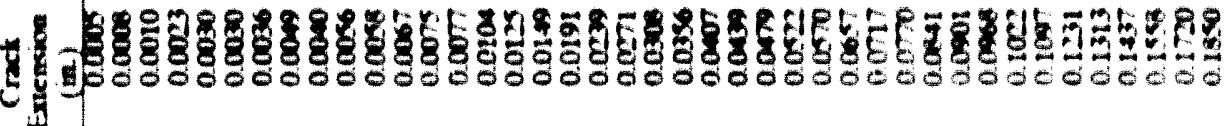

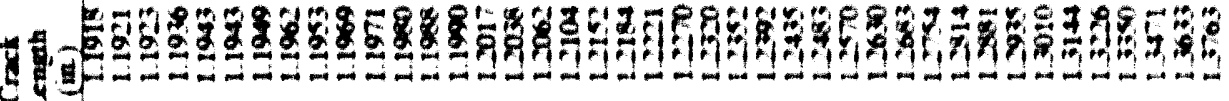
gy

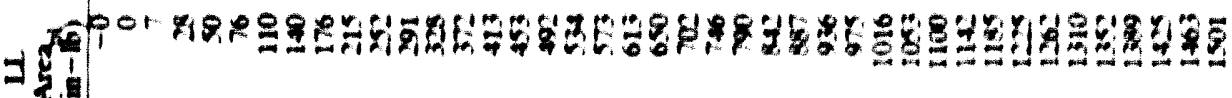

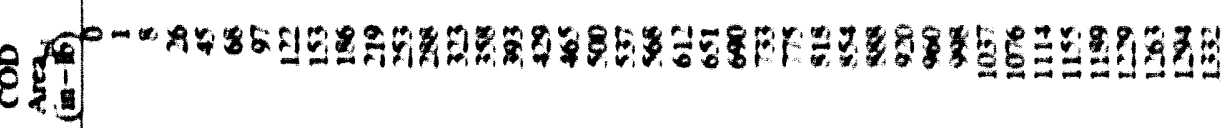

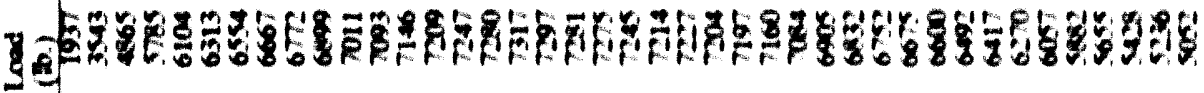

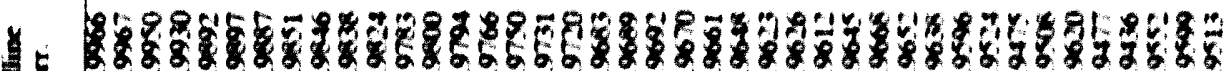

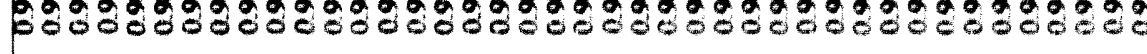

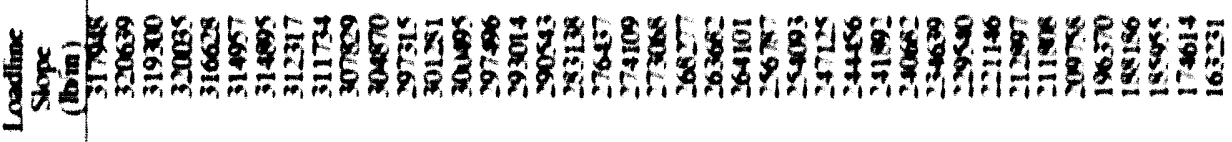

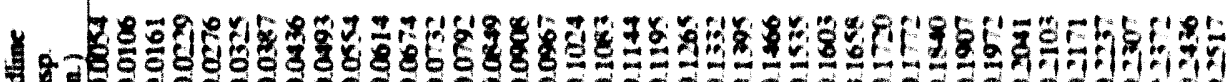

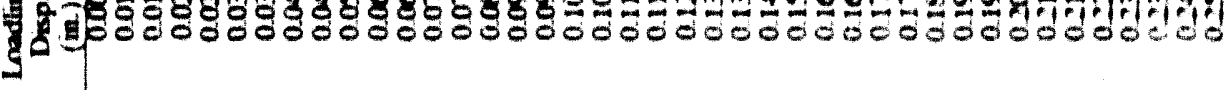
है

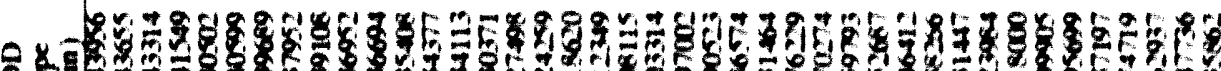

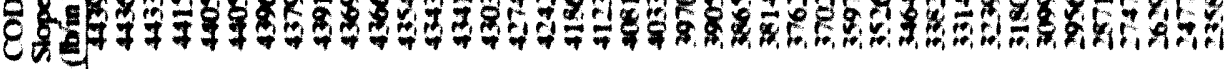

न 8

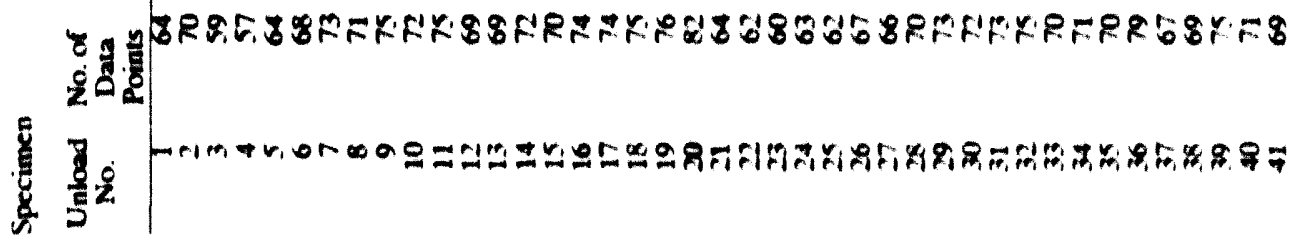




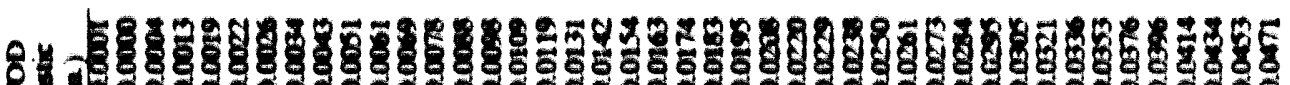
ำ

8ำ ع 4苟

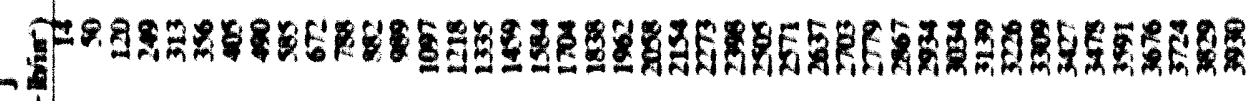

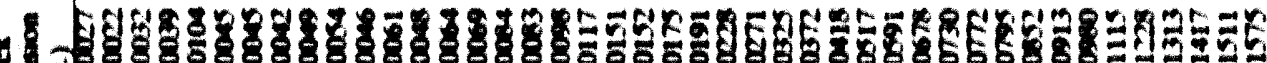

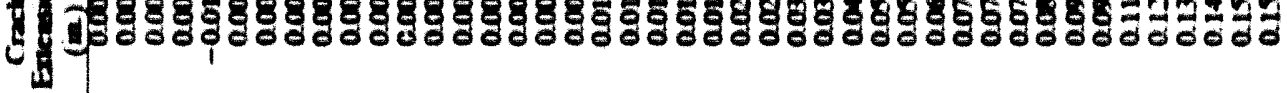

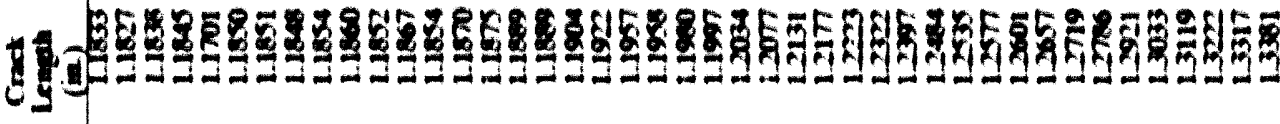

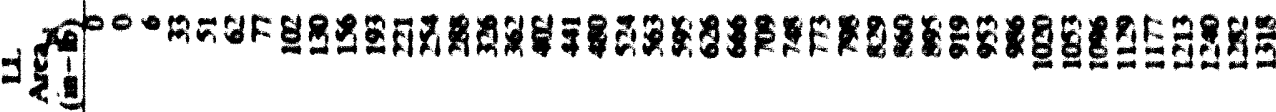

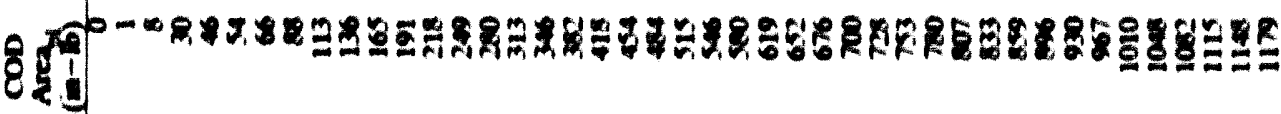
马อ

4 F⿻ำ

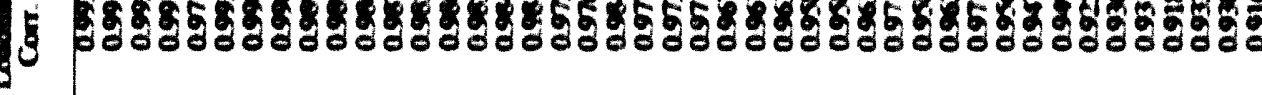

Y

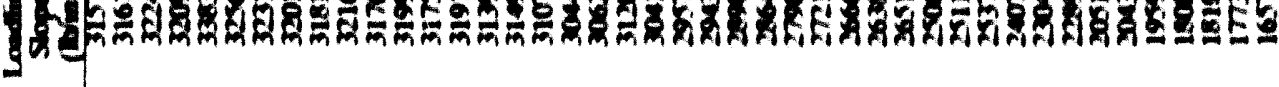
与ิ

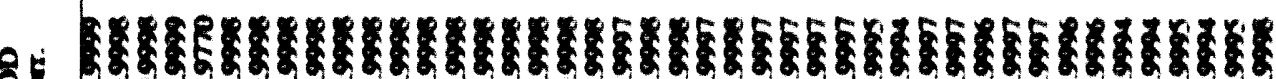

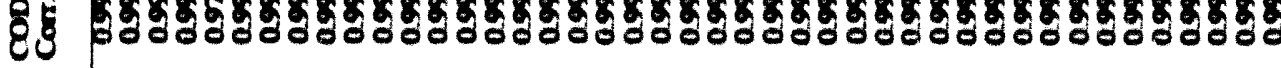
จ

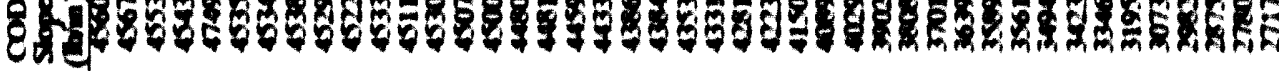

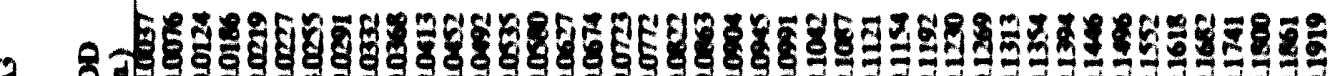

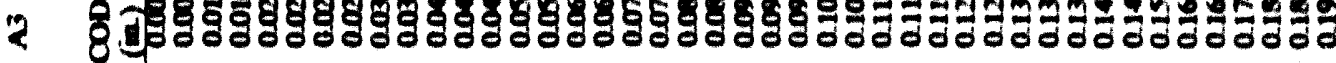

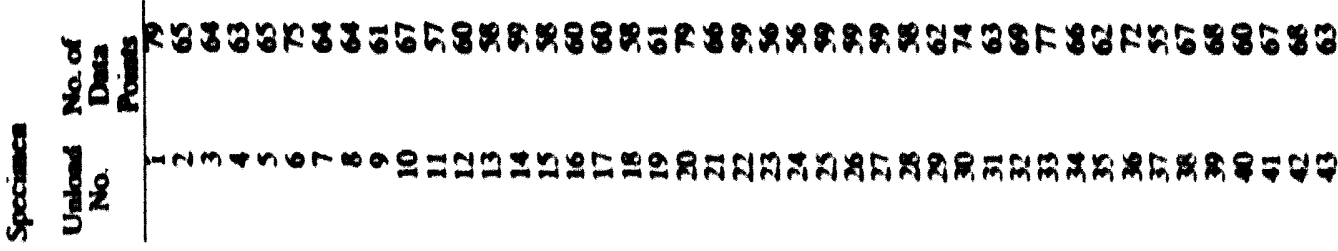




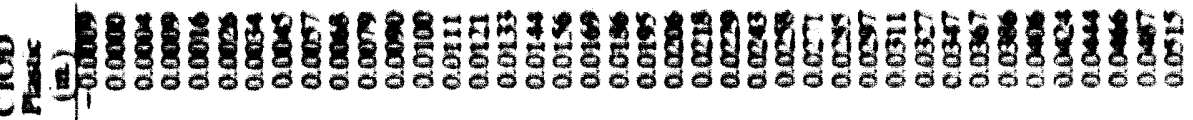

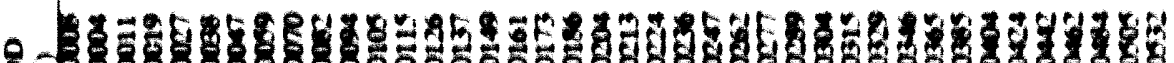
ל구

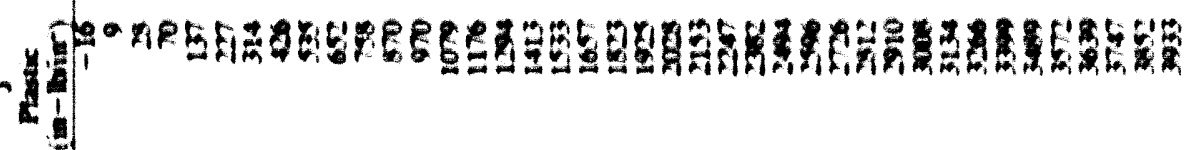

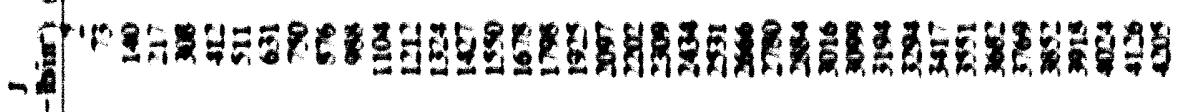

H. Mำ Jo

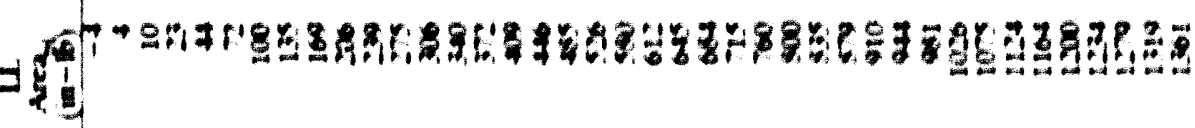
8.

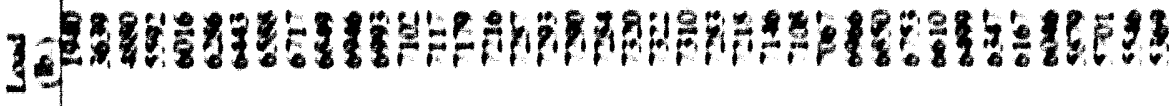

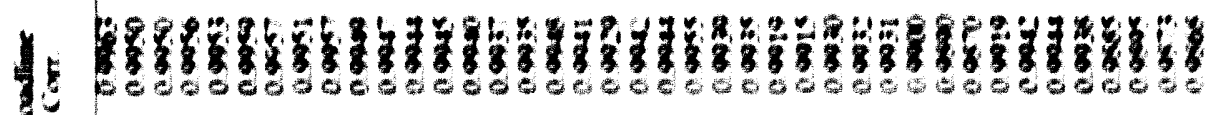

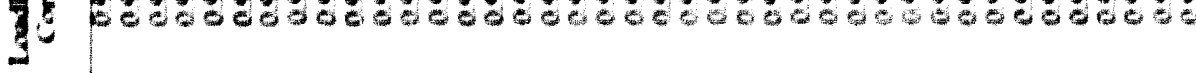

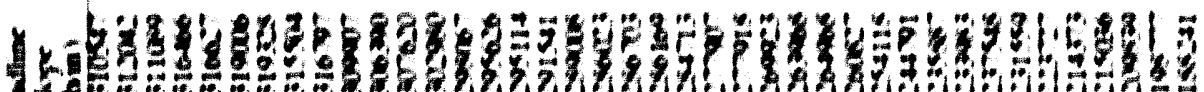
Ho

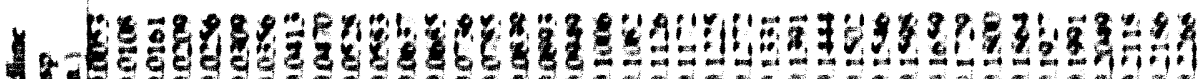

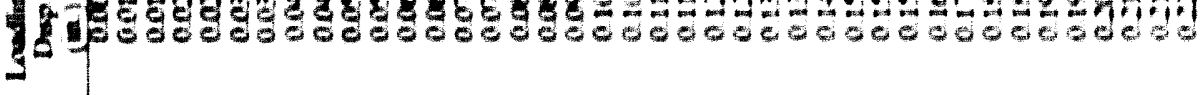
宅

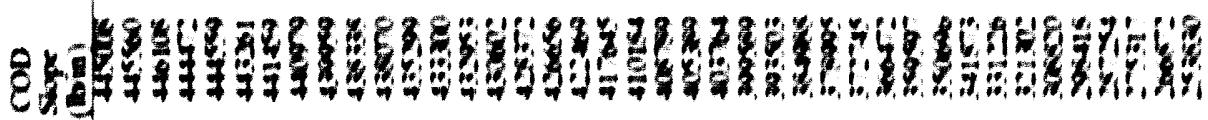

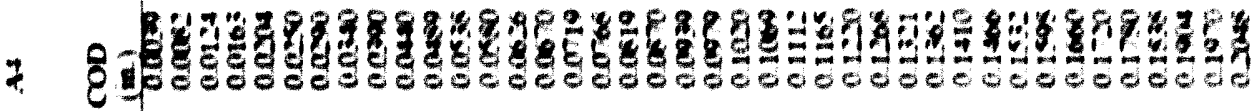
7. I

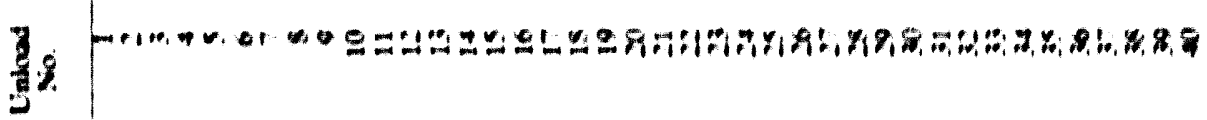




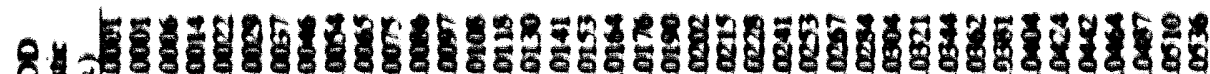
ำ 8ำ $-1$

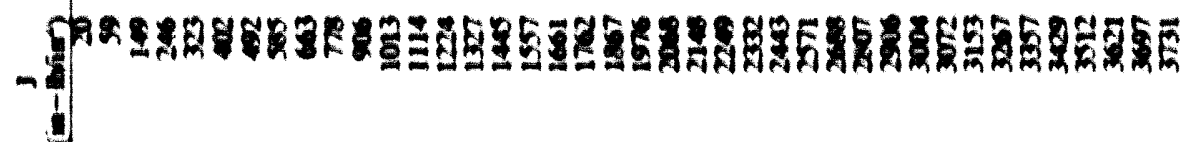
ไ|

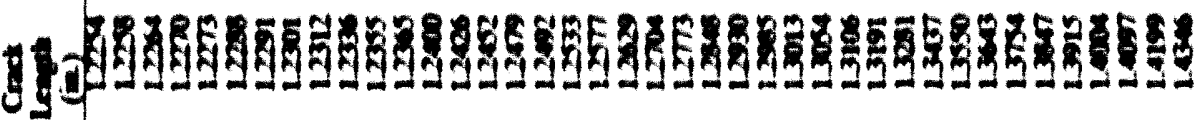

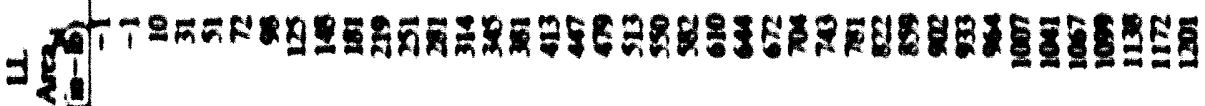

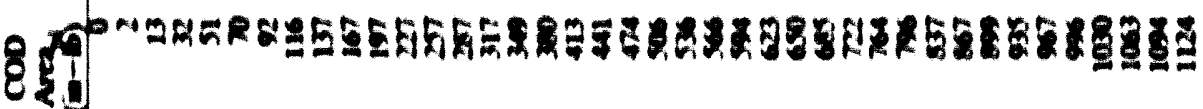

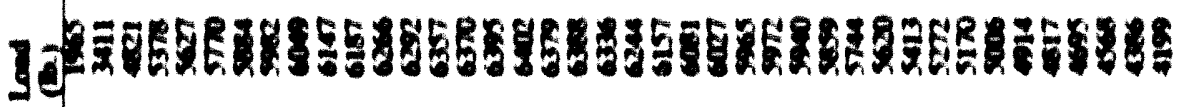
|15 5)

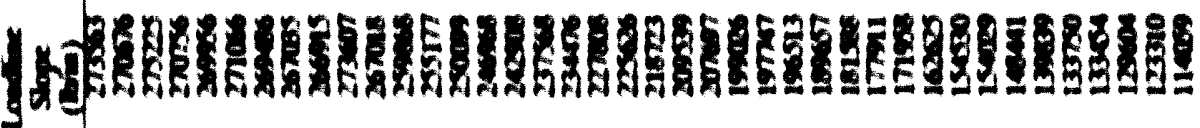
76 | 8ร

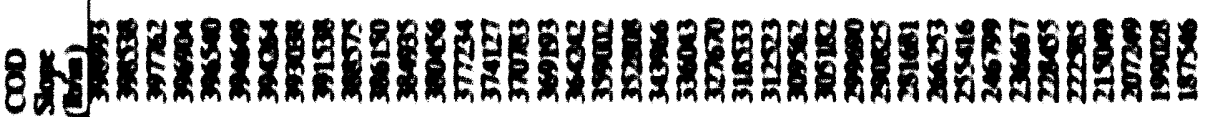

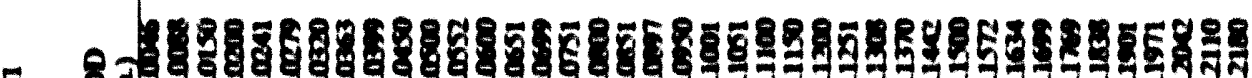
0 ำ

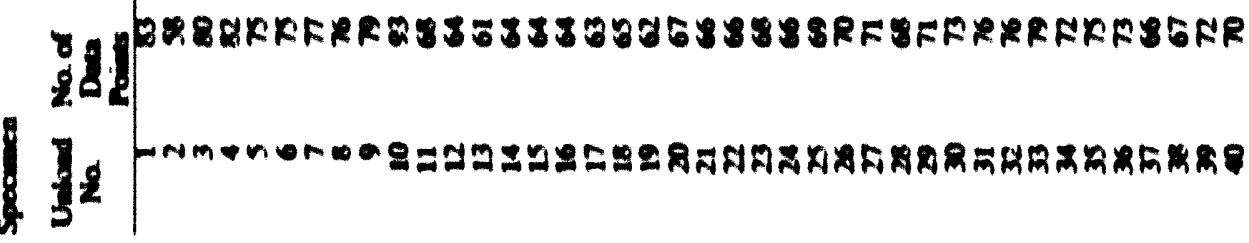




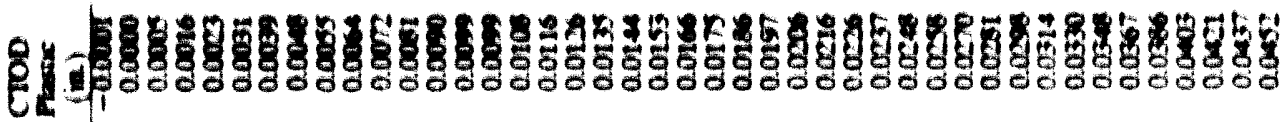

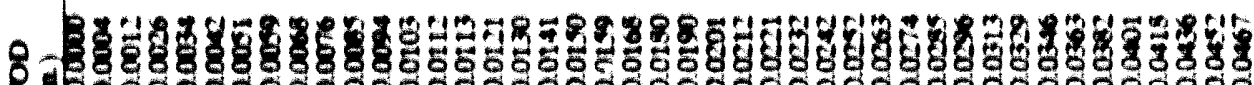

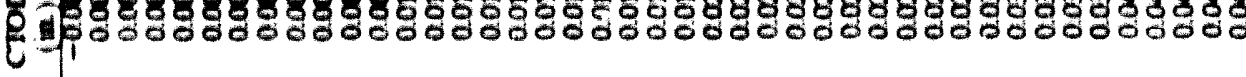

- 1 100. 勿

U|

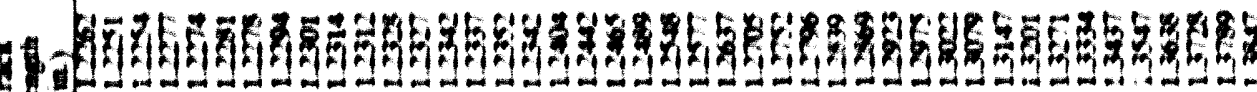
19.

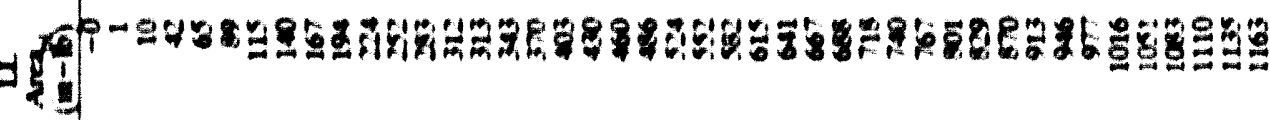
8. 16)

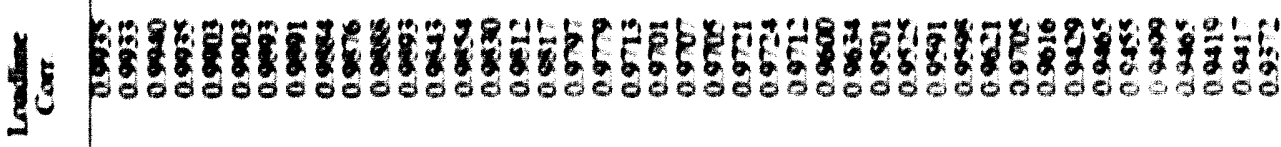

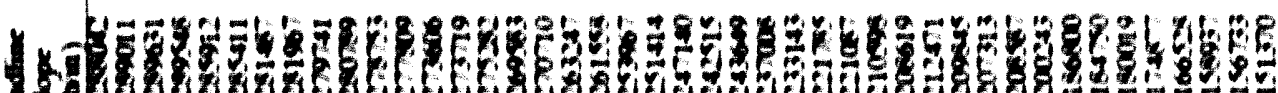

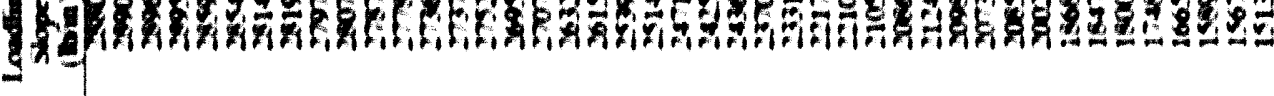

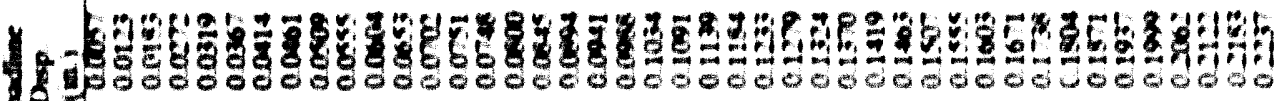
He

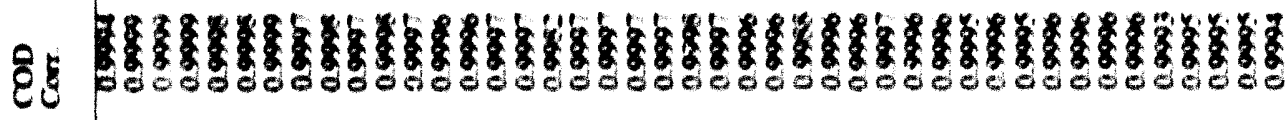

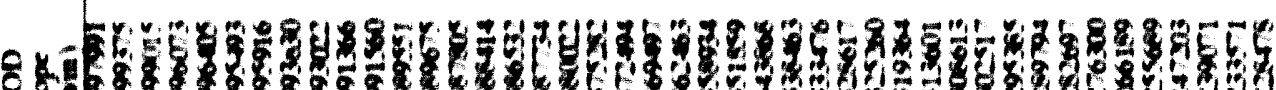
E.

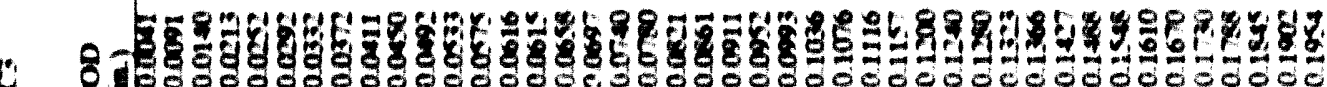

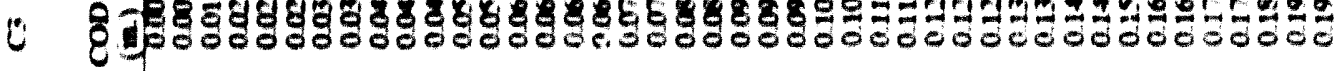
E int

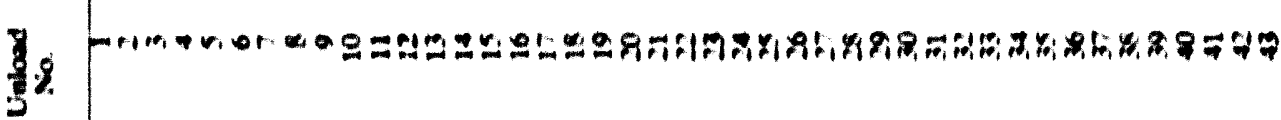




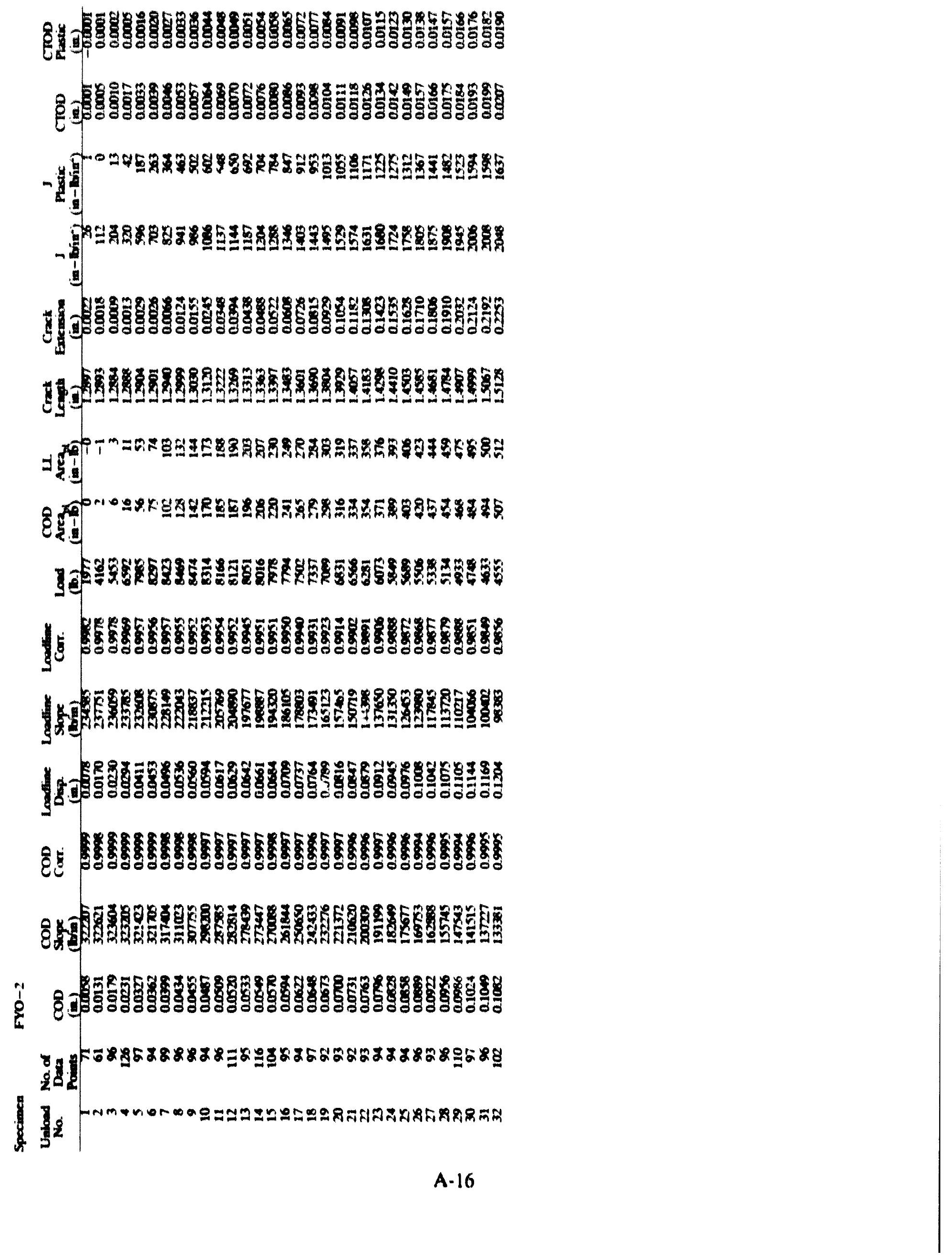




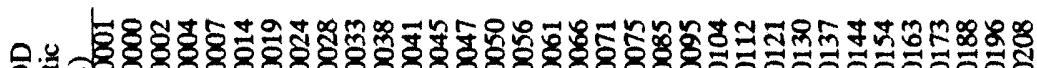
2 (1)

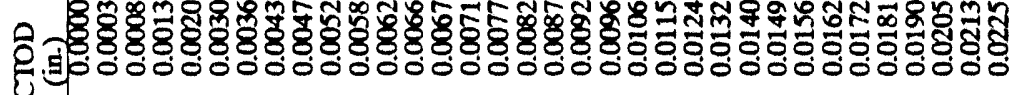

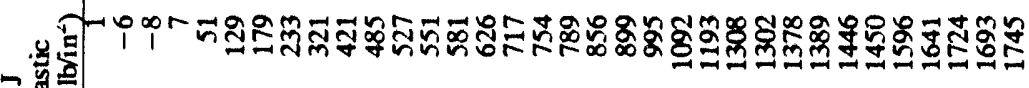

$\frac{\pi}{2 !}$

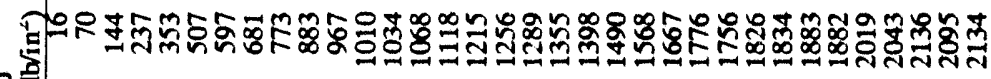

$\sim$ 两

s

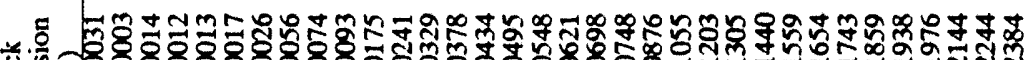
过

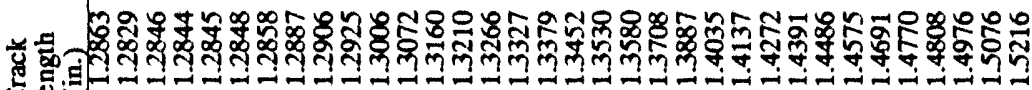

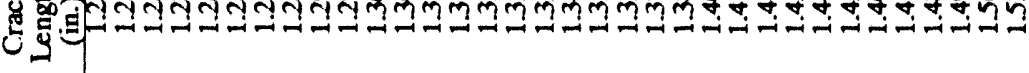

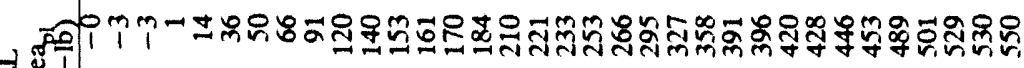

4.5

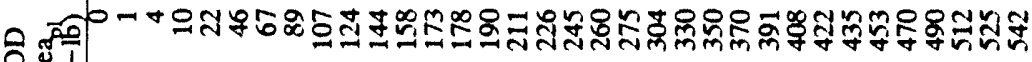

8

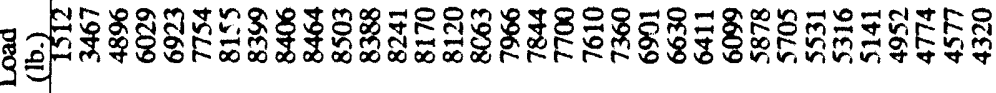

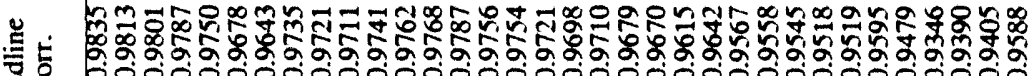

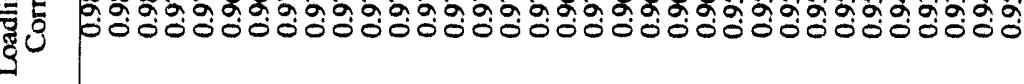

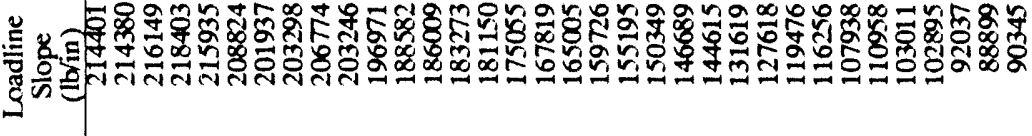

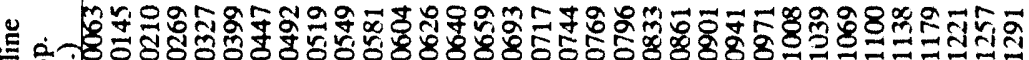
象 1000000000000000000000000000000000

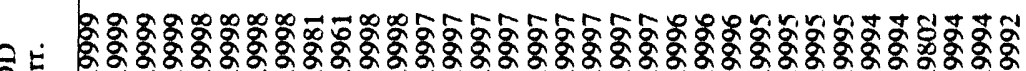

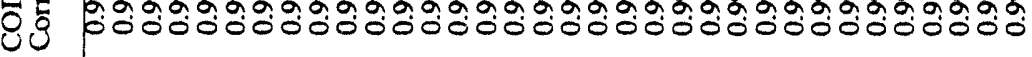

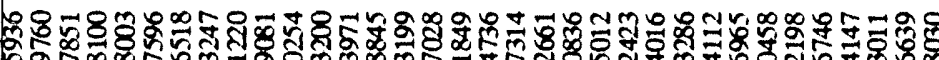

ठ응

¡

社

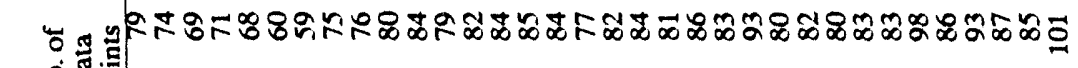

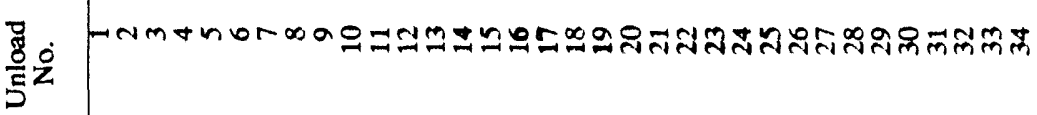




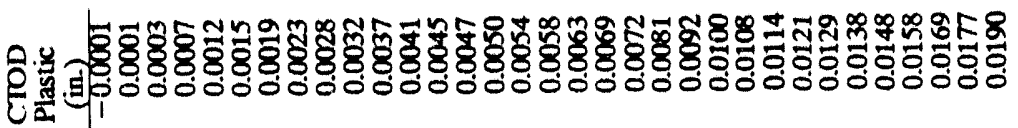

E) 实 $\frac{\mathrm{g}}{\mathrm{a}}$

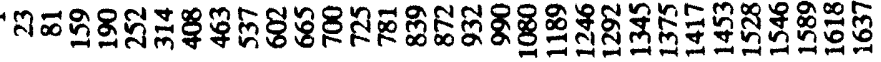

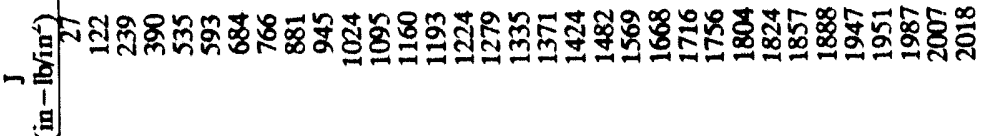

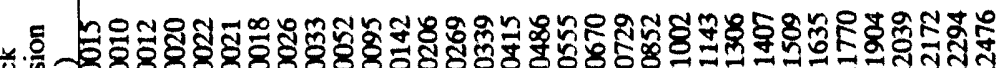

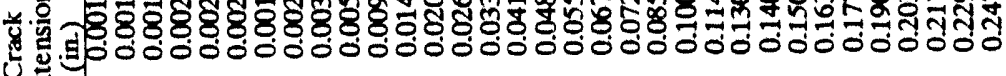
西

บ

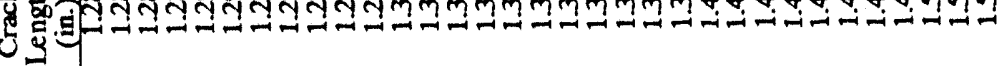

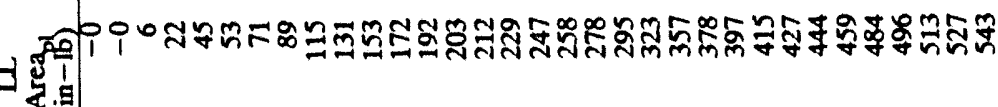
ค ㅇำ 84.

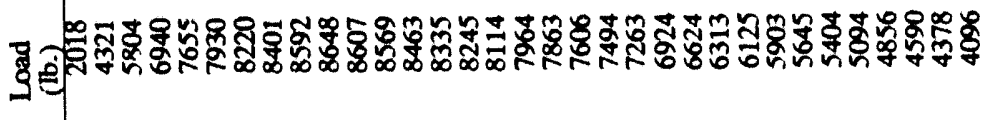

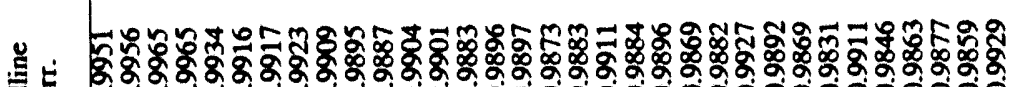

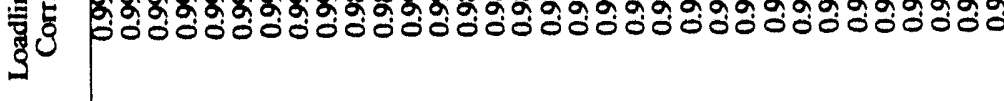

气 8

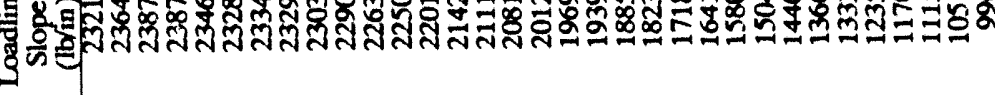

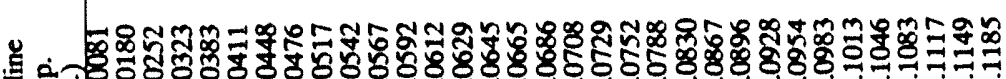

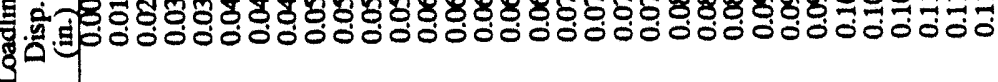

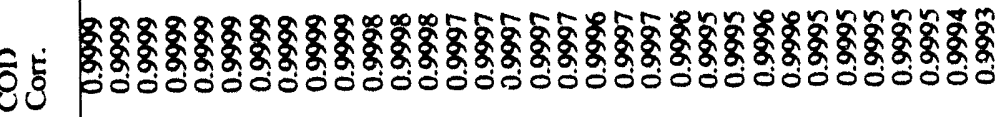

Mm

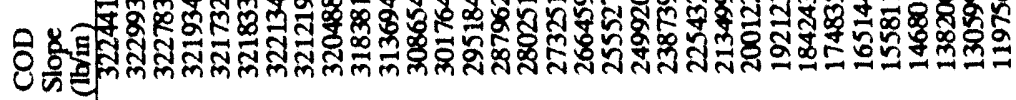

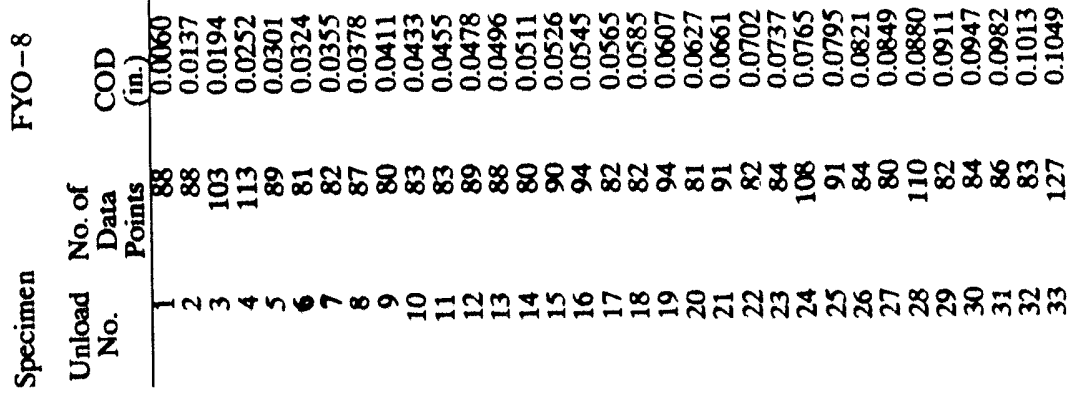




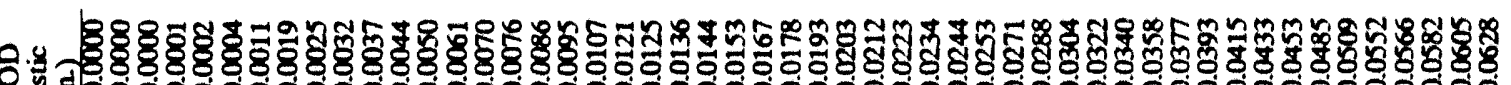

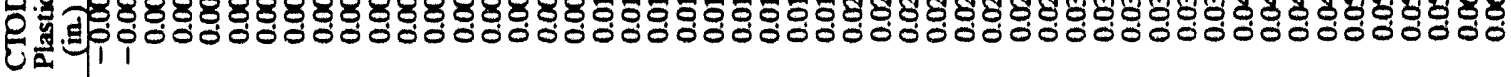

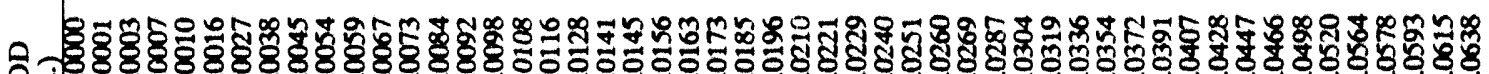
ำ

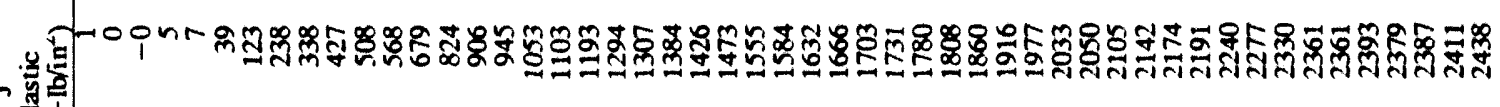

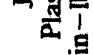
늘

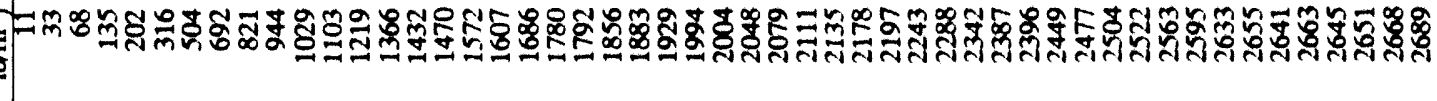

苛 u.

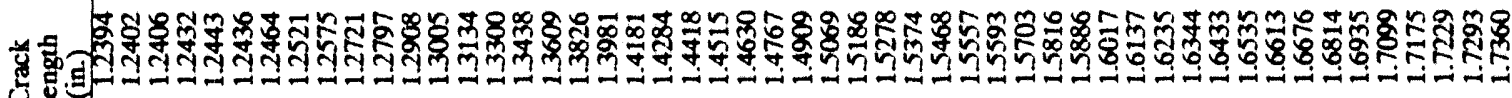

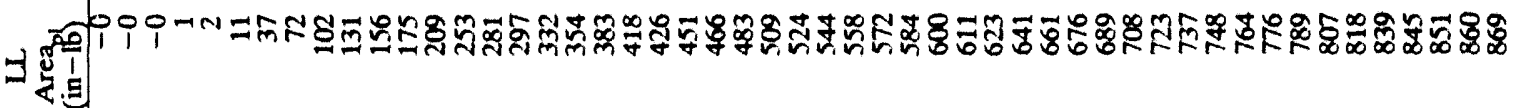

ㅇำ

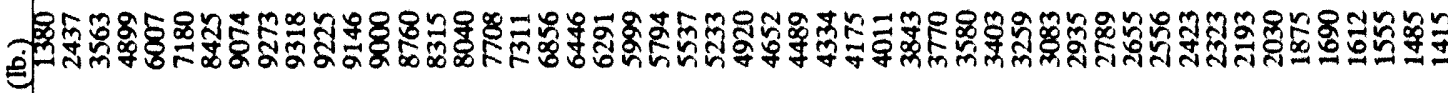

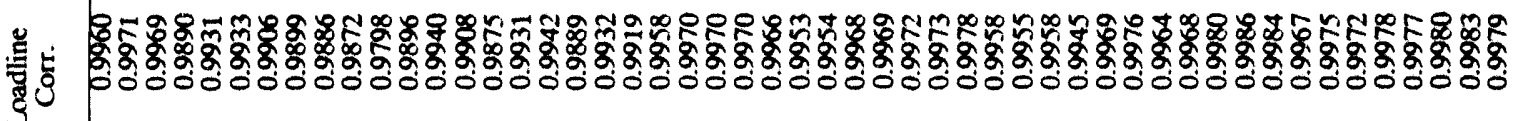

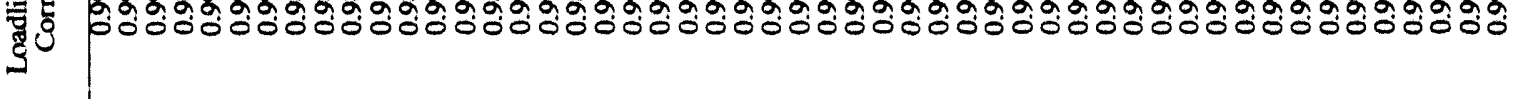

ะ

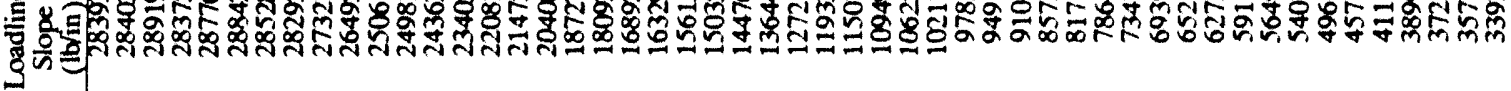

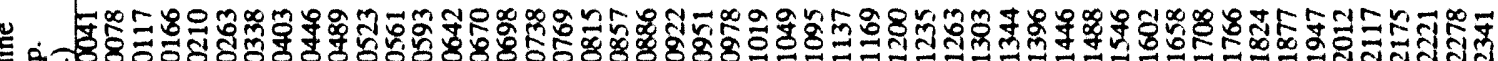

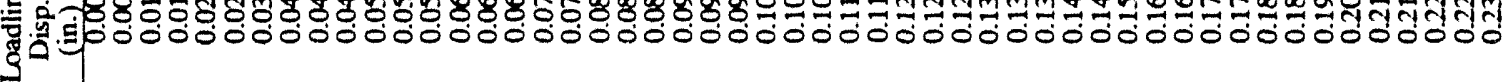

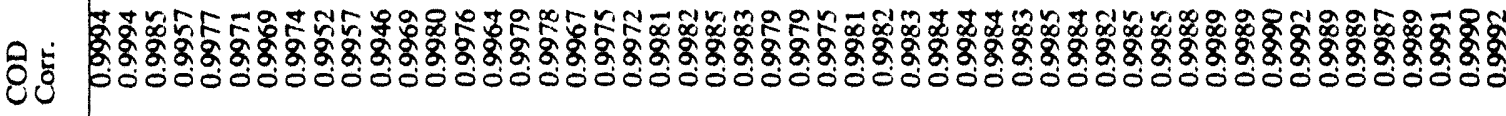

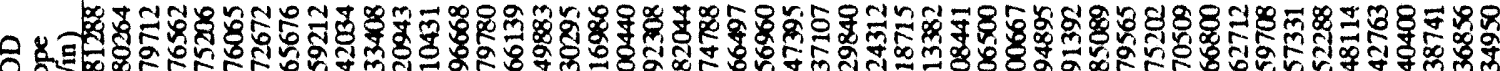
o

ㄱ

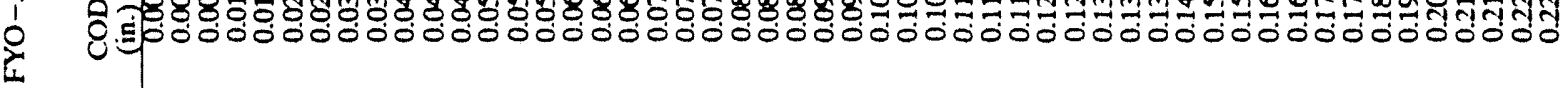

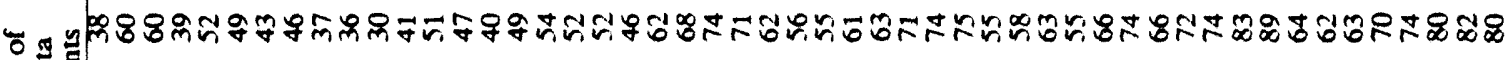
之o:

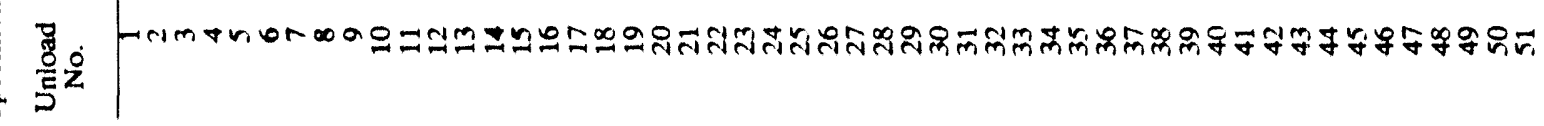




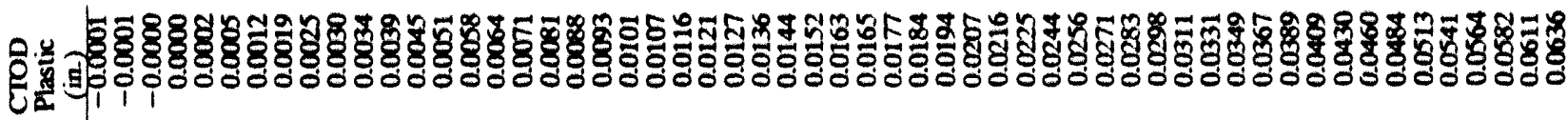

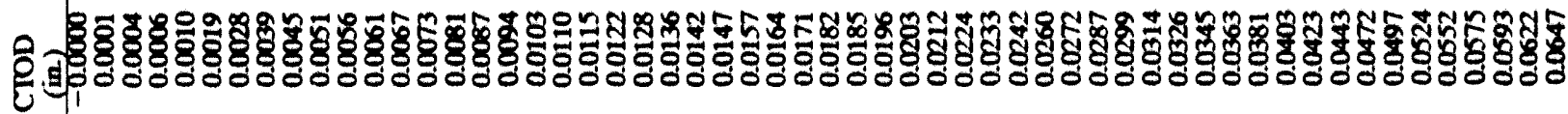
$-\frac{3}{3}$

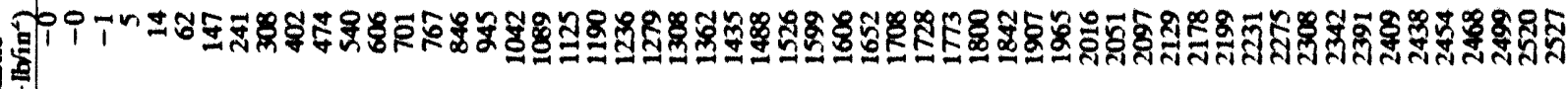

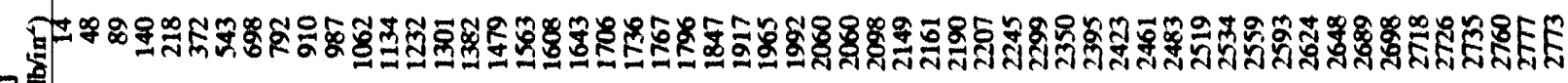
定

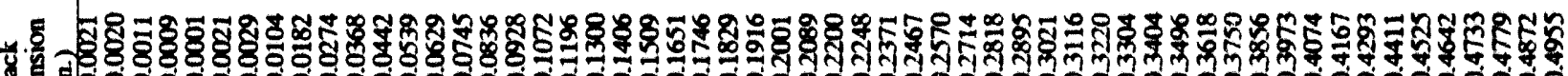

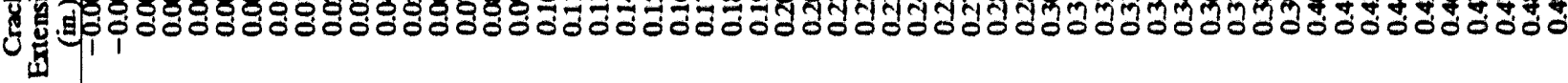

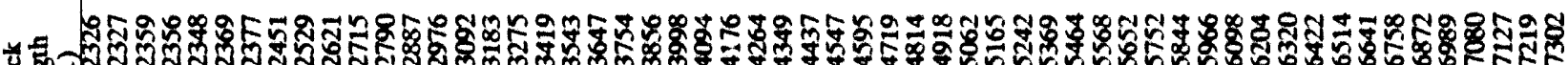

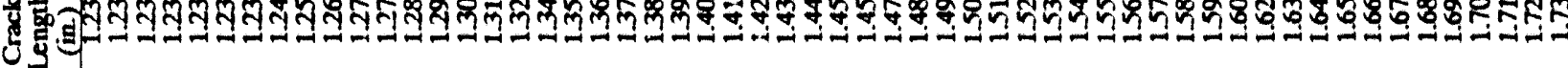

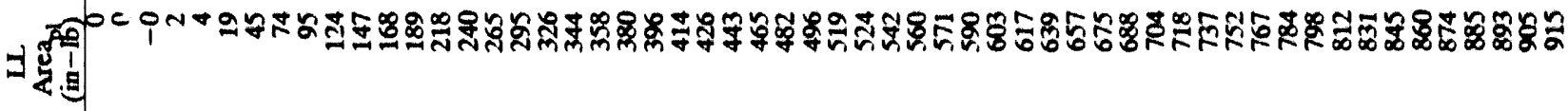

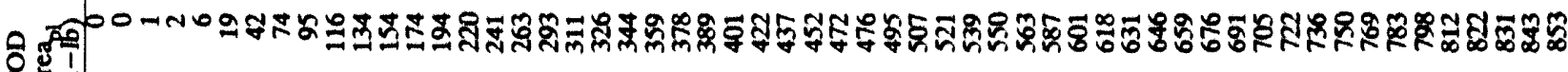
8 过

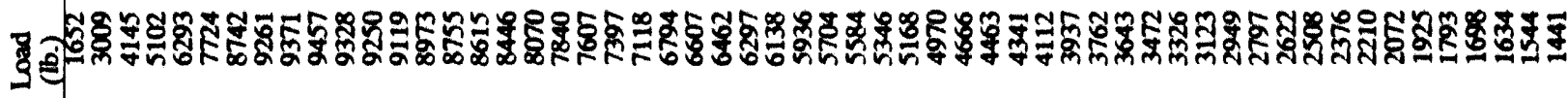

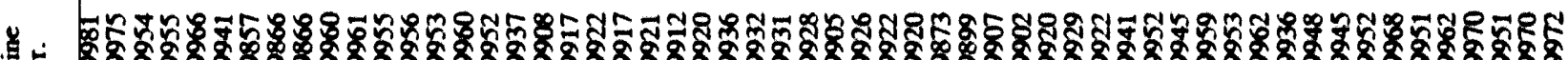
费

4 88 \%

\%

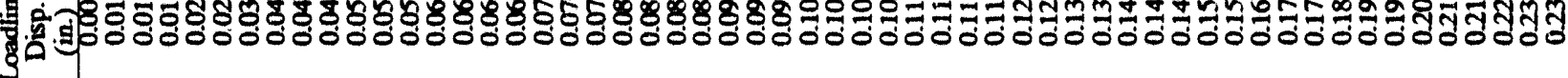

Q

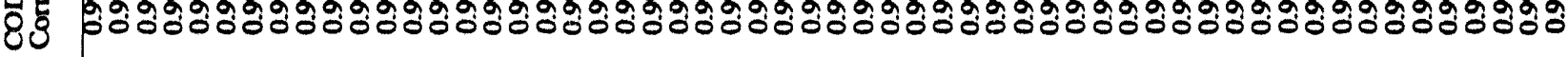

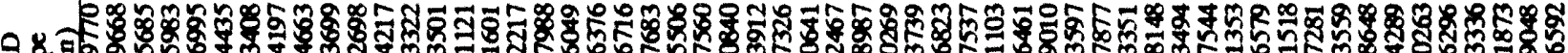

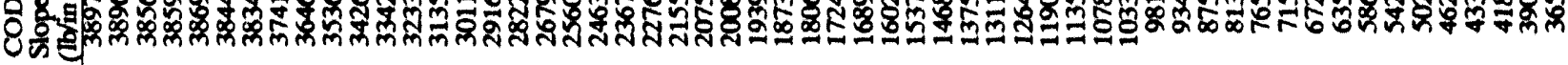

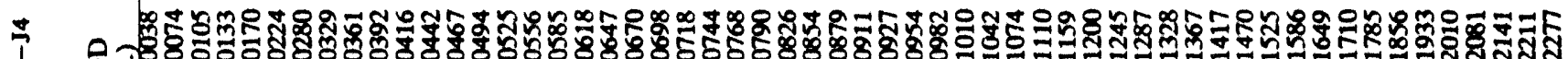
ठำ

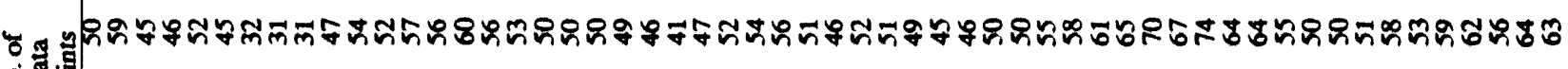
之ंต 햄 鄫完

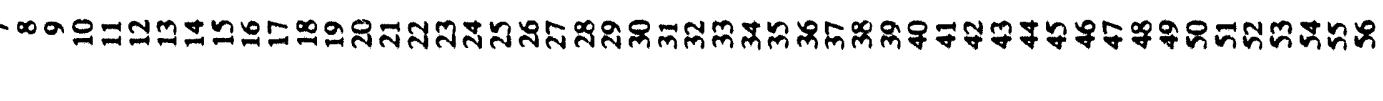




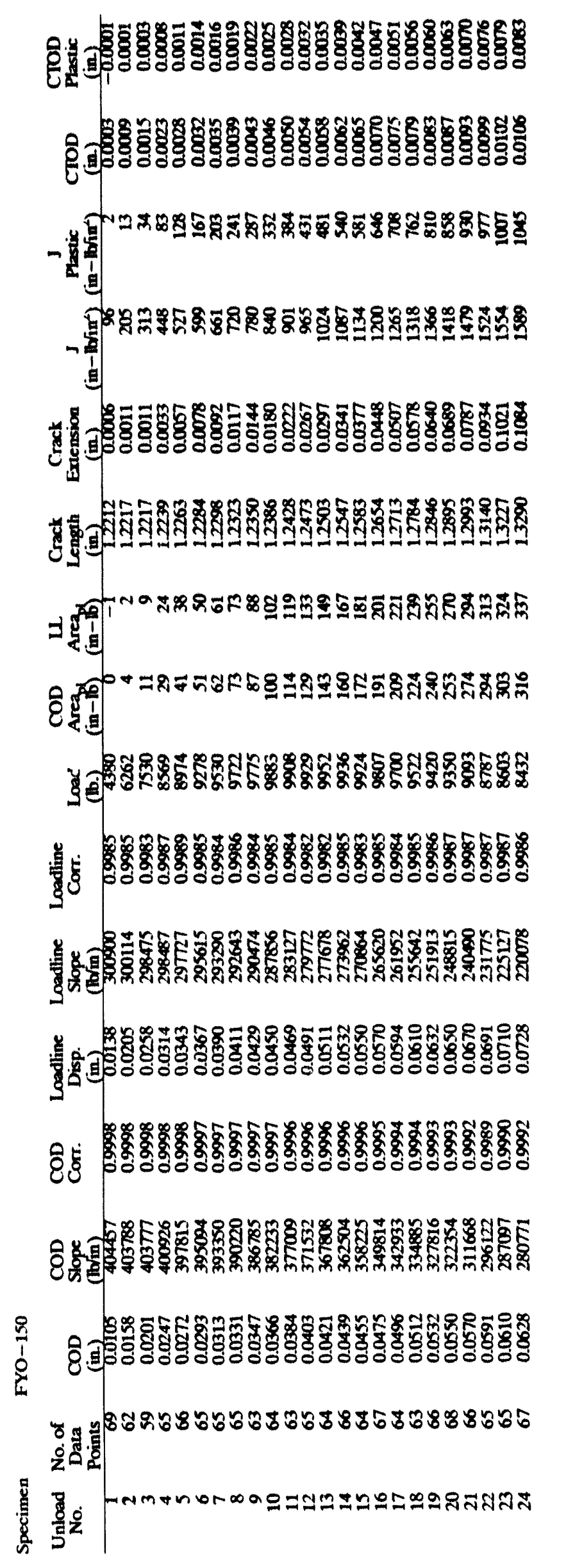




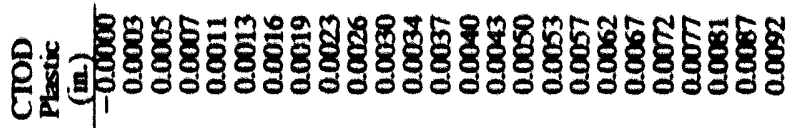

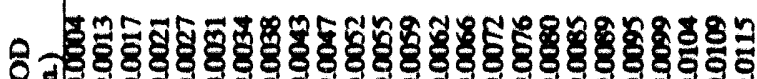

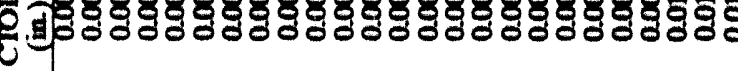

一贯曷

. -

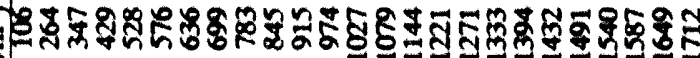
政

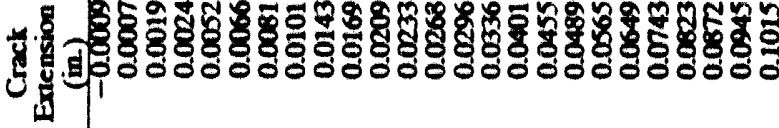

20ㅇำ

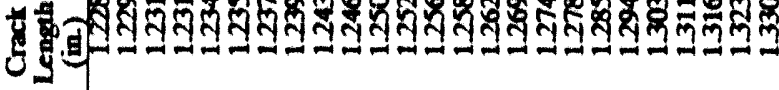

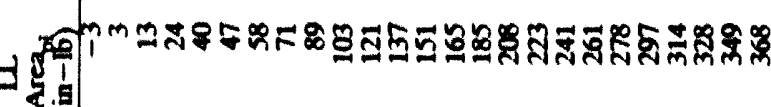

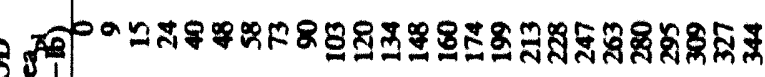
84.

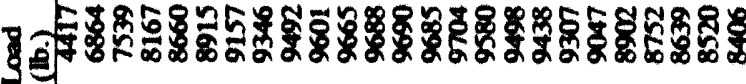
苑

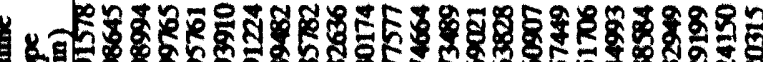

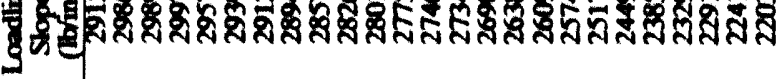

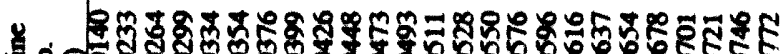

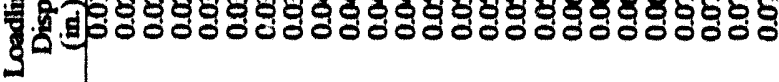

Q

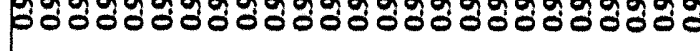

0 8

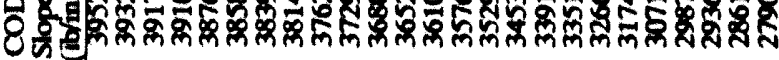

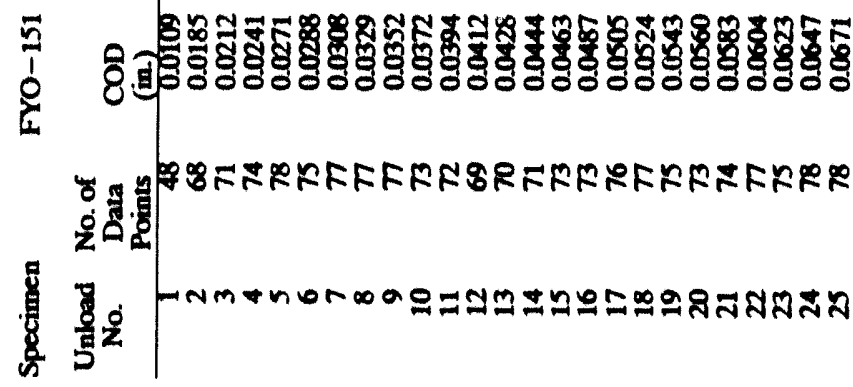




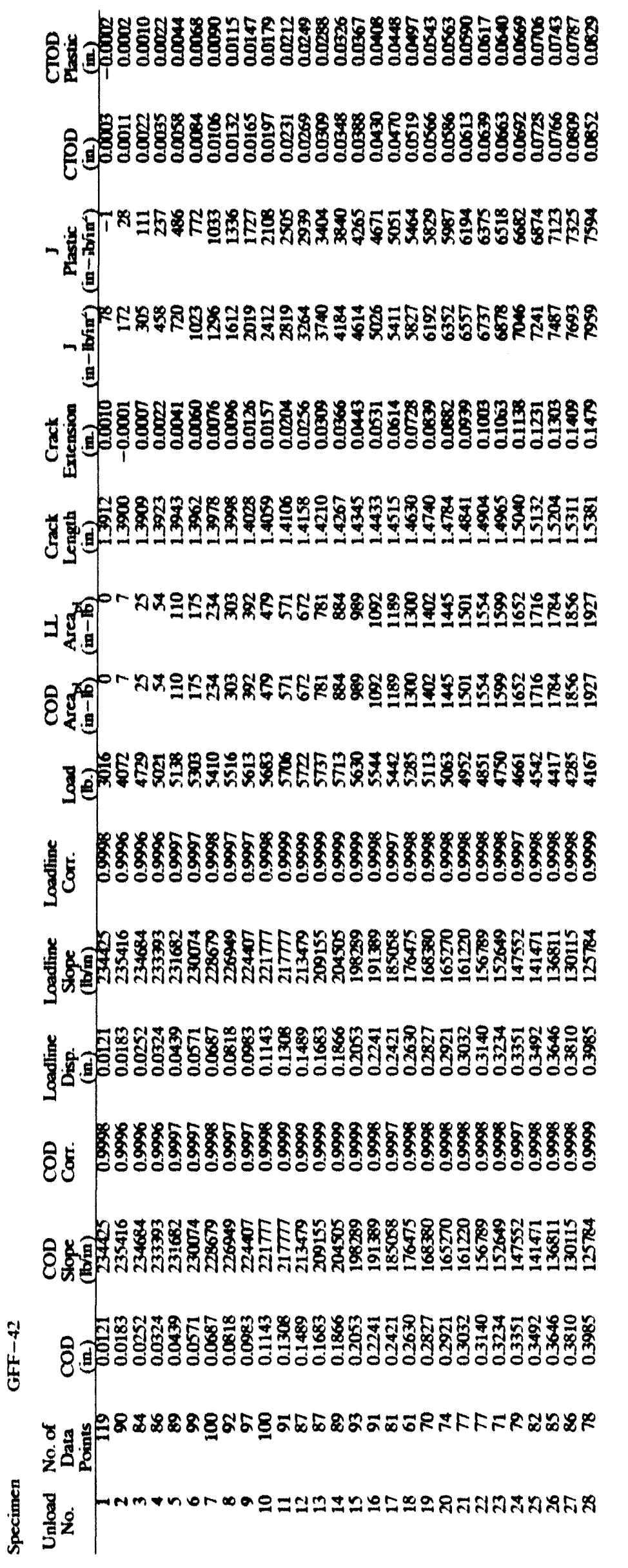




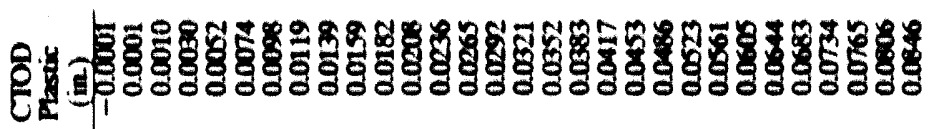

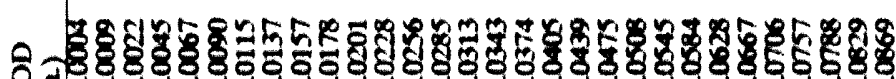
Eำ

- 最要

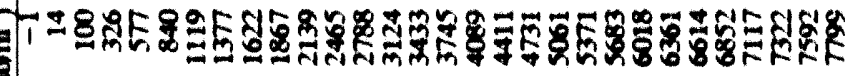

$-\frac{5}{1}$

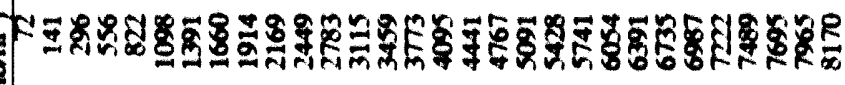
:

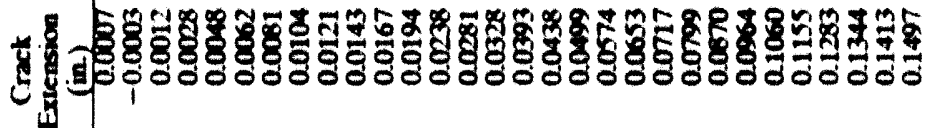

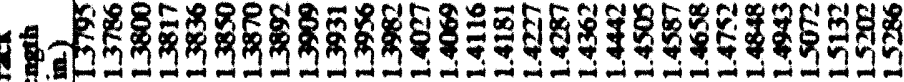
ได

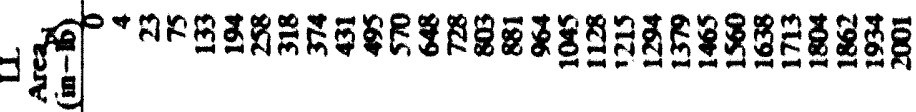

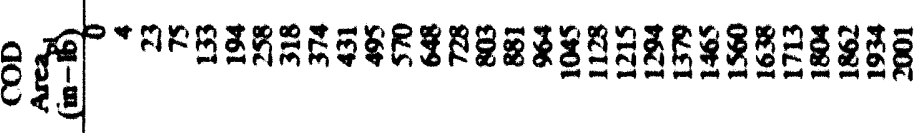

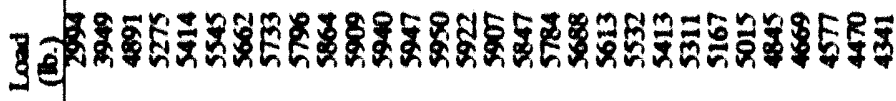

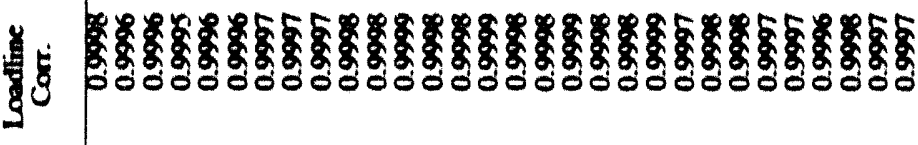

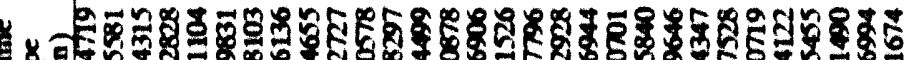
ร)

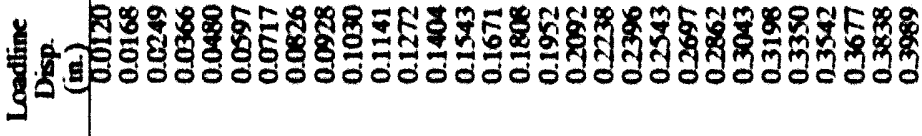

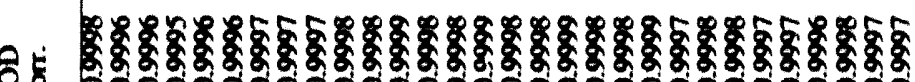

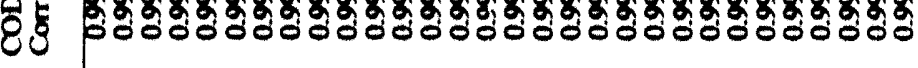

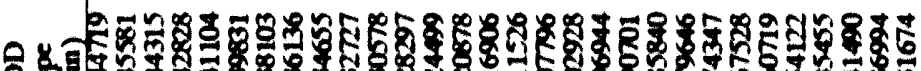
8:ำ

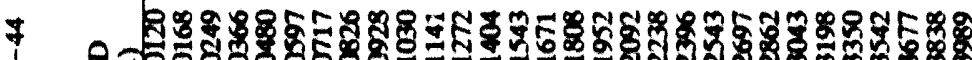
4 8 골

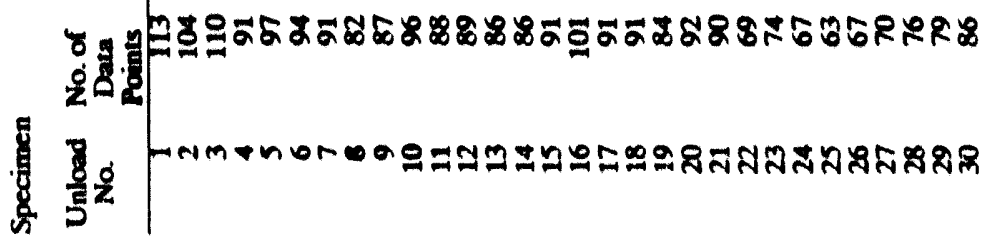




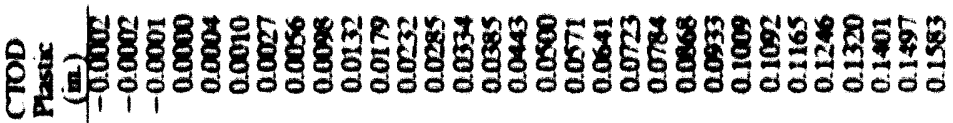

\&ำ

ยุด

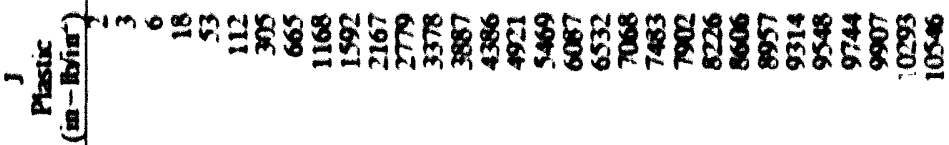

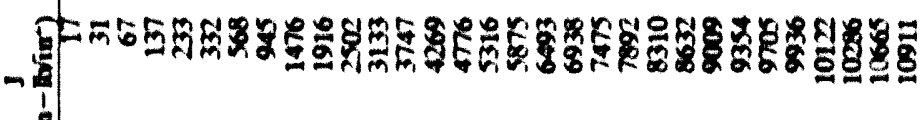

.

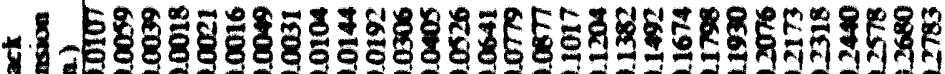

8)

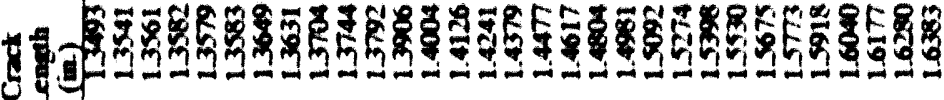

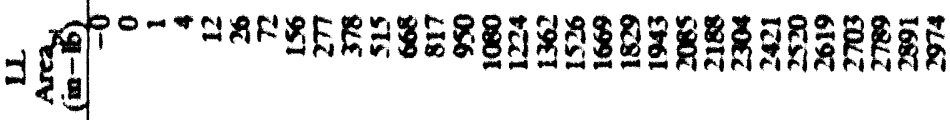

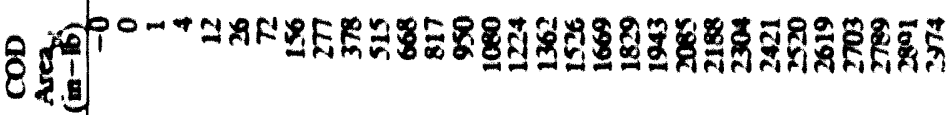
งอง 13

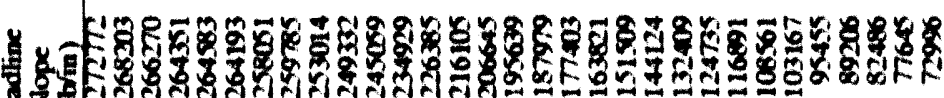

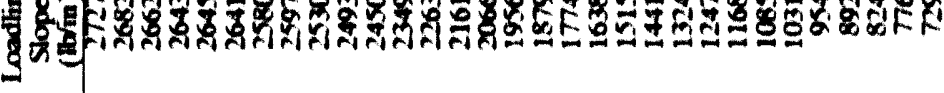
1) |冖:

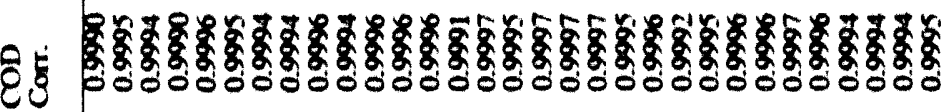

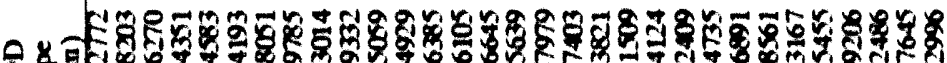

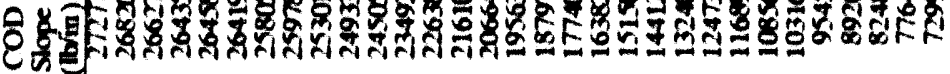

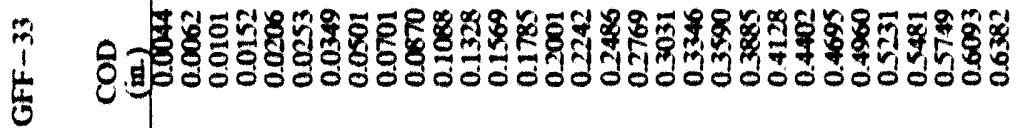

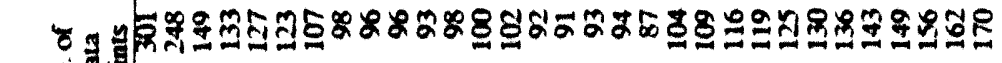
兽 z

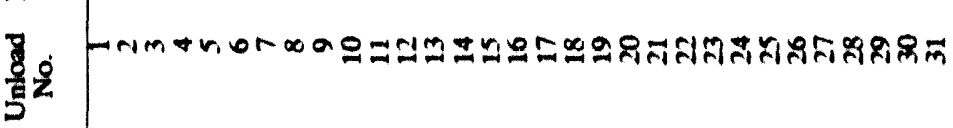




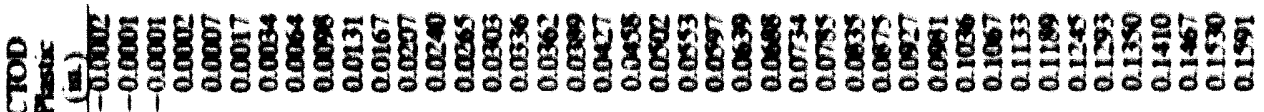

을 ใำ ำ

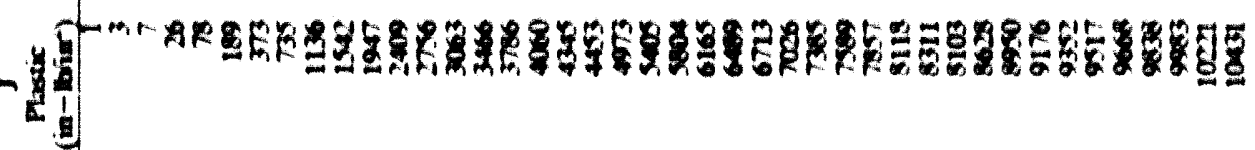
.

4 ได

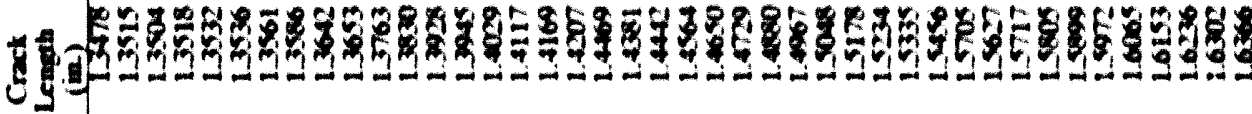

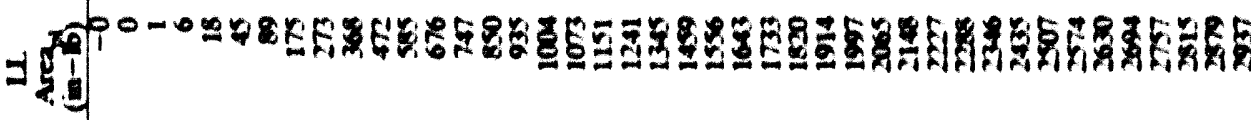

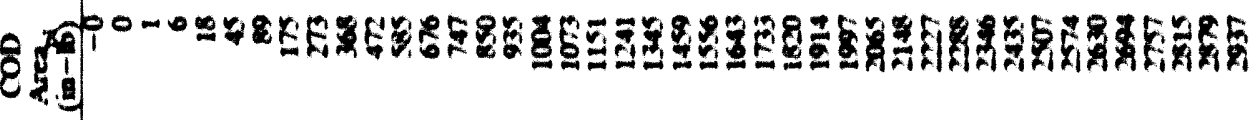

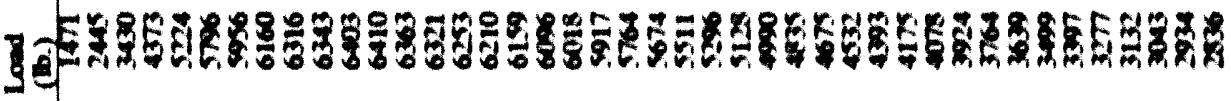

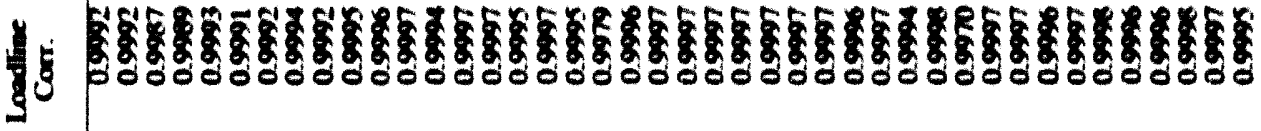

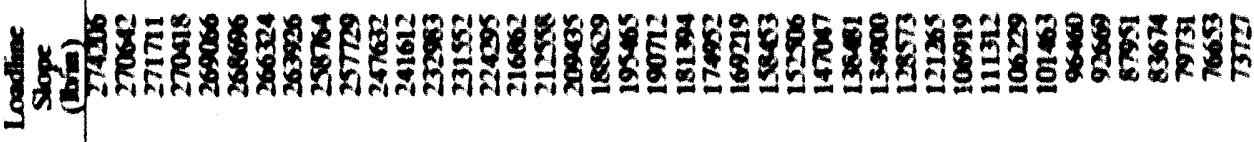

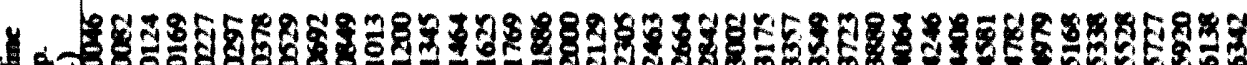
ป⿻

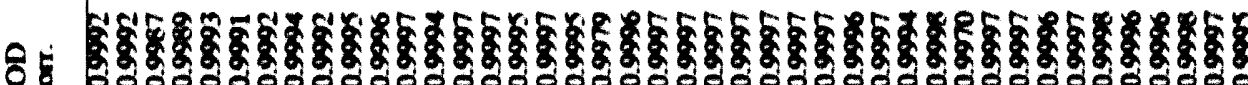
8ิ

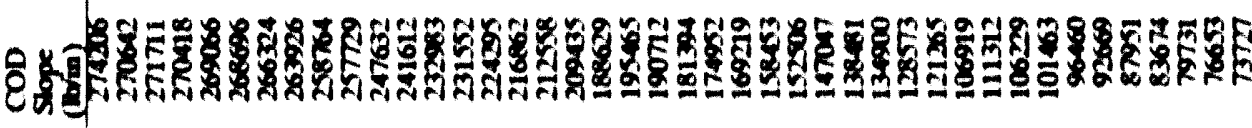

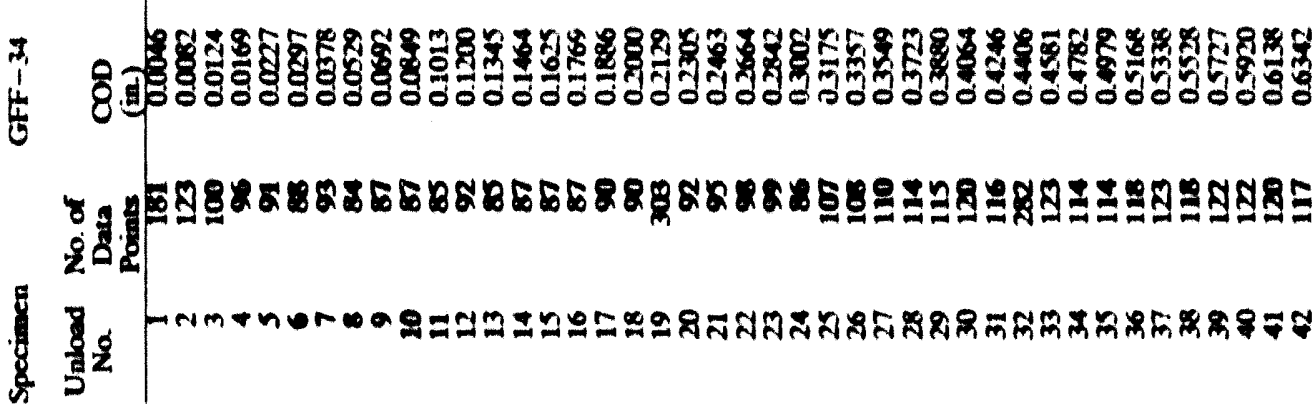




\section{ช้ำ}

H) ช้อง $-8$

7 -

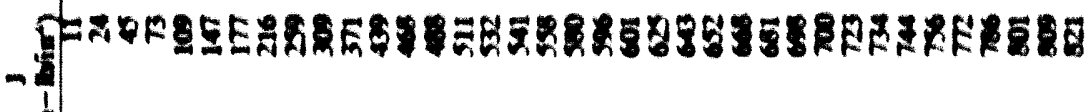
!

ไ|ำ

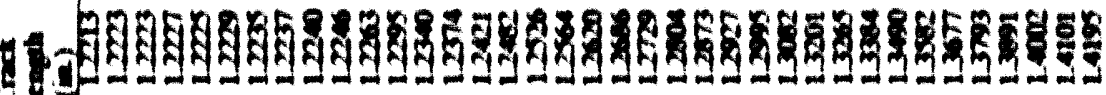
37

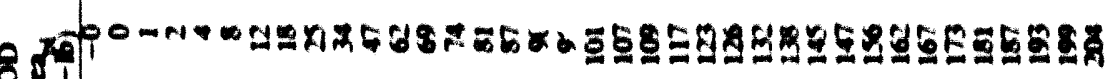
85

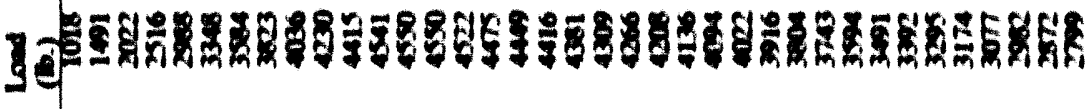

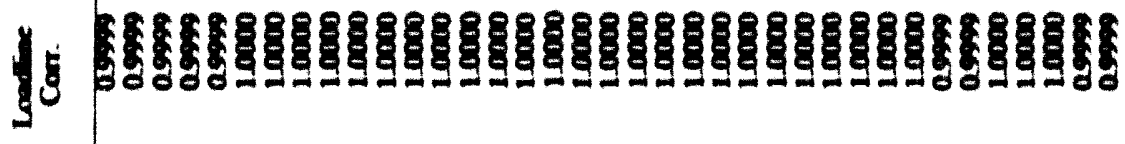
|ง 4. 14

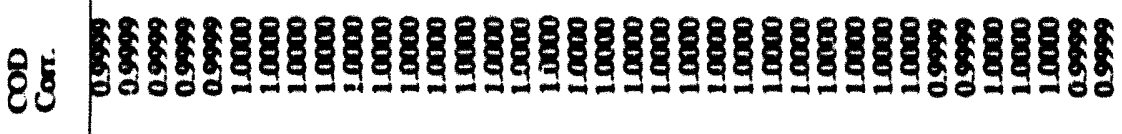

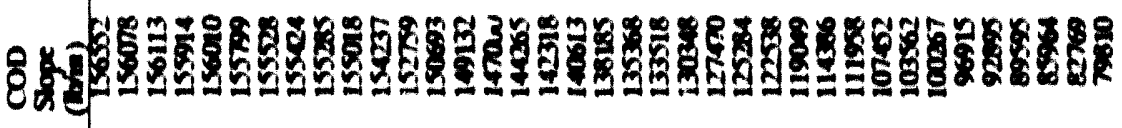

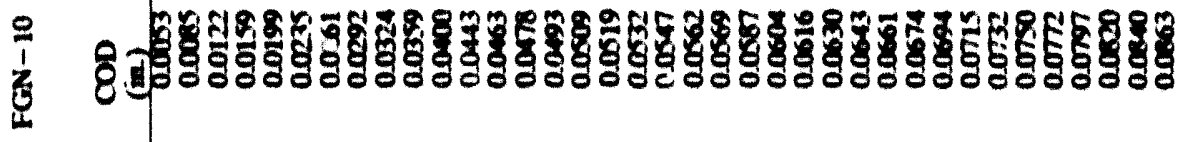
ช 尊官 - 


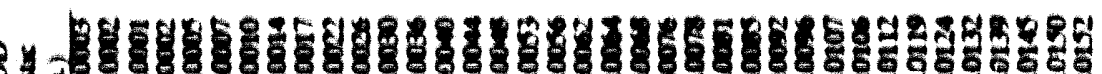
ำㄴำ 8) ع. $-7$

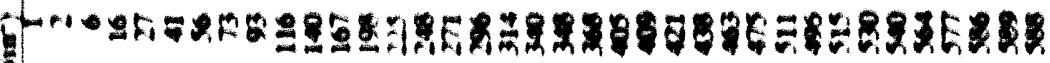

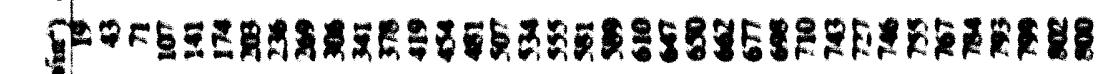
$-\frac{8}{1}$ .

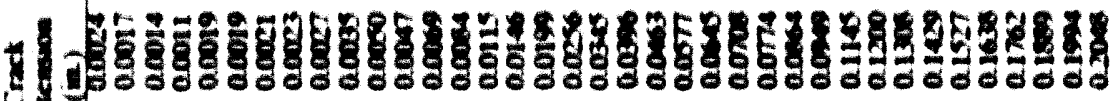
Mด

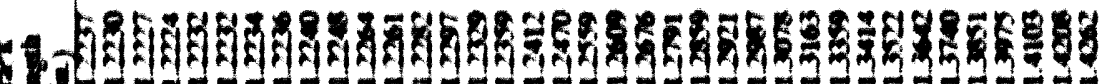
$65.02-2-2-2-12$

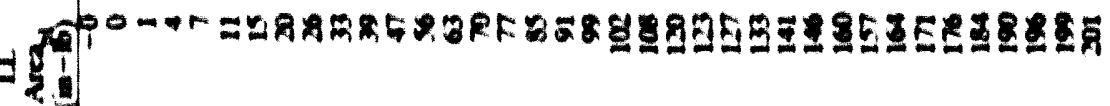

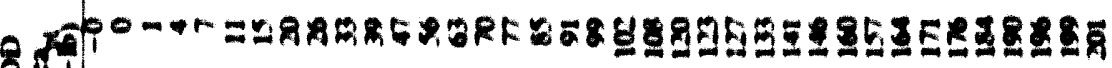
8.

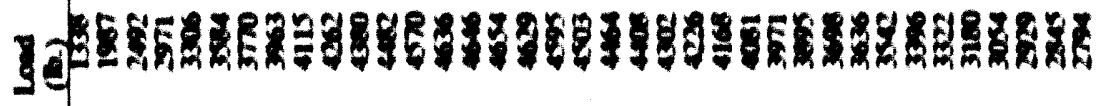

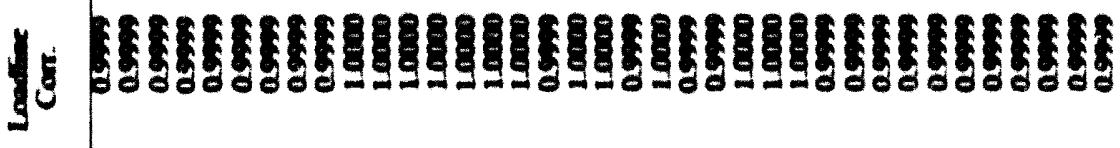
|1 15

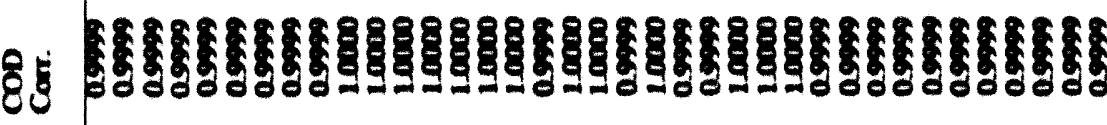

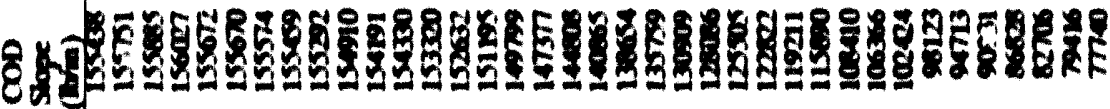

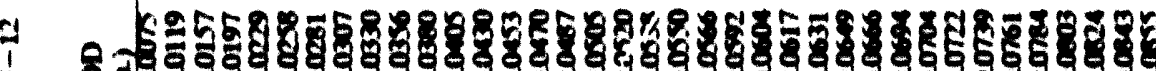
8ㄱำ Id:

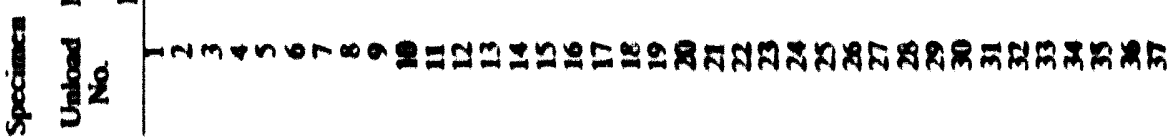




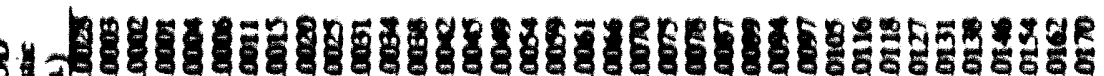
ช้ำ ำำ - 䀜 비

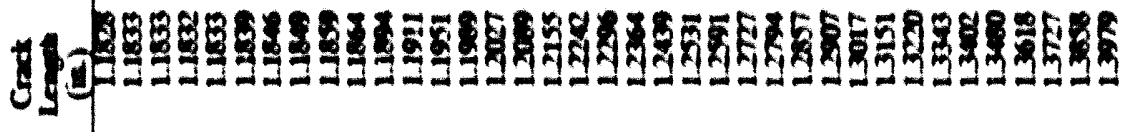

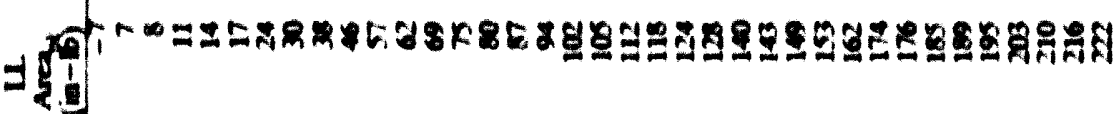

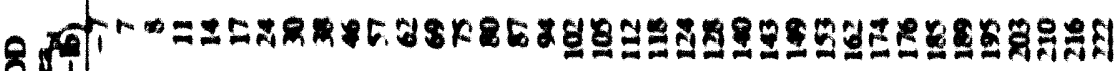
81

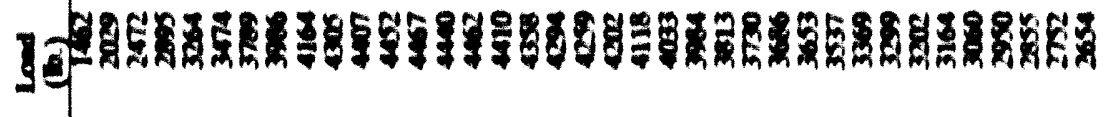

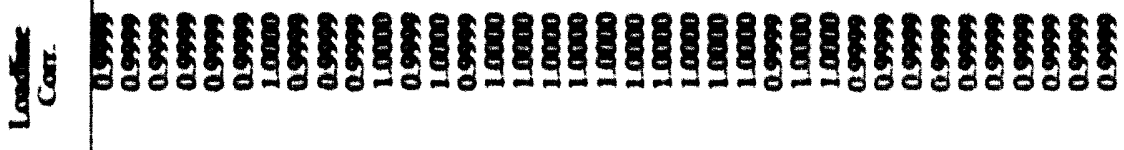
แำ

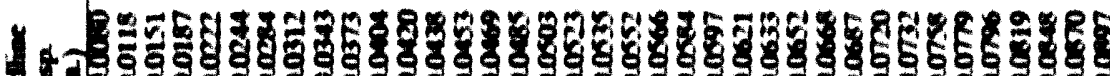
빈

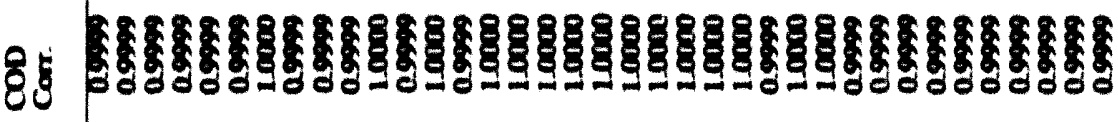

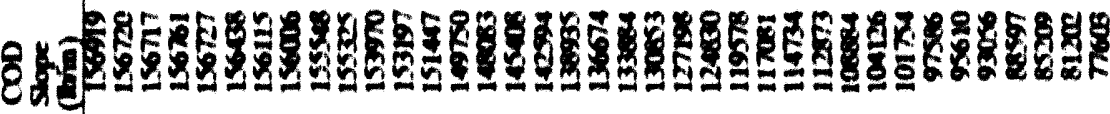

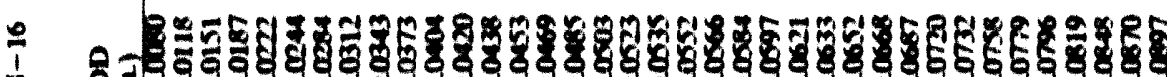

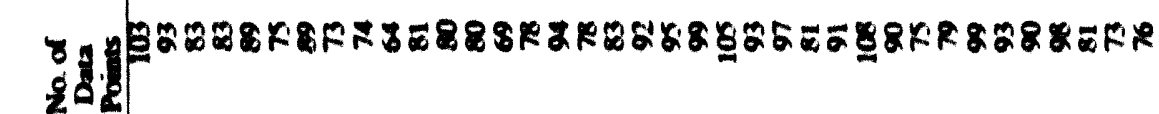
8 $\frac{1}{5}$ - 


\section{ำ

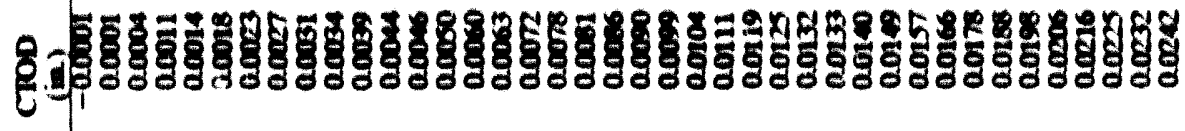 H 年

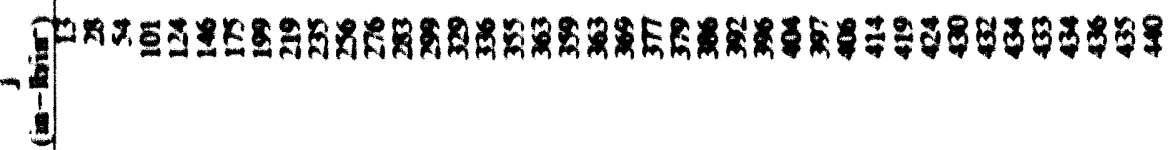

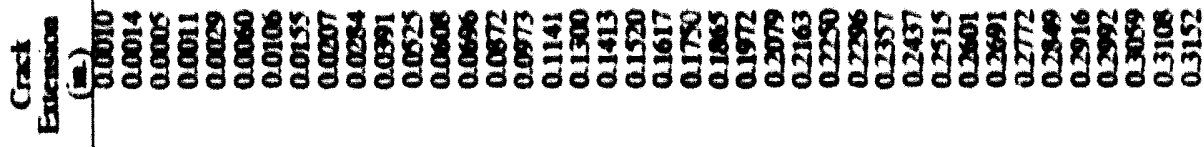

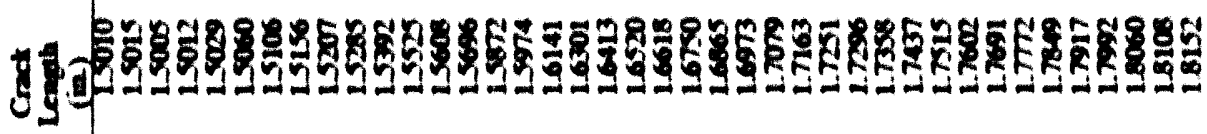 士 8ร 9.

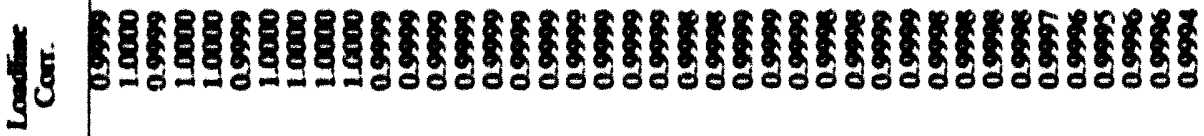 与ัด

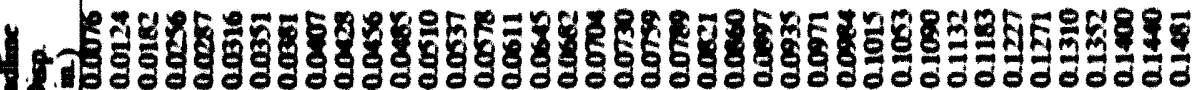

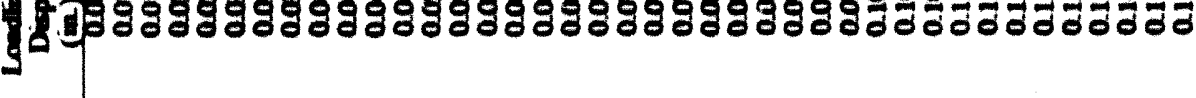

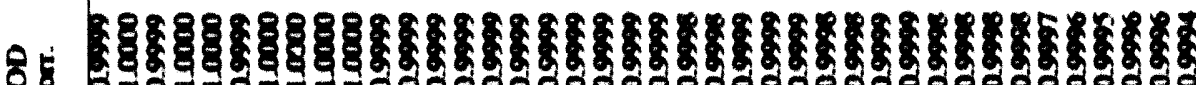

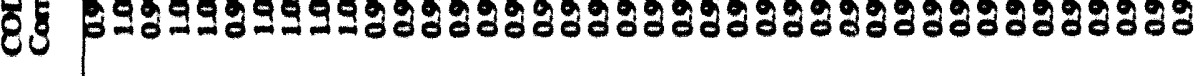

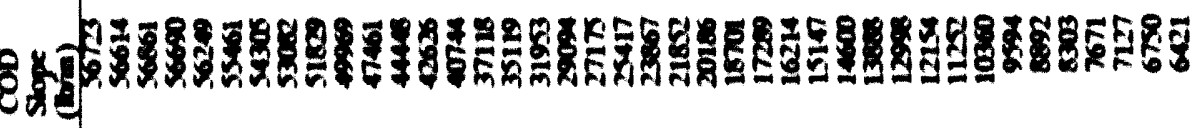

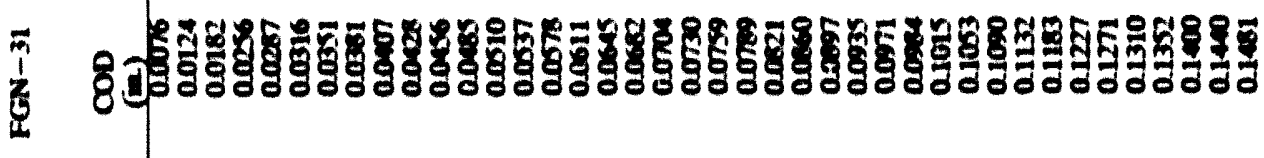

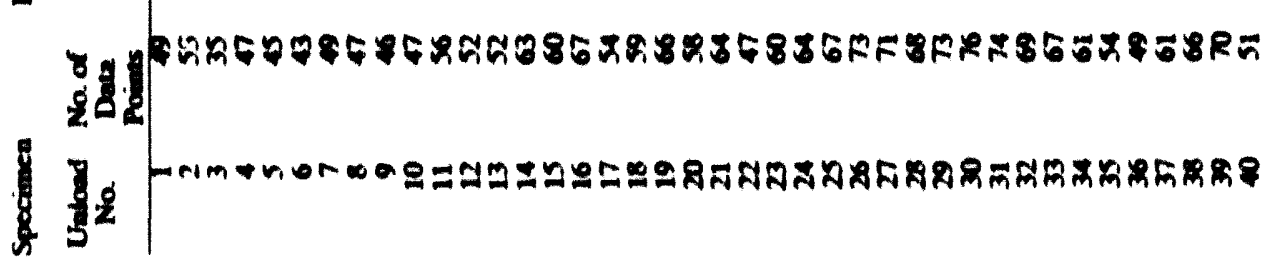




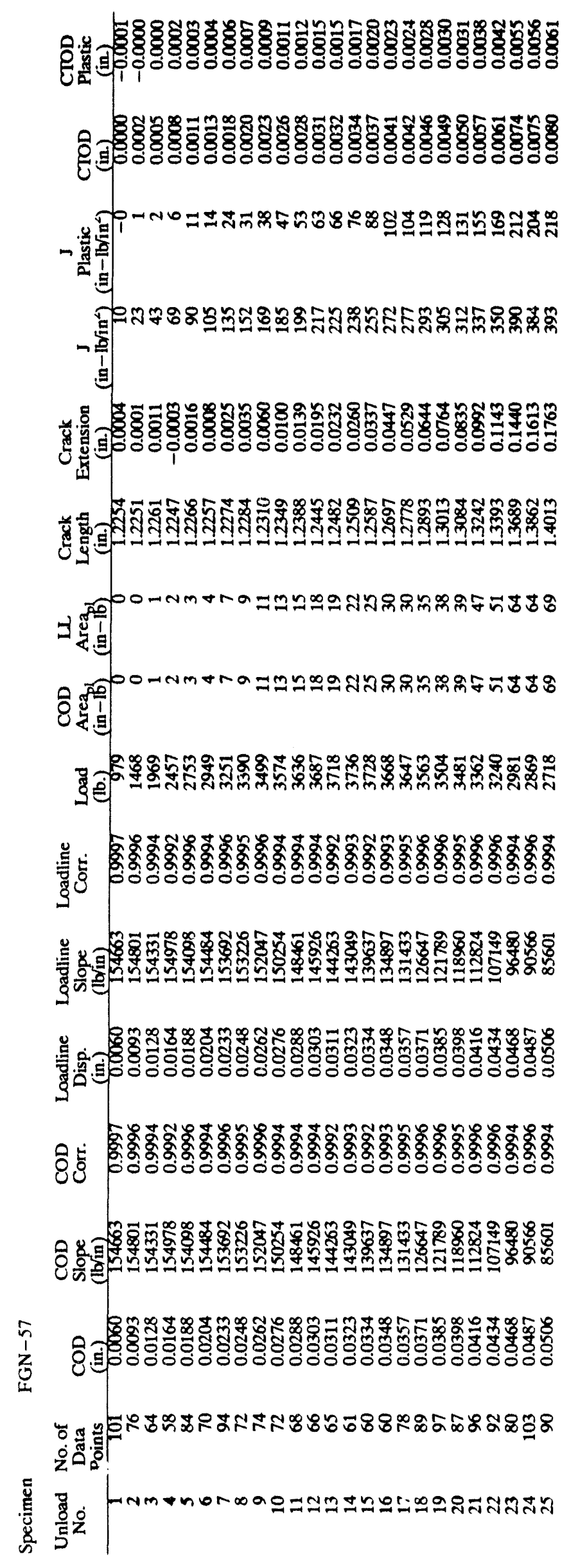




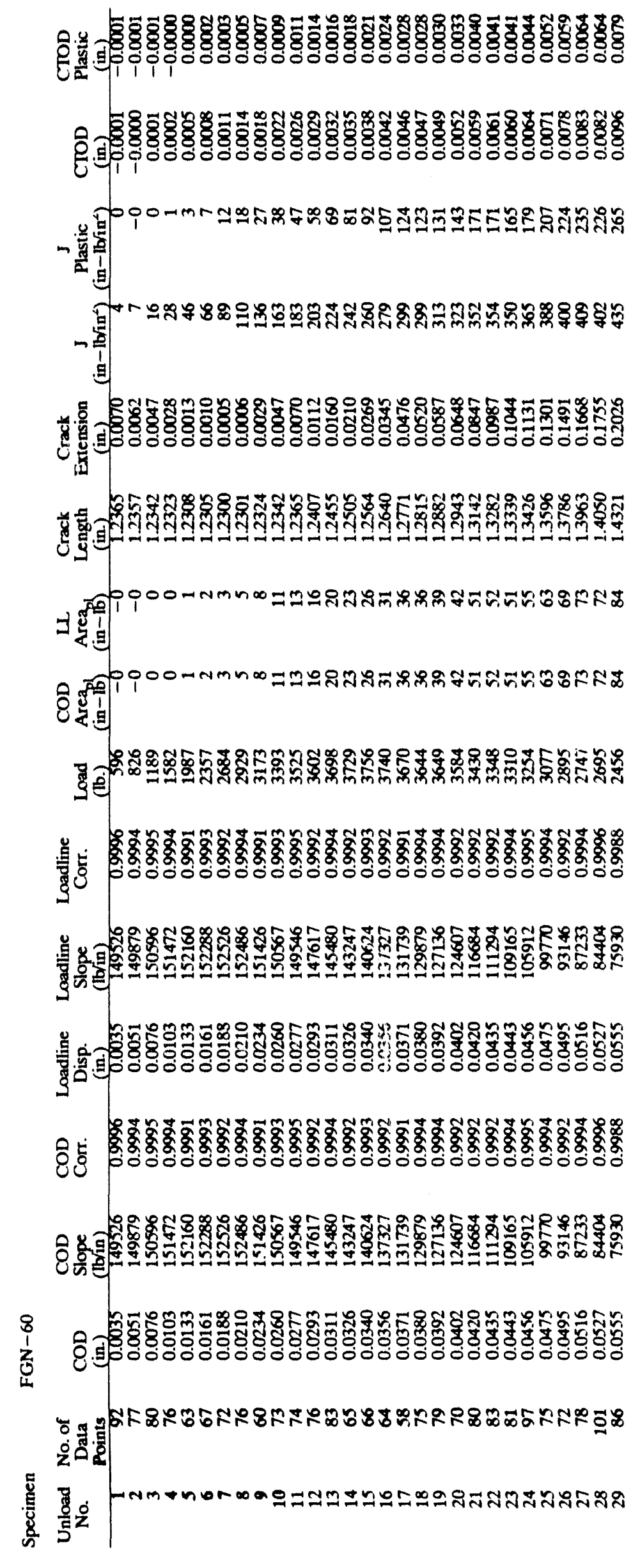




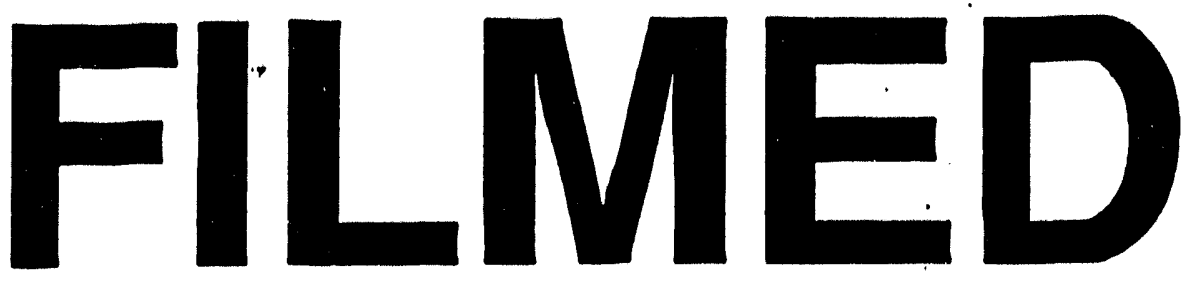

II
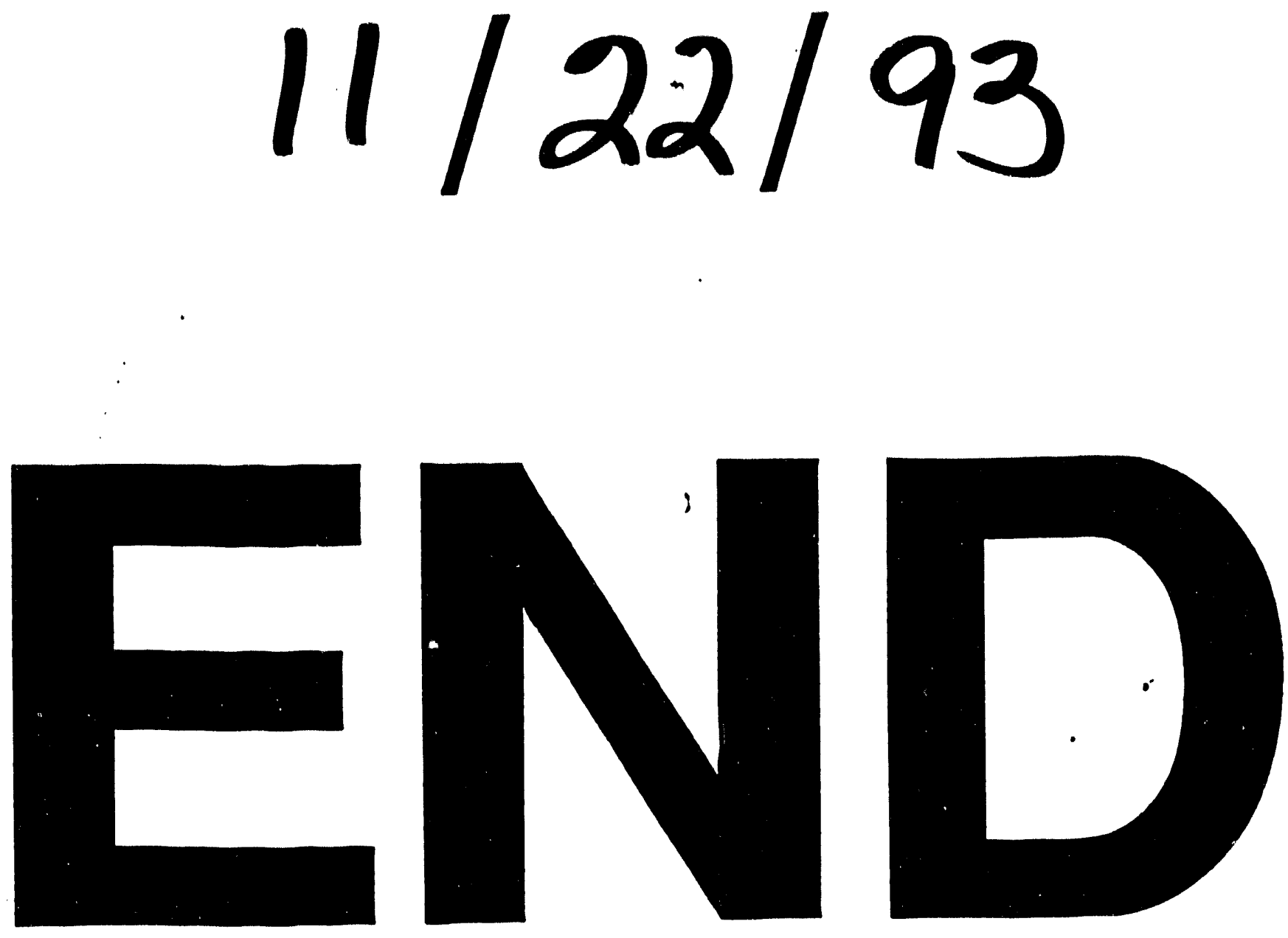
